\title{
Blended cognitive behavior therapy: efficacy and acceptability for treating depression in the adult and adolescent population
}

\author{
Naira Topooco
}

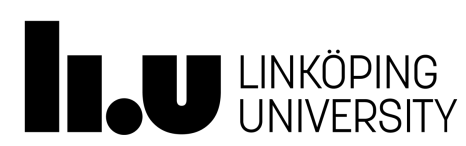

Linköping Studies in Arts and Sciences No. 740

Linköping Studies in Behavioural Science No. 206

Faculty of Arts and Sciences

Linköping 2018 
Linköping Studies in Arts and Sciences No.740

Linköping Studies in Behavioural Science No. 206

At the Faculty of Arts and Sciences at Linköping University, research and doctoral studies are carried out within broad problem areas. Research is organized in interdisciplinary research environments and doctoral studies mainly in graduate schools. Jointly, they publish the series Linköping Studies in Arts and Science. This thesis comes from the Division of Psychology at the Department of Behavioural Sciences and Learning.

Distributed by:

Department of Behavioural Sciences and Learning Linköping University

58183 Linköping

Naira Topooco

Blended cognitive behaviour therapy: efficacy and acceptability for treating depression in the adult and adolescent population

\section{Edition 1:1}

ISBN 978-91-7685-297-2

ISSN 1654-2029

ISSN 0282-9800

(C) Naira Topooco

Department of Behavioural Sciences and Learning, 2018

Cover by: Juni Crisp Topooco \& Jonas Topooco

Printed by: LiU-tryck, Linköping 2018 




\begin{abstract}
Depression is the most burdensome disorder worldwide in terms of health loss. The potential of internet and technologies to scale up psychological treatment resources is substantial. A blended treatment approach, reducing therapist time and combining sessions with online self-help components, could enhance availability of psychological treatment, while maintaining and possibly enhancing effect of treatment. The aim of this thesis was to develop and investigate the blended treatment approach, in terms of acceptance among key stakeholders, and clinical effect in treatment of depression in the adult and adolescent population.

Study I investigated acceptance of the blended treatment approach among mental health care stakeholders by means of a European survey. The results demonstrated that the majority readily accepted blended treatment for management of mild and moderate depression.

Study II evaluated blended treatment compared to standard face-toface psychotherapy in treatment of adult depression in a controlled non-inferiority trial. The results showed a similar decrease in depression from both interventions at post-treatment, with decreased levels maintained over six months. Non-inferiority for the blended treatment could not be statistically established.

Study III was a controlled non-inferiority trial evaluating blended treatment compared to treatment as usual. The results indicated superiority for the blended treatment at post-treatment and partly at six months. After twelve months the outcomes in the two conditions were similar.

Study IV evaluated blended treatment for adolescent depression in a controlled superiority trial, where the therapist time was not reduced, but sessions delivered via chat for improved reach and efficiency. Compared to attention control, the blended treatment significantly reduced depression symptoms, with effects indicated to be maintained over six months.

Study V was a controlled superiority trial, evaluating an improved version of the blended treatment used in Study IV to similar
\end{abstract}


methods and in a similar population. In comparison to minimal attention control, the blended treatment significantly reduced depression symptoms at post-treatment, corresponding to a large treatment effect.

Across Study II to V, estimates indicated that the amount of therapist time that could be saved in blended treatment, compared to standard psychological treatment, was around $40 \%$.

In conclusion, a gradual, blended integration of technology into psychological treatment i) performed well in treatment of adult and adolescent populations, ii) could substantially reduce therapist time in comparison to standard face-to-face psychological treatment, and iii) was accepted by patients as well as other mental health care stakeholders.

The thesis demonstrates the potentials of technology-assisted blended treatment models to deliver treatment of depression in the young and adult population in accordance with the current, urgent need to increase availability of psychological treatment as well as increase acceptance of technology-assisted mental health interventions.

Keywords: acceptance, adolescents, adults, blended treatment, cognitive behavioral therapy, depression, digital, internet-delivered, e-mental health, stakeholders, technology-assisted 


\section{LIST OF PUBLICATIONS}

I. Topooco, N., Riper, H., Araya, R., Berking, M., Brunn, M., Chevreul, K., Cieslak, R., Ebert, D. D., Etchmendy, E., Herrero, R., Kleiboer, A., Krieger, T., García-Palacios, A., CergaPashoja, A., Smoktunowicz, E., Urech, A., Vis, C., \& Andersson, G. on behalf of the E-COMPARED Consortium (2017). Attitudes towards digital treatment for depression: A European stakeholder survey. Internet Interventions, 8, 1-9.

II. Ly, K. H., Topooco, N., Cederlund, H., Wallin, A., Bergström J., Molander, O., Carlbring, P., \& Andersson, G. (2015).

Smartphone-supported versus full behavioural activation for depression: a randomised controlled trial. PLoS One, 10, e0126559.

III. Topooco, N., Luuk, L., Backlund, L., Bengtsson, L., Vernmark, K., Bergman Nordgren, L., Ödéhn, E., Radvogin, E., Riper, H., Kleiboer, A., \& Andersson, G. Blended face-toface and internet-assisted cognitive behavior therapy versus treatment as usual for depression: a controlled noninferiority trial. (Submitted for publication)

IV. Topooco, N., Berg, M., Johansson, S., Liljethörn, L., Radvogin, E., Vlaescu, G., Bergman Nordgren, L., Zetterqvist, M., \& Andersson, G. (In press). Chat- and internet-based cognitive behavioural therapy in treatment of adolescent depression: randomised controlled trial. British Journal of Psychiatry Open.

V. Topooco, N., Byléhn, S., Dahlström, E., Holmlund, J., Lindegaard, J., Johansson S., Åberg, L. Bergman Nordgren, L., Zetterqvist, M., \& Andersson, G. Internet-supported cognitive behavior therapy including chat sessions in treatment of adolescent depression: a randomized controlled trial. (Submitted for publication) 


\section{CONTENTS}

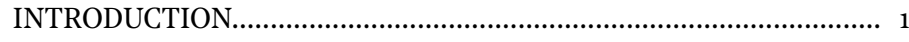

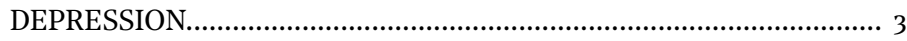

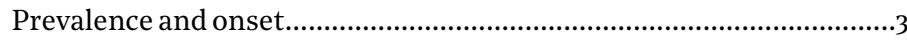

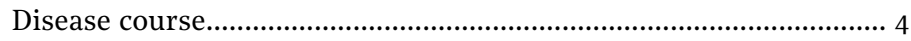

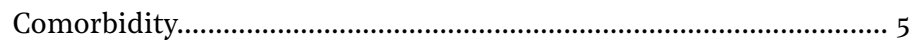

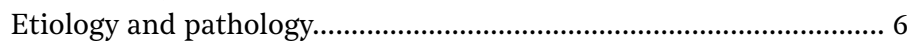

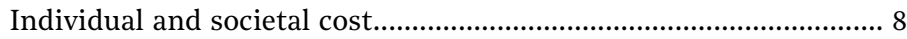

MANAGEMENT...........................................................................

Diagnostic assessment......................................................................... 9

Acute treatment............................................................................... 9

Pharmacotherapy.................................................................................. 11

Cognitive behavioral therapy.............................................................. 11

Empirical support..................................................................... 13

Clinical practice guidelines............................................................. 14

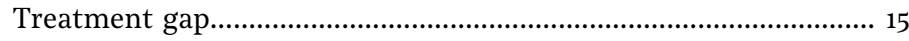

INTERNET-BASED COGNITIVE BEHAVIOR THERAPY..................... 17

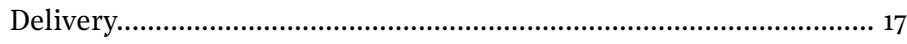

THE ROLE OF HUMAN SUPPORT.................................................... 19

Clinical effect and attrition................................................................ 19

Stakeholder experience................................................................... 22

BLENDED TREATMENT...................................................................... 25

What is blended treatment?......................................................... 26

Approaches for depression..................................................................26

Therapist sessions in blended treatment........................................... 27

Definition in this thesis..................................................................... 29

Development in this thesis............................................................ 29

AIMS OF THE THESIS......................................................................... 31

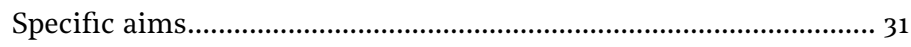

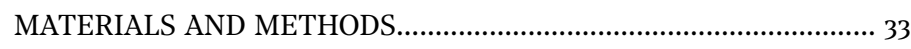

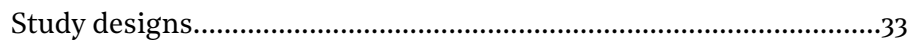

Study samples.................................................................................. 34

Instruments and eligibility criteria............................................... 36 


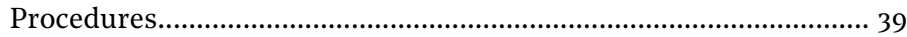

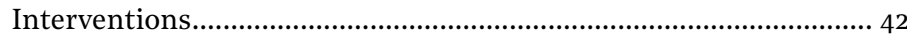

Analyses....................................................................................... 51

Sample calculation......................................................................... 53

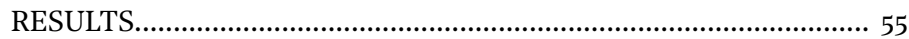

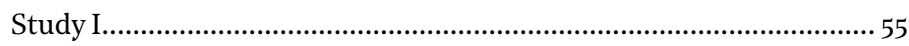

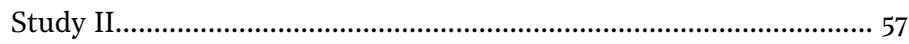

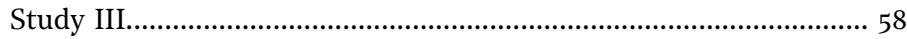

Study IV

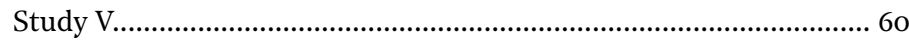

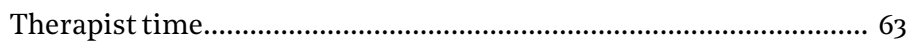

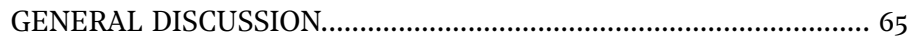

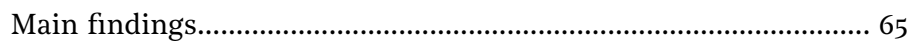

Acceptance of blended treatment...................................................... 65

Clinical effect of blended treatment..................................................... 66

Therapist time in blended treatment..................................................... 69

Negative effects of blended treatment................................................. 70

Generalizability of findings........................................................... 71

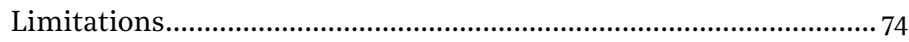

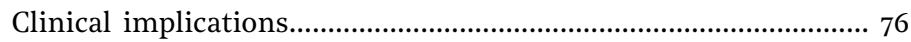

Conclusion and future research directions......................................... 77

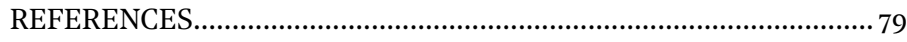

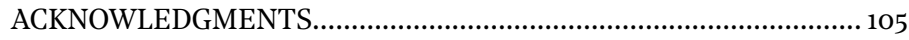





\section{INTRODUCTION}

The potential of online communication and technologies to increase capacity, access and precision in health care and mental health care is unprecedented. As part of the expansion of digital health, a myriad of technologies are being developed to assist in screening, monitoring, consultation and management of somatic and mental conditions (Duggal, Brindle \& Bagenal, 2018; Hollis et al., 2015; Mesko, Drobni, Benyei, Gergely \& Gyorffy, 2017; Vis et al., 2018). New technologies and methods - artificial intelligence, non-intrusive behavioral data collection, natural language processing and virtual reality - open the door to new intervention paradigms (Mohr, Weingardt, Reddy \& Schueller, 2017). The ability to access information, including objective personal data, is empowering to patients in initiating, making decisions about and managing their own wellbeing (Hollis et al., 2015; Mesko et al., 2017). Especially for young individuals, the combination of access, autonomy and discretion provided in the online arenas is attractive and sometimes critical to taking the first step toward mental health management (Gulliver, Griffiths \& Christensen, 2010; Hollis et al., 2015).

The demand for digital health services is high, and the innovation and uptake are not necessarily taking place within care settings. Private users who are willing to pay for services themselves are driving the expansion in mental health mobile apps, and start-ups, tech companies and insurance companies are developing interventions and services alongside mental health care experts (Patrick et al., 2016). Considerable focus has been put on the novel technologies and their possibilities, and less focus on the active mechanisms, strategies and goals of the interventions delivered (Mohr, Riper \& Schueller, 2018). A critical responsibility for mental health experts is to develop and evaluate digital psychological interventions in relation to sound psychological theory and make them visible and available where they are expected and needed (Hill et al., 2017; Hollis et al., 2015; Holmes et al., 2018). 
The aim of this thesis was to develop and investigate technologyblended psychological treatment delivery, blended treatment, in the management of adult and adolescent depression. Treatments are designed to address the current treatment shortages, and the need to improve scalability and access of psychological treatment.

The thesis consists of an initial survey, investigating attitudes towards blended treatment in mental health care target audiences, followed by a series of randomized controlled trials aimed at producing evidence on the short- and long-term outcomes of blended treatment in adult and adolescent depression - including aspects of acceptance, resource consumption and potential negative effects. Specifically, the thesis investigates acceptance of blended treatment among mental health care stakeholders on a European level, and the effect of blended treatment based on cognitive behavioral principles in relation to i) face-to-face psychotherapy and treatment as usual for adult depression, and ii) attention control in the management of adolescent depression.

Special attention has been focused on development of a blended treatment model for the adolescent population in relation to design and delivery, the aim being to improve treatment outreach and achieve high engagement and clinical effect. 


\section{DEPRESSION}

Depression is a mental disorder characterized by multiple and persistent behavioral, cognitive and physical symptoms, which significantly impair the individual's capacity to function in daily life. Individuals suffering depression experience low mood, sadness, guilt and loss of interest or pleasure in the things usually enjoyed, and they often experience changes in sleep, appetite, activity and cognition. It is not uncommon to have thoughts about death. When symptoms persist over weeks and are so intensive that it is difficult, or not possible, to function in daily life, the criteria for clinical depression, Major Depressive Disorder (MDD), are met (American Psychiatric Association; APA, 2013).

\section{Prevalence and onset}

On a global level, about 4 to $6 \%$ of the world's population suffer from depression each year (Bromet et al., 2011; World Health Organization; WHO, 2017). In 2015, this corresponded to more than 320 million individuals (WHO, 2017). The lifetime prevalence of MDD is estimated to be $15-20 \%$ (Bromet et al., 2011; Otte et al., 2016). Prevalence varies across studies and in different countries, which has been attributed to cultural and methodological differences (Otte et al., 2016; Weissman et al., 1996). In the WHO World Mental Health Surveys, 12-month prevalence figures across a range of low-income, middle-income and high-income countries have been found to be similar ( 5.5 to $5.9 \%$ ), establishing depression as a highly prevalent and stable disorder worldwide (Seedat et al., 2009).

Depression can develop at any age, with the peak risk ranging from middle to late adolescence up to early middle age (Bromet et al., 2011). Through adolescence and most of adulthood, when the prevalence rate of depression increases, a strong female preponderance in depression is observed (Kuehner, 2017). Overall, depression occurs roughly twice as often in girls and women as in boys and men (Hyde, Mezulis \& Abramson, 2008; Seedat et al., 2009). The global point prevalence for depression is $5.5 \%$ in women and 
3.2\% in men (Ferrari et al., 2013). In Sweden, age specific incidence rates of depression in women increase from adolescence to the age of 46-50 years followed by a marked decrease, whereas the incidence rates in men are stable throughout adulthood and therefore show a marked gender difference around middle age (Bogren, Bradvik, Holmstrand, Nobbelin \& Mattisson, 2018).

The median age of onset of depression has been estimated to about 25 years (Bromet et al., 2011), and it has been increasingly acknowledged that most individuals experience their first depressive episode already in adolescence (Hankin, 2006; Thapar, Collishaw, Pine \& Thapar, 2012). In pre-pubertal children, the prevalence of depression is low, with about $1 \%$ affected (Kessler, Avenevoli \& Ries Merikangas, 2001). Starting at puberty, the average levels of depressive mood and symptoms rise substantially. In early adolescence, the one-year prevalence of depression is 4 to $5 \%$, and by the end of adolescence, the cumulative probability for depression can be as high as $20 \%$, although estimates vary (Costello, Egger \& Angold, 2005; Hankin, 2006; Lewinsohn, Rohde, Klein \& Seeley, 1999). There is a strong continuity in recurrence of depression from adolescence to adult life, and depression in adolescence can be viewed as a sub-form of adult depression (Thapar et al., 2012). In a prospective longitudinal study that followed an entire birth cohort, $75 \%$ of adults suffering from depression were found to have had their first experience of a depressive disorder in late childhood or adolescence (Kim-Cohen et al., 2003).

\section{Disease course}

Although many individuals only experience one episode, depression can present an episodic and highly recurrent and chronic course and accompany the individual over the entire lifespan (Kessler, Berglund, et al., 2005; Vos et al., 2004). The gender disparity in depression prevalence entails more frequent depressive episodes in women than men rather than longer episodes (Otte et al., 2016). In population-based samples, the mean duration of a depressive episode is between three and seven months, with about 70-90\% of those affected recovering within one year (Keller et al., 1992; Otte et 
al., 2016; Ustun \& Kessler, 2002). However, more than half will experience a subsequent episode, typically within a 5-year period (Belsher \& Costello, 1988; Dunn \& Goodyer, 2006; Lewinsohn et al., 1999). In outpatient settings, recovery-rates not as favorable; less than $50 \%$ of patients show remission from depression within one year (Penninx et al, 2011; Wells, Burnman, Rogers, Hays \& Camp, 1992). For individuals who have experienced two depressive episodes, the risk of additional relapse increases to 80-90\% (APA, 2013; Keller, 1994; Kupfer, Frank \& Wamhoff, 1996; Post, 1992). It has been estimated that, on average, an individual with a history of depression will experience depressive episodes somewhere between five to nine times over their life-time (Kessler \& Walters, 1998; Kessler, Zhao, Blazer, \& Swartz, 1997).

\section{Comorbidity}

Depression is frequently diagnosed together with other mental disorders (Flint \& Kendler, 2014). In particular, the co-occurrence of depression and anxiety disorders is more the rule than the exception in adolescents as well as in the adult population (Balazs et al., 2013; Kessler, Chiu, Demler, Merikangas \& Walters, 2005; Penninx, 2015). The lifetime comorbidity of depression and one or several anxiety disorders has been estimated to be as high as $73 \%$ (Kessler, Chiu et al., 2005). Findings from longitudinal studies indicate a bidirectional connection between anxiety and depression (Avenevoli, Stolar, Li, Dierker \& Ries Merikangas, 2001; Moffitt et al., 2007), and suggested explanations include shared risk factors for multiple disorders, and anxiety disorders comprising risks or consequences of depressive disorder (Thapar et al., 2012). Comorbid anxiety disorders have been discussed as a diagnostic challenge in relation to possible over-detection of depressive disorder (Kupfer, Frank \& Phillips, 2012). For those individuals suffering from depression, a comorbid anxiety disorder is associated with more severe illness, higher chronicity, poorer psychosocial functioning, poorer treatment outcome and more suicide attempts (Hirschfeld, 2001; Karlsson et al., 2006; Lewinsohn, Rohde \& Seeley, 1995). 


\section{Etiology and pathology}

Today, our understanding of the interaction between genetic, neurobiological and environmental factors in the development of depression is limited, and no established mechanism can fully explain the etiology of the disease (Hasler, 2010; Otte et al., 2016). Depression is a heterogeneous disorder and the underlying physiological mechanisms are yet not understood (Belmaker, 2008). The established hypotheses of genetics, monoamine deficiency and stress with the involvement of the hypothalamic-pituitary-adrenal (HPA) axis as well as hormonal and growth factors have not been able to fully explain the pathogenesis of depression (Hassler, 2010; Belmaker, 2008).

Depression is known to cluster within families, and there is convincing evidence for a genetic contribution to disease susceptibility (Flint \& Kendler, 2014, Wray et al., 2018). The heritability of MDD has been quantified to $35-38 \%$ in meta-analyses (Cuijpers, Vogelzangs et al., 2014; Kendler, Gatz, Gardner \& Pedersen, 2006). Twin studies show that heritability is higher in women than in men (Kendler, Gardner, Neale \& Prescott, 2001; Kendler et al., 2006). Several environmental factors are associated with depression, in particular experiences of stress during childhood, such as sexual, physical or emotional abuse (Belmaker \& Agam, 2008; Li, D'Arcy \& Meng, 2016). Individuals with a history of such trauma are two times more likely than others to develop depression (Heim \& Binder, 2012), and show higher severity and poorer treatment response compared to depressed individuals without a history of trauma (Hovens et al., 2012; Weersing, Jeffreys, Do, Schwartz \& Bolano, 2017). Other environmental stress factors associated with depression are experience of illness, isolation, loss of family members, unemployment and altered sleep patterns (Kessler, 1997; Lorant et al., 2003). Investigation of molecular mechanisms that underlie gene-environment interactions indicates involvement of epigenetic regulation (Klengel \& Binder, 2015). At the neurobiological level, depression is associated with abnormalities in monoamine metabolism, growth factors, impaired corticosteroid receptor signaling, and GABAergic deficits (Flint \& Kendler, 2014). 
The findings of smaller hippocampal volumes and alteration in the neural connectivity or activation, e.g. the affective-salience network and the control network, have attracted considerable attention (Etkin, Buchel \& Gross, 2015; Otte et al., 2016). Physiological response to environmental stressors and altered HPA axis activation is a well-established hypothesis due to the glucocorticoid resistance and HPA axis dysregulation often seen in depression (Otte et al., 2016). Different endocrine modulation of neurotransmitter systems from sex hormones has been hypothesized as a possible explanation of the different incidence patterns in men and women (Kuehner, 2017).

In the adolescent population the disease mechanisms are less researched. The adolescent brain is in a period of neurodevelopment with learning, emotional and experience dependent plasticity, and at the same time exposed to a stressful psychosocial environment (Fischer, Camacho, Ho, Whitfield-Gabrieli \& Gotlib, 2018). The hormonal and environmental effects on depression are less well understood in the adolescent population as in the adult due to the marked hormonal and physiological changes from adrenarche through puberty and young adulthood. As for example the relationship between sleep patterns and cortisol changes is less clear among adolescents compared to adults (Rao et al. 1996).

The increasing availability of neuroimaging and neurophysiological technology in combination of molecular studies and genetic insights could allow further understanding of the pathophysiologic changes and perhaps provide future biomarkers for both diagnostics and treatment response (Kupfer et al., 2012; Otte et al., 2016). At this time, the literature does not provide support for any theory over others. Given the heterogeneity seen at the genetic and environmental level, it has been discussed whether depression may serve as a symptomatology of a multitude of independently acting mechanisms (Flint \& Kendler, 2014). 


\section{Individual and societal cost}

Given the typical early onset - during the time of educational attainment, and the forming of peer and relationships - depression can effectively disrupt development and accomplishments in a range of important life domains. Early depression onset is associated with decreased academic achievement, school dropout, teen pregnancy, poor educational and work performance, unemployment, impaired quality of family life, friendships as well as relationships (Kessler, 2012; Kim-Cohen et al., 2003; Ormel et al., 2008; Patel, Flisher, Hetrick \& McGorry, 2007), and predicts a downward spiral into additional and worsened mental and physical illness, including substance abuse and bipolar disorder (Avenevoli, Knight, Kessler \& Merikangas, 2008; Bardone et al., 1998; Copeland, Shanahan, Costello \& Angold, 2009; Kim-Cohen et al., 2003). At its worst, depression may lead to death. It has been estimated that half of all committed suicides in the world occur in the presence of a depressive episode (Hawton \& van Heeringen, 2009; WHO, 2016).

On a societal level, depressive disorder comprises the single largest contributor to non-fatal health loss in the world, posing an enormous economic burden in terms of loss of work capacity, sick leave and increased health and social care expenditures (Bloom et al., 2011; Hu, 2006; WHO, 2017). It has been estimated that every year, more than 12 billion days of productivity are lost globally due to depression and anxiety disorders. This corresponds to more than 50 million years of work being lost each year, at a cost of US 925 billion (Chisholm et al., 2016). By the year 2030, the economic cost of depression and other common mental disorders has been projected to US 6.o trillion (Bloom et al., 2011). 


\section{MANAGEMENT}

\section{Diagnostic assessment}

For diagnosis of depression and other mental disorders, two systems are used: The International Classification of Diseases system (ICD-10) and The American Diagnostic and Statistical Manual of Mental Disorders (DSM-5). The ICD-10, developed by the World Health Organization, is the international standard for the classification and reporting of all diseases and health conditions (WHO, 1992). The DSM-5 system, developed by the American Psychiatric Association (APA), focuses specifically on classification of mental disorders in children and adults (APA, 2013). The criteria for Major Depressive Disorder are largely similar but not identical in the ICD and DSM systems (Saito et al., 2010). Box 1 on page 10 presents the DMS-5 diagnostic criteria for Major Depressive Disorder, used for diagnosis in this thesis (APA, 2013).

\section{Acute treatment}

Depression management is divided into three phases: acute treatment to achieve clinical response and remission of symptoms; continuation management to prevent depression relapse; and maintenance management, focusing on prevention of the development of new episodes (Emslie, Mayes \& Ruberu, 2005). For acute treatment of depression - the focus of this thesis - there are currently two main initial treatment options: psychotherapy and pharmacotherapy (Otte et al., 2016). 


\section{BOX 1. DSM-5 DEFINITION OF \\ MAJOR DEPRESSIVE DISORDER; AMERICAN PSYCHIATRIC ASSOCIATION, 2013}

1. PRESENCE OF AT LEAST FIVE OF THE FOLLOWING SYMPTOMS PRESENT MOST OF THE DAY, NEARLY EVERY DAY, OVER A PERIOD OF TWO WEEKS, INCLUDING AT LEAST ONE OF THE CARDINAL SYMPTOMS FOR DEPRESSION, DEPRESSED MOOD OR LOSS OF INTEREST OR PLEASURE FOR ACTIVITIES:

- CARDINAL SYMPTOM: DEPRESSED MOOD MOST OF THE DAY, NEARLY EVERY DAY. FOR CHILDREN AND ADOLESCENTS, IRRITABLE MOOD IS ALLOWED A CARDINAL CRITERION RATHER THAN DEPRESSED MOOD

- CARDINAL SYMPTOM: MARKEDLY DIMINISHED INTEREST, OR LOSS OF PLEASURE IN ALMOST ALL ACTIVITIES.

- $\quad$ SIGNIFICANT WEIGHT CHANGE (5\% IN A MONTH), OR APPETITE DISTURBANCE NEARLY EVERY DAY

- $\quad$ SLEEP DISTURBANCE (INSOMNIA OR HYPERSOMNIA)

- PSYCHOMOTOR AGITATION OR RETARDATION (OBSERVABLE BY OTHERS)

- $\quad$ FATIGUE OR LOSS OF ENERGY

- FEELINGS OF WORTHLESSNESS OR EXCESSIVE INAPPROPRIATE GUILT (WHICH MAY BE DELUSIONAL)

- DIMINISHED ABILITY TO THINK AND CONCENTRATE, OR INDECISIVENESS (EITHER BY SUBJECTIVE ACCOUNT OR AS OBSERVED BY OTHERS)

- $\quad$ RECURRENT THOUGHTS OF DEATH, SUICIDAL IDEATION WITHOUT A SPECIFIC PLAN, SUICIDE ATTEMPT, OR A SPECIFIC PLAN FOR COMMITTING SUICIDE

2. THE EXPERIENCED SYMPTOMS CAUSE CLINICALLY SIGNIFICANT DISTRESS OR IMPAIRMENT ON SOCIAL, OCCUPATIONAL OR OTHER IMPORTANT AREAS OF FUNCTIONING.

3. SYMPTOMS ARE NOT BETTER EXPLAINED BY SCHIZOPHRENIA SPECTRUM AND OTHER PSYCHOTIC DISORDERS

4. SYMPTOMS ARE NOT ATTRIBUTABLE TO PHYSIOLOGICAL EFFECTS OF A SUBSTANCE OR TO ANOTHER MEDICAL CONDITION.

5. THE INDIVIDUAL HAS NOT EXPERIENCED A MANIC OR HYPOMANIC EPISODE. 


\section{Pharmacotherapy}

A range of antidepressant drugs, categorized according to their different mechanisms of action, are available for treatment of depression. The five major classes include tricyclic- (TCA), selective serotonin reuptake inhibitors (SSRI), selective serotoninnoradrenaline reuptake inhibitors (SNRI), monoamine oxidase inhibitors (MAOI) and atypical antidepressants (Kupfer et al., 2012). Among these, the most commonly prescribed are SSRI and SNRI (Bauer et al., 2008). The common proposed mechanism of action for antidepressants is alteration of chemical balances in the brain - the antidepressant drug is designed to target and modify the distribution of neurotransmitters associated with mood. Neurotransmitter(s) targeted include serotonin, noradrenaline, dopamine, histamine, tyramine and/or tryptamine - different drugs are proposed to work in different ways and to have different effects on neurotransmission (Otte et al., 2016). The exact mechanisms underlying the effect of antidepressants are very complex and not fully understood (e.g., Cipriani et al., 2018; Otte et al., 2016).

\section{Cognitive behavioral therapy}

Psychotherapy is a universal term for a multitude of therapeutic approaches. Among these, cognitive behavior therapy represents one of the best empirically supported paradigms (e.g., Butler, Chapman, Forman \& Beck, 2006; Cristea et al., 2017; Driessen \& Hollon, 2010). The theoretical framework of CBT includes a family of multiple learning and cognitive theorems, which share the central assumption that depression is caused and maintained by unhelpful, maladaptive cognitions and behaviors (Hofmann, 2011; Wenzel, 2017). The behavioral theory of depression (often shortened to BT) focuses on the individual's own behaviors in relation to the establishment and maintenance of depression. The approach was developed in the 1970s in different variants and based on use of learning theory principles to modify unwanted behavior and emotional reactions (Dimidjian, Barrera, Martell, Muñoz \& Lewinsohn, 2011). Learning theory looks for general principles to explain how the individual learns new associations between stimuli 
(events in the environment) and responses (own observable and measurable reactions (Kennerley, Kirk \& Westbrook, 2011). The behavioral approach that remains the most prominent today was developed by Peter Lewinsohn and colleagues (e.g., Lewinsohn, 1974). This approach is founded on classical conditioning and operant learning and explains depression as a lack of responsecontingent positive reinforcements in life - the individual receives too little reward in the environment, for example, positive rewards for his/her own efforts (Wenzel, 2017). As a consequence, the individual loses hope, becomes more passive, helpless and depressed. This leads to even fewer positive rewards. In response to this, behavioral activation was developed as a strategy to reinstate and reinforce behaviors in the individual that can increase the chances of positive consequences, thus elevating mood (Mazzuchelli, Kane \& Rees, 2009). Treatment with behavioral activation targets behaviors considered to be maladaptive and to maintain depression and focuses on changing these into behaviors that can generate positive consequences (Kennerley et al., 2011).

The Beckian theory of depression (CT), developed by Aaron Beck in the 1960-70s, is a comprehensive theory on the cause and maintenance of depression, central to which is the role of cognition - more specifically inaccurate beliefs and maladaptive processing of information (Powers, de Kleine \& Smits, 2017). Beck described the different cognitions that occur in depression as the negative cognitive triad: 1) negatively biased views of oneself, 2) of the world in general, and 3) of the future (Kennerley et al., 2011). Beck's cognitive model of depression suggests that the correction of maladaptive thinking patterns seen in the triad can reduce depression and moreover the likelihood of future relapse into depression (Powers et al., 2017).

Over subsequent years, BT and CT eventually merged together, forming what we now most commonly refer to as cognitive behavior therapy ,CBT, which entails both the behavioral and cognitive approach and the core strategies connected to the respective domains (Kennerley et al., 2011). 
The principles of treatment in CBT include the therapist and patient being active in all treatment phases, and the delivery of treatment in a structured and collaborative manner. First, a customized case formulation and treatment plan are formed, including treatment goals. Thereafter, the therapist assists the patient in the process of mastering focused and targeted CBT treatment strategies, the aim being to achieve treatment goals and mitigate depression (Wenzel, 2017). Depression is not seen as fundamentally different from the normal state, rather as an exaggerated or extreme version at the end of a continuum, with normal processes at the other end. Thus, psychological problems can occur in anyone (Kennerley et al., 2011).

\section{Empirical support}

For management of adult depression, psychotherapy and antidepressants are at this time thought to produce similar effects (Amick et al., 2015; Cuijpers et al. 2013). Recent studies have suggested a small advantage of medication over CBT (Cuijpers \& Cristea, 2015) or no meaningful differences between treatment approaches in self-rated depression measures or in remission-rates from depression diagnosis (Weitz et al., 2015). For antidepressants, no meaningful differences in efficacy are in general have been found between different classes (e.g. Gartlehner et al., 2011). A review on the effect of 21 different antidepressants in over 100,000 patients concluded that all antidepressants are more effective than a placebo (SMD Cohen's $d=0.30$ ) and that there are no differences between different kinds of antidepressants (Cipriani et al., 2018). The effect of CBT in comparison to non-active control in treatment of depression has been estimated to be overall $g=0.72$ (Cristea et al., 2017). Psychological treatment with behavioral activation only (BT) produces effects similar to those of CBT (e.g., Richards et al., 2016). Combination treatment using pharmacotherapy and psychotherapy has been found to outperform either treatment alone (Cuijpers, de Wit, Weitz, Andersson, \& Huibers, 2015; Cuijpers, Dekker, Hollon \& Andersson, 2009; Cuijpers, Sijbrandij et al., 2014; Cuijpers, van Straten, Warmerdam \& Andersson, 2009; Karyotaki et al., 2016). 
For adolescents, the evidence regarding the relative effect of treatments, including combined psychotherapy and antidepressant treatment, is more limited and somewhat unclear (e.g., Brent et al., 2008; Cox et al., 2014; March et al., 2004). SSRI (Fluoxetine) has been shown to be superior to placebo treatment and to have few side effects (Cipriani et al., 2016; Hetrick, McKenzie, Cox, Simmons \& Merry, 2012). Effect sizes for CBT were initially large, but have become more modest as analyses have become more rigorous (e.g., Weisz, McCarty \& Valeri, 2006; Zhou et al., 2015). A meta-analysis that scoped and reviewed all trials conducted up to 2015 found CBT to be the best supported psychotherapy approach for adolescent depression. However, there was considerable inter-trial heterogeneity, in that not all included trials found CBT to be reliably efficacious (Weersing et al., 2017).

Adverse effects of psychotherapy are rare but occur (e.g., nonresponse, deterioration; Rozental, 2016), while such effects are more common for antidepressants. Nausea, insomnia, headaches, dizziness, sexual dysfunction, sleep disturbance and weight gain are documented for SSRI and SNRI (Cassano \& Fava, 2004), which are the antidepressants considered to cause least side effects (Kupfer et al., 2012). For the young population, there are concerns about antidepressants possibly being associated with suicidal thinking and behavior (Friedman \& Leon, 2007).

\section{Clinical practice guidelines}

Across Europe and America, clinical practice guidelines give psychotherapy and pharmacotherapy similar priority in the acute treatment of mild to moderate depression (APA, 2010; Davidson, 2010; National Institute for Health and Care Excellence; NICE, 2009; Parikh et al., 2016; The National Board of Health and Welfare, 2017a), with more emphasis being put on pharmacological treatment in the American guidelines. For the young population, clinical guidelines put more emphasis on psychotherapy (Birmaher et al., 2007; Cheung et al., 2007; MacQueen et al., 2016; McDermott et al., 2010; NICE, 2005; The National Board of Health and Welfare, 2017a). 


\section{Treatment gap}

Clinical practice does not always follow the stated recommendations. There has been a long tradition of inadequate care investments in relation to the burden of mental health disorders. As a result, there is currently a crisis in mental health care, where public care systems worldwide are grossly underpowered to manage the burden of depression (Chisholm et al., 2016). People in need of treatment for mental health conditions do not have access to care services (Saxena, Thornicroft, Knapp \& Whiteford, 2007), experience long waiting times (Kessler, Berglund et al., 2001), face high care expenditures (Wittchen et al., 2011) or do not receive evidence-based treatment (Kessler et al., 2003; Wang et al., 2005). Based on estimates for $80 \%$ of the world's population, the gap between those in need of depression treatment and the resources available is currently estimated to $72-93 \%$, depending on country income level (Chisholm et al., 2016).

The current financial constraints and the limited number of clinicians trained to provide treatment are key barriers, in particular to the provision of psychotherapeutic treatment. Although the majority of patients prefer psychotherapy to antidepressants (McHugh, Whitton, Peckham, Welge \& Otto, 2013), the immediate costs and resource requirements of psychotherapy are too high to allow such treatment to be widely administered as needed. Across 144 low- and middle-income countries, a shortage of over 1 million mental health care workers has been estimated (WHO, 2011). In comparison, antidepressants are cheaper, more available and administering them requires considerably fewer resources (Andrews et al., 2018). It has been estimated that of the primary care patients treated for depression, about $70 \%$ are treated with antidepressants (Olfson, Blanco \& Marcus, 2016; Sleath, Rubin \& Huston, 2001; Verhaak, van Dijk, Nuijen, Verheij \& Schellevis, 2012). In the field of psychological treatment, initiatives focused on how treatments can be scaled up to reduce the treatment gap for depression and other mental disorders are a top priority (Holmes et al., 2018). 


\section{INTERNET-BASED COGNITIVE BEHAVIOR THERAPY}

The possibility to automatize psychological treatment delivery with technology- and internet-assistance, means that treatments can be scaled up and made available to many more patients (Andersson, 2016; Hollis et al., 2015). Given its structured and focused delivery, CBT is thought to be particularly well suited to adaption in digital format. The first early versions evolved in the 9os, in the form of CD-ROM delivered on a stationary computer. Then and thereafter, internet-delivered CBT approaches (ICBT) have continuously been designed to adhere closely to the outline of traditional CBT (Andersson, 2009; Wozney et al., 2017). The experience of traditional CBT and that of ICBT, however, are hardly equivalent. The delivery of ICBT is highly standardized - while available 24 hours a day for patients, treatment delivery requires minimal resources from the clinician, if any at all. This is the fundamental rationale for ICBT: It can reach people for whom there are no therapists available, who cannot take time off from work, who cannot afford treatment, or who fail to seek other help for reasons of stigma or fear of being judged by others (Rosenberg, 2015).

\section{Delivery}

Just as face-to-face CBT is divided into individual sessions, the delivery of ICBT is arranged into digital chapters, often called modules or sessions. Modules usually consist of informative text and connected homework assignments, and pictures, movie clips and figurative instructions are included to a varying extent. For adult patients, an ICBT treatment for depression contains about eight to fifteen modules (Andersson \& Carlbring, 2017). Programs for younger populations tend to be shorter and to include more interactive elements (Merry et al., 2012; Wozney et al., 2017). ICBT therapy is often time limited, and the patient is usually expected to work through one module each week, focusing on understanding and applying the principles of a specific CBT technique (Andersson, 
2016). The treatment is accessed in an online treatment platform. The interfaces of treatment platforms have been compared to that of internet banking (Andersson \& Carlbring, 2017).

ICBT can either be delivered as pure self-help or include limited support from a clinician or a trained coach. Unguided ICBT can be viewed as a massive open online course (MOOC), free to everyone, and providing information on what affects mental health and how to manage personal wellbeing in a structured manner. Programs can offer motivational prompts such as automated reminders and feedback on tests, but no individual assistance. They can be powerful tools to prevent depression at an early level, teaching resilience on a population-based level. Indeed, openly available interventions such as unguided ICBT have been conceptualized massive online interventions, or MOOIs (Muñoz et al., 2016).

Guided ICBT adds some degree of clinician contact. The role of the clinician is to administer modules, review and provide feedback on treatment progress and answer questions. Therapist-patient contact usually takes the form of platform messages, where the therapist provides regular semi-standardized or individual feedback (Andersson, Carlbring, Berger, Almlöv \& Cuijpers, 2009). Support can also be provided via telephone (e.g., Holst et al., 2017). An alternative approach is support on-demand, where the patient specifically requests feedback from the clinician. Administration time for the clinician usually does not extend beyond 15 min per week and patient (Baumeister, Reichler, Munzinger \& Lin, 2014; Hedman, Ljotsson, \& Lindefors, 2012). Compared to standard faceto-face treatment, guided ICBT has been estimated to save therapist time by up to $85 \%$ (Hedman et al., 2012). 
One of the most important findings concerning ICBT is that human support matters. Clearly the social element - having someone to talk to or just knowing someone is there, monitoring one's effort - is important to maintaining motivation to continue ICBT depression treatment and improving because of it.

\section{Clinical effect and attrition}

In adult populations, guided ICBT, as opposed to unguided programs, is associated with larger treatment effects (Andersson \& Cuijpers, 2009; Andersson \& Titov, 2014; Baumeister et al., 2014; Richards \& Richardson, 2012). ICBT with clinician guidance has been found to be effective for depression and other common mental disorders (e.g., Andersson, Cuijpers, Carlbring, Riper \& Hedman, 2014; Cuijpers, Donker, van Straten \& Andersson, 2010; Kuester, Niemeyer \& Knaevelsrud, 2016: O'Mahen et al., 2014), insomnia (Trockel, Karlin, Taylor \& Manber, 2014) as well as a range of somatic conditions (e.g., Andersson, 2016; Cuijpers et al., 2010; Cuijpers, van Straten \& Andersson, 2008). In one of the more recent reviews, the overall treatment effect for ICBT for depression, based on 32 trials and 5642 patients, was estimated to $g=0.67$ (Andrews et al., 2018). Reviews that have compared guided ICBT against a full standard CBT depression protocol suggest that ICBT is no less effective (e.g. Andersson, Topooco, Havik \& Nordgreen, 2016). In comparison, selfhelp programs produce small treatment effects that sometimes merely surpass the lower cut-off point for what is considered clinical relevance in treatment of depression (Ebert \& Baumeister, 2017; Karyotaki et al., 2017). The effects for self-help ICBT might also be overestimated, because in research settings self-help ICBT often includes therapist contact in the initial assessment, for example in one-on-one diagnostic interviews with a clinician before and after treatment completion. Thus, the self-help programs can be said to provide some form of support (Baumeister et al., 2014). A closer investigation by Johansson and Andersson (2012) found that mean effect estimates become increasingly higher with increased support. 
Trials including no contact produced lower effects $(d=0.21)$ compared to trials that provided contact before intervention, such as diagnostic interviews $(d=0.44)$, contact also during intervention $(d=0.58)$, and trials that provided contact before and during intervention $(d=0.76)$. True self-help programs, conducted without any support or interaction, show among the highest dropout rates and smallest effects in the field. For example, among 82,0oo users who accessed a public online CBT self-help program, $27 \%$ completed one module and $10 \%$ completed two or more of the five modules available (Batterham, Neil, Bennett, Griffiths \& Christensen, 2008).

For the young population, systematic reviews have shown that guided ICBT can produce significant improvement in adolescents presenting with MDD, subthreshold depression, or who are at risk of developing depression (Ebert, Zarski et al., 2015; Pennant et al., 2015; Richardson, Stallard \& Velleman, 2010). Many programs are transdiagnostic and target both depression and anxiety (Wozney et al., 2017). In a recent review, the overall effect for ICBT targeting depression youth was $g=0.76$ (Ebert, Zarski et al., 2015). One example of the effect of guidance on completion shows how $60 \%$ of adolescent users terminated their use after the first module when conducting self-help ICBT, whereas when the same program included monitoring and support, this dropout rate decreased to 10\% (Neil, Batterham, Christensen, Bennett \& Griffiths, 2009). Studies on ICBT for adolescents, however, have tended to show poorer outcomes in general (Pennant et al, 2015), and for guided ICBT as well there have been reports of limitations in relation to enrollment (Crutzen, Bosma, Havas \& Feron, 2014; Stasiak, Hatcher, Frampton \& Merry, 2014), attitudes toward programs (Bradley et al., 2012; Gerrits, van der Zanden, Visscher \& Conijn, 2007; Stallard, Velleman \& Richardson, 2010; Stasiak et al., 2014), and program completion (Calear, Christensen, Mackinnon, Griffiths \& O'Kearney, 2009; O'Kearney, Kang, Christensen \& Griffiths, 2009).

There are inconsistencies in findings (Königbauer, Letsch, Doebler, Ebert \& Baumeister, 2017) and differences in sampling may be a confounder: self-help programs tend to have community-based participants, while guided interventions include primary care 
samples (Richards \& Richardson, 2012; Zagorscak et al, 2018). It has been shown that samples including less depressed individuals tend to produce poorer outcomes (Bower et al., 2013). It is also possible that results on guidance are being confounded with technological development (Baumeister et al., 2014). It could be that limitations in effects and attrition seen for ICBT are related to programs being rather simplistic and outdated, thus not fully taking advantage of persuasive design components, and that more modern and sophisticated programs will demonstrate improved effects and completion rates. There are examples of the effect of unguided ICBT improving when automatic prompts were included in treatment (Titov, Andrews, Choi, Schwencke \& Johnston, 2009; Titov, Andrews, Choi, Schwencke \& Mahoney, 2008). However, observing consumer markets, e.g., mHealth, where technologies are developed to be appealing and engaging so they will stand out and attract customers, most of them are struggling to engage the user beyond the initial download as well. High levels of attrition are observed (Payne, Lister, West \& Bernhardt, 2015). There is a trend toward innovation moving beyond self-reliant apps to apps or multi-platform services that include some form of contact or consultation. Examples include therapist messaging services (e.g., Talkspace, 2018), automated conversational agents (e.g., Fitzpatrick, Darcy \& Vierhile, 2017; Ly, Ly $\&$ Andersson, 2017) and apps that feature peer-to-peer support (e.g., Baumel, Tinkelman, Mathur \& Kane, 2018; Colón-Semenza, Latham, Quintiliani \& Ellis, 2018; Gulliver et al., 2017).

Unguided ICBT interventions offered to the community, means that many people can join these interventions. Accordingly, many dropouts can be expected as well. This is not necessarily a problem no additional cost is associated to repeated use of the intervention, and still a large number of users will potentially benefit from the interventions (Munoz et al., 2016). However, in the contexts of patients suffering clinical level of depression, the differences in completion and effects between guided and unguided interventions starts to become more relevant. This can be exemplified by a recent study by Holst and colleagues, which assessed primary care patients' experiences of guided ICBT for depression. The authors found that 
patients appreciated the support that was included via email and phone - it was described as a needed push to move forward in treatment (Holst et al., 2017). Despite the support, the patients expressed feeling left alone with too much individual responsibility. Having someone would listen was perceived as important and lacking. Patients desired real-time interaction with a therapist to get feedback and to be able to progress in treatment. There were also patients who felt offended being offered ICBT, feeling this indicated that they were not prioritized or cared for (Holst et al., 2017).

Adolescents interviewed about their expectations and preferences concerning online interventions for mental health have expressed that the discretion of online support is a great advantage (Bradley, Robinson \& Brannen, 2012; Sindahl, 2013; World Childhood Foundation, 2012). This is important, given that limited mental health literacy, stigma and fear of others knowing about one's mental illness is especially prevalent among young people and hamper help-seeking (e.g., Coles et al., 2016; Gulliver et al., 2010; Melas, Tartani, Forsner, Edhborg \& Forsell, 2013; Vanheusden et al., 2008). However, as previously mentioned, adolescents have also been found not to complete self-help ICBT, and comments about non-completion concern the need to talk to someone, not to go through a program (e.g., Lillevoll, Vangberg, Griffiths, Waterloo \& Eisemann, 2014). Indeed, the need to talk to someone for reasons of mental health is evident from online counseling services and chatsupport lines for youth (e.g., Children's Rights in Society, 2013; Rickwood, Webb, Kennedy \& Telford, 2016; Sindahl, 2013).

\section{Stakeholder experience}

Acceptance from key mental health care target users, for example those that would recommend and use internet-based treatments format is necessary to allow transfer of ICBT from research settings into real world care settings. This movement has however been slow with uptake rates lagging behind its potential (Ebert, Berking et al., 2015, Vis et al., 2015). Multiple studies have investigated clinician's views on internet interventions, and have found that attitudes range are often positive but cautious (e.g., Stallard, Richardson \& 
Velleman, 2010; Vigerland et al., 2014; Schröder et al., 2017). There are findings of clinicians being more reserved towards online treatment than potential patients (Schröder et al., 2017). A primary concern seems to be perceived limitations when it comes to deal with crisis situations online, such as when a patient indicates significant deterioration or suicidal ideation (Perle, Langsam \& Nirenberg, 2011). Other concerns include doubts about treatment effect and possible negative effects in the form of limited therapistpatient alliance in treatment (e.g., Becker \& Jensen-Doss, 2013). Internet interventions are regarded more appropriate for milder forms of depression (Gun, Titov \& Andrews, 2011). On organizational perspective, clinicians interviewed have also highlighted lack of ethical guidelines for the conductions of online therapy (Feijt, de Kort, Bongers \& IJsselsteijn, 2018). 


\section{BLENDED TREATMENT}

Blended treatment is emerging as an innovative treatment approach that combines the benefits of standard and online psychological treatment (Kleiboer et al., 2016). The focus is on investigating how therapist contact and online standardized treatment components can support each other, interplay, and possibly enhance the effect of psychological treatment (Erbe, Eichert, Riper \& Ebert, 2017). While still rather novel as regards scientific evaluation, blended treatment can be said to have existed for a long time in the everyday settings of clinicians. Some fifteen years ago, an English survey showed that almost all CBT therapists in the survey used bibliotherapy as a supplement to face-to-face therapy (Keeley, Williams \& Shapiro, 2002). Therapists have also long used text messaging and emails between sessions (Eonta et al, 2011; Murdoch \& Connor-Greene, 2000). Today, the many technologies available to assist psychological treatment has prompted comprehensive guides for clinicians concerning how to incorporate technology into everyday practice (e.g., Magnavita, 2018). For the formalization of blended treatment that is taking place within research settings, these observations are promising and indicate acceptance and perceived relevance among those who would be using blended treatment formats.

As regards to the development and investigation of blended treatment, the expectation is that this format may be advantageous for a number of reasons, including: 1) it mirrors the gradual integration of technology seen in daily life and clinical practice (Eonta et al, 2011) and may thus facilitate acceptance, 2) it is in line with findings on the importance of guidance to provide clinical effect and maintain engagement in online interventions (Baumeister et al, 2014), 3) it may significantly reduce therapist sessions compared to standard treatment (e.g., Wright et al., 2005), 4) it retains the advantages of increased availability by means of saved travel time, discretion and allowing the patient to process treatment at his/her own pace, and 5) it can, like ICBT, help prevent therapist drift and ensure that standard treatment quality criteria are met (e.g., Erbe et al., 2017; Urech, 2018). 


\section{What is blended treatment?}

No universal definition of blended treatment and what it comprises exists (Erbe et al., 2017; Wentzel, van der Vaart, Bohlmeijer \& van Gemert-Pijnen, 2016). However, the assumption seems to be that the therapist contact refers to face-to-face sessions. The term 'blended' have been used to describe varying interventions that include online components either between therapist sessions, prior to sessions, or following standard face-to-face treatment as a form of supplementary post-intervention. In a recent review focusing on mental disorders in adults, blended treatment was defined as treatments that use elements of both face-to-face sessions and internet-based treatment components, combined in an integrated or sequential manner (Erbe et al., 2017). Integrated refers to designs where online treatment and face-to-face components are mixed in order, and sequential refers to programs where the online part is delivered prior to or following standard sessions. The rationale and aim for blended treatment approaches vary depending on whether the blended treatment is integrated or sequential. Integrative approaches tend to focus more on the potential in blended treatment to save clinician time by delegating elements in therapy to online and automatized treatment delivery. The objectives for sequential blended approaches have for example been to bridge waiting time to therapy, or to include treatment alternatives in a stepped care framework, where online components are offered initially, followed by face-to-face therapy if the initial online treatment fail to produce improvement (Erbe et al., 2017).

\section{Approaches for depression}

Focusing on blended approaches evaluated for treatment of depression, several promising findings have been reported. Results for integrated programs include several small randomized controlled trials, where the authors have concluded that blended CBT treatment seems to produce effects similar to standard treatment for adolescent and adult depression, and to do so using less therapist time than standard treatment (e.g., Sethi, Campbell \& Ellis, 2010; Wright et al., 2005). A small explorative study also 
investigated a type of on-demand blended treatment approach (Jacmon, Malouff \& Taylor, 2009). Here, adult patients suffering from depression were assigned to an online treatment program, and informed that if they needed more support they could request up to nine additional face-to-face sessions. Patients on average requested 3.7 standard sessions in addition to the online program. The authors concluded that the blended treatment seemed to produce treatment effects similar to face-to-face CBT, but to use substantially less faceto-face time. Recently, a larger randomized controlled trial evaluated blended treatment compared to face-to-face CBT treatment for management of adult depression. The blended treatment was estimated to reduce therapist time to one third. At post-treatment, and after six months, no differences were found between the two conditions in terms of improvement on the primary outcome measures and depression remission rates (Thase et al., 2018). Promising findings on sequential blended treatments include a randomized controlled trial where patients with MDD underwent a ten-week ICBT program after completing face-to-face treatment (Holländare et al., 2011). Here, the authors found that patients who were provided the ICBT program relapsed to a significantly lesser degree compare to patients who were not, and the between-group effects were retained over six months. The early findings on CBT blended treatments for depression are promising and indicate that the approach can be effective while requiring fewer therapist resources. The suggested advantages should be further established.

\section{Therapist sessions in blended treatment}

While the therapist-support in guided ICBT is brief and typically asynchronous, e.g. platform messages, blended treatment is characterized by the inclusion of therapist-sessions. As noted, no universal definition of blended treatment exists, but it seems that therapist sessions are assumed to be conducted face-to-face (Erbe et al., 2017). This makes sense, given that face-to-face therapy is considered best practice and blended approaches thus relate to this standard. However, there are several alternative ways to conduct 
therapy sessions, which may also be advantageous and further reduce barriers to psychological treatment. For example, using telephone and video calls has been proven to be an effective method of treatment delivery (Mohr et al., 2005; Mohr, Vella, Hart, Heckman \& Simon, 2008; Osenbach, O'Brien, Mishkind \& Smolenski, 2013; Simpson \& Reid, 2014). These formats have the strength of overcoming geographical barriers to treatment. They are not focused on reducing therapist time (Gros et al., 2013), however increased efficiency may be possible due to the flexibility of location and work-arounds before and after the session. Conducting therapist sessions using text messaging and instant messaging (chat) overcomes distance as well. Moreover, this approach could potentially reduce therapist time in comparison to face-to-face, video or phone contact. Conducting multiple parallel chat sessions for reasons of time-efficiency is established practice in business customer-support settings (TELUS, 2015) and is used in some chathelp lines for youth as well (Sindahl, 2013). Commercial and nonprofit services that provide chat-based support for mental health issues are at present rather common (e.g., Hoermann, McCabe, Milne \& Calvo, 2017; Rickwood et al, 2016; Sindahl, 2013; Talkspace, 2018). In particular young people seem to appreciative the medium. It has been reported that, in Sweden, the capacity for incoming chat requests can be as low as 5\% (Children's Rights in Society, 2013). Characteristic of these services is that they provide immediate and individual support, while ensuring anonymity, or at least privacy. Users have reported that they can talk openly without fear of being judged or embarrassed, that they can better express themselves in writing, and that not seeing another person's judgment is helpful, as is the possibility to go through emotional reactions in privacy (e.g., Sindahl, 2013; World Childhood Foundation, 2012). There are few but promising examples of ICBT taking advantage of the chat medium in treatment of depression (e.g., Gerrits et al., 2007; van der Zanden, Kramer, Gerrits \& Cuijpers, 2012). 


\section{Definition in this thesis}

Because many different formats of blended treatment exist, the definition and underlying arguments for the blended treatment approaches developed and investigated in this thesis are summarized here.

The focus is on the integrated approach to blended treatment, where therapist sessions and online self-help components are mixed in a given order. The rationale for this is to take advantage of the therapist throughout the treatment in terms of providing support, maintaining engagement and ensuring that treatment strategies are understood and applied. In this format, the online part of treatment can be framed as reaching out a continuous and extended therapist arm between sessions.

The focus is for blended treatment to be relevant in terms of scalability and cost-savings. This means that the treatments developed and investigated aim at reducing the total therapist time in comparison to standard face-to-face treatment.

The definition of blended treatment is not restricted to therapist sessions that are conducted face-to-face. Alternative ways to provide therapist support while reducing the total time spent by therapists are explored as well.

Blended treatments are based on CBT or BT, thus relying on the empirical support accumulated for standard CBT treatment (e.g., Cristea et al., 2017; Parikh et al., 2016), standard behavioral activation (e.g., Jacobson et al., 1996; Richards et al., 2016) and internet-based CBT, respectively (e.g., Andrews et al., 2018).

\section{Development in this thesis}

The first blended approach developed in this thesis (Study II, Study III) acknowledged that elimination of therapist-patient contact has been perceived as a limitation of ICBT, including guided ICBT (e.g., Holst et al., 2017; Kivi et al., 2015; Schröder et al., 2017), while online treatment components have been positively viewed and shown to be effective in blended formats that include standard sessions (e.g., Jacmon et al., 2009; Kivi et al., 2015; Richards \& Richardson, 2012; 
Sethi et al., 2010; Thase et al., 2018). This blended approach included face-to-face sessions, though the number of sessions was reduced in comparison to standard treatment.

The second blended approach developed in this thesis (Study IV, Study V) specifically targeted the adolescent population. In addition to clinical outcome, the design and delivery of the blended treatment focused on stigma-decreasing aspects and user engagement optimization. This blended approach included chatbased sessions and was conducted fully online. In comparison to standard delivery, sessions were not reduced - instead, enhanced therapist efficiency relied on the principle of parallel sessions. 


\section{AIMS OF THE THESIS}

The overall aim of the thesis was to develop and investigate blended treatment approaches to depression based on CBT principles. In development of blended treatment, the focus was on maintaining the active therapist-patient collaboration in therapy and complementing it with online components in an integrated treatment approach.

\section{Specific aims}

1. To investigate attitudes toward blended treatment among mental health stakeholders who would be involved in or affected by the integration of such treatments into regular care practices.

2. To investigate the feasibility and clinical effect of blended behavioral activation for adult depression, compared to a full behavioral activation protocol.

3. To investigate the clinical effect of blended CBT treatment for adult depression, compared to treatment as usual.

4. To investigate the effects of blended CBT treatment for adolescent depression, compared to attention control, with treatment offered in community settings. 


\section{MATERIALS AND METHODS}

\section{Study designs}

Study I was a survey, conducted in eight European countries (France, Germany, the Netherlands, Poland, Spain, Sweden, Switzerland and the United Kingdom) between March and June 2014. Participants were contacted via email and completed the survey online on behalf of their organization.

Study II was a parallel, two-arm non-inferiority individually randomized trial, conducted in a Swedish community setting (two sites) between January and October 2013. Participants were randomized to nine weeks of blended treatment or ten weeks of standard face-to-face therapy (1:1 ratio). The study time frame was 10 months, with depression level assessed at baseline, posttreatment (10 weeks) and 6 months after treatment. The primary outcome was self-reported depression level at post-treatment.

Study III was a parallel, two-arm non-inferiority individually randomized trial, conducted mainly in a Swedish primary care setting (three sites) between January 2015 and May 2017.

Participants were randomized to ten weeks of blended treatment or to treatment as usual (1:1 ratio). The study time frame was 12 months, with depression level assessed at baseline, post-treatment, six months and at 12 months following baseline. The primary outcome was self-reported depression level at post-treatment.

Study IV was a parallel, two-arm individually randomized trial, conducted in a community setting at the national level in Sweden between January 2015 and October 2015. Participants were randomized to eight weeks of blended treatment or to attention control (1:1 ratio). The study time frame was ten months, with depression level assessed at baseline, post-treatment (both allocations) and six months following treatment. Controls were offered blended treatment following post-treatment assessment. The primary outcome was self-reported depression level at post-treatment.

Study $\mathbf{V}$ was a two-arm individually randomized trial, conducted in a community setting at the national level in Sweden between January 
and April 2017. Participants were randomized to eight weeks of blended treatment or to minimal attention control (1:1 ratio). The study time frame was four months, with depression level assessed at baseline and post-treatment (eight weeks). The primary outcome was self-reported depression level at post-treatment.

\section{Study samples}

Study I involved 175 organizations from the following mental health care stakeholder groups: a) government bodies b) care providers and professionals, c) researchers at universities and institutes, d) service funders, e.g., insurance companies, e) technology developers/ providers of online services within mental health, and f) patient/user associations.

Study II involved 93 adults suffering from major depressive episode (DSM criteria), who were recruited via newspaper advertisements in two Swedish counties (Stockholm and Östergötland). The typical study participant was female, 31 years of age, cohabiting, had an above-average level of education, was employed or studying, and had previous depression treatment experience.

Study III involved 141 adults suffering from major depressive episode (DSM criteria), who were enrolled mainly through primary care settings in three Swedish counties (Stockholm, Östergötland and Västmanland). The typical study participant was female, 34 years of age, cohabiting, had an above-average level of education, was studying, and had concurrent depression and anxiety disorder.

Study IV and Study V each involved 70 adolescents 15-19 years of age, suffering from depressive symptoms including, but not restricted to, major depressive episode. Participants were recruited at the national level by means of social media postings and postings in public areas at schools. The typical participant (both studies) was female, 17 years of age, lived in a rural area or small town, and suffered concurrent major depressive episode and anxiety disorder.

Table 1 presents a comparative overview of study design and participant characteristics for Study II-V. 
Table 1. Comparative overview of study design and participant characteristics, Study II-V

\begin{tabular}{|c|c|c|c|c|}
\hline & Study II & Study III & Study IV & Study V \\
\hline Design & RCT & RCT & RCT & RCT \\
\hline Year & 2013 & $2015-2017$ & 2015 & 2017 \\
\hline Setting & $\begin{array}{l}\text { Community, } \\
\text { Self-selection }\end{array}$ & $\begin{array}{c}\text { Clinics/ } \\
\text { Self-selection }\end{array}$ & $\begin{array}{l}\text { Community, } \\
\text { Self-selection }\end{array}$ & $\begin{array}{l}\text { Community, } \\
\text { Self-selection }\end{array}$ \\
\hline Comparative & $\begin{array}{c}\text { Face-to-face } \\
\text { protocol }\end{array}$ & $\begin{array}{c}\text { Treatment } \\
\text { as usual }\end{array}$ & $\begin{array}{c}\text { Attention } \\
\text { Control }\end{array}$ & $\begin{array}{l}\text { Attention } \\
\text { control }\end{array}$ \\
\hline Study therapists & 26 & 11 & 4 & 6 \\
\hline Sample size & 93 & 141 & 70 & 70 \\
\hline Female (\%) & 69.9 & 73.0 & 94.3 & 95.7 \\
\hline Age $(M)$ & 30.6 & 34.1 & 17.0 & 17.5 \\
\hline $\begin{array}{l}\text { Previous } \\
\text { treatment } \\
\text { experience }^{1}(\%)\end{array}$ & 52.7 & 56.7 & 38.6 & 35.7 \\
\hline $\begin{array}{l}\text { Major depressive } \\
\text { episode }^{2}(\%)\end{array}$ & 100 & 100 & 75.7 & 75.7 \\
\hline $\begin{array}{l}\text { Concurrent } \\
\text { anxiety } \\
\text { diagnosis, one or } \\
\operatorname{more}^{2}(\%)\end{array}$ & 44.1 & 54.6 & 75.7 & 70.0 \\
\hline
\end{tabular}

${ }^{1}$ Refers to psychotherapy treatment and/or psychotropic medication

${ }^{2}$ Confirmed in The Mini- International Neuropsychiatric Interview 


\section{Instruments and eligibility criteria}

The primary outcome for Study II-V was change in level of depression from baseline to post-treatment, as measured using depression selfreport scales. In addition, clinical diagnostic interviews to determine major depressive disorder were conducted at baseline and at post-treatment in all studies via telephone. Table 2 presents a comparative overview of primary instruments in Study II-V. Beyond the instruments presented here, studies included additional and varying secondary outcomes. For more details, please see each study.

Beck Depression Inventory II (BDI-II) is a 21-item multiple-choice self-report instrument that measures symptoms of depression according to DSM criteria (Beck, Steer \& Brown, 1996). BDI-II is intended for use from $\geq 13$ years of age. Items are rated on a scale ranging from o to 3, with higher scores indicating more severe symptoms, and the total score ranging from o to 63. Used cut-off values are 0-13 (minimal), 14-19 (mild), 20-28 (moderate) and 29-63 (severe depression). The BDI-II has been found to possess excellent psychometric qualities, including high internal consistency (Beck et al., 1996).

Patient Health Questionnaire-9 (PHQ-9) is a brief 9-item multiplechoice self-report instrument that measures severity of depression according to DSM criteria (Kroenke, Spitzer \& Williams, 2001). The total score ranges from o to 27, with higher scores indicating more severe depression. Each item scores from o (not at all) to 3 (every day). The cut-off points of 5, 10, 15 and 20 represent the thresholds for mild, moderate, moderate-severe and severe depression, respectively. The PHQ-9 has shown good psychometric properties (Gilbody, Richards, Brealey \& Hewitt, 2007; Wittkampf, Naeije, Schene, Huyser \& van Weert, 2007), including an internal consistency of $\alpha=0.74-0.81$ (Titov et al., 2011).

The Quick Inventory of Depressive Symptomatology (QIDS-16) is a 16-item multiple-choice self-report instrument that measures severity of depression. The total score ranges from o to 48 , with 
higher total scores being indicative of a higher severity of depressive symptoms. Each item scores 0-3. The cut-off points of 6, 11, 16 and 21 represent the thresholds for mild, moderate, severe and very severe depression, respectively. The QIDS-16 includes symptom domains of major depressive disorder based on DSM and Research Diagnostic Criteria (RDC). The QIDS-16 has shown highly acceptable psychometric properties, with an internal consistency of $\alpha=.86$ (Rush et al., 2003).

The Mood and Feelings Questionnaire (MFQ) is a 33-item self-report measure developed to assess depression severity in children and young people. The MFQ measures severity of depression according to DSM criteria (Angold et al., 1987). Items are rated based on recent symptom experience on a scale ranging from o (not true) to 2 (true), with the total sum score ranging from o to 66. A Cronbach's $\alpha$ of 0.95 for the MFQ has been reported, suggesting high internal consistency (Daviss, Birmsher \& Melhem, 2006). Validation research suggests that a score of $\geq 20$ indicates any depressive disorder and $\geq 29$ a likely current major depressive episode (Daviss et al., 2006).

The M.I.N.I. International Neuropsychiatric Interview (MINI) is a structured diagnostic interview based on the DSM-criteria and the ICD-criteria for depression. The MINI is used in clinical and research practice, and compares well with other structural clinical interviews used to assess mental disorders, such as the Structural Clinical Interview for DSM-IV Disorders and the Composite International Diagnostic Interview (Lecrubier et al., 1997; Sheehan et al., 1998). The full MINI was administered at baseline to assess presence of depression and other psychiatric disorders. At posttreatment and follow-ups, the sections covering depression, anxiety and other diagnostic criteria that participants met at baseline (individual level) were re-administered to assess recovery. Interviews were conducted over the telephone with study therapists. Phone administration has been shown to be reliable in psychiatric assessment (Rhode, Lewinsohn \& Seeley, 1997). At baseline, interviews were conducted prior to randomization; at posttreatment and at follow-up, assessors were not blinded to participant allocation, with the exception of Study II. 
Eligibility criteria to take part in Study II-V were: score above the cut-off for mild depression on the primary outcome (BDI-II/PHQ-9), presenting at least five symptoms of (Study IV and V) or fulfilling diagnosis (Study II and III) of major depressive disorder, and no severe comorbid psychiatric condition that might interfere with the treatment (e.g., bipolar affective disorder, psychotic illness, substance misuse, alcohol misuse or high suicidal ideation), assessed using the MINI, not currently being in psychotherapy treatment, or present other medical problems that would require other treatments. Comorbid anxiety disorders were accepted if depression was the primary concern. Current medication for ADHD, anxiety or depression was accepted, if the dose had been fixed during the past month and was kept constant throughout the study.

The Credibility Expectancy Questionnaire, CEQ (Devilly \& Borkovec, 2000) was administered after the first week of treatment to assess perceived treatment credibility of the blended treatment.

The Working Alliance Inventory, WAI-S (Hatcher \& Gillaspy, 2006; Tracey \& Kokotovic, 1989) was administered to blended treatment participants the third week of treatment to assess alliance.

Table 2. Comparative overview of depression assessment, Study II-V

\begin{tabular}{lcccc}
\hline & Study II & Study III & Study IV & Study V \\
\cline { 2 - 5 } $\begin{array}{l}\text { Primary } \\
\text { outcome }\end{array}$ & BDI-II & PHQ-9 & BDI-II & BDI-II \\
$\begin{array}{l}\text { Secondary } \\
\text { outcome }\end{array}$ & PHQ-9 & QIDS-16 & PHQ-9 & MFQ \\
$\begin{array}{l}\text { Clinical } \\
\text { interview }\end{array}$ & $\begin{array}{c}\text { MINI } \\
\text { (DSM-IV) }\end{array}$ & $\begin{array}{c}\text { MINI } \\
\text { (DSM-IV) }\end{array}$ & $\begin{array}{c}\text { MINI } \\
(\text { DSM-IV })\end{array}$ & $\begin{array}{c}\text { MINI } \\
(\text { DSM-5) }\end{array}$ \\
\hline
\end{tabular}




\section{Procedures}

The following procedures applied for Study II-V.

Study therapists were recruited from Swedish psychologist training programs to conduct blended treatments and diagnostic interviews (MINI). Therapists were within one year from degree, with completed or ongoing CBT-oriented clinical training. Prior to treatment, therapists were trained in conducting diagnostic interviews (half-day seminar including practice) and in the fundamentals of providing CBT treatment within an online treatment platform (half-day + on-demand). Study II included training in the smartphone application. Literature on CBT, BA treatment and ICBT delivery was provided prior to treatments. For the treatments that included face-to-face sessions (Study II and Study III), a detailed treatment manual was provided for sessions. Clinical psychologists specialized in CBT and ICBT supervised the therapists in a group format during the course of the treatment (approximately 7-8 hours in total per study).

The treatment platform used for the online components of the blended treatments is owned by Linköping University and run on a non-profit basis. The functionality and appearance of the treatment platform include 1) a public web page that is used to present full information about the study in the recruitment phase, and 2) secured web pages for the delivery of treatment and therapistpatient contact. Data security features of the platform adhere to the data security authority in Sweden. Participants log in to the platform using two-factor authentication. All data communication between the servers and the users, as well as audio/video chat, takes place via encrypted (https/TLS) protocols. No confidential information is sent in emails or in text messages to phones.

Safety parameters included creating an action plan prior to each study start, to address potential crises. Following inclusion, study participants received instructions on how to contact their therapist and/or study contact person in case of significant deterioration. Participants who indicated significant deterioration were contacted by the study therapist by messages in the treatment platform and telephone. In the studies that included adolescents, participants 
were informed that the study would break confidentiality (i.e., contact guardians) in the event of significant deterioration. Adolescents who did not complete the weekly depression assessments were contacted by their study therapist. A study psychiatrist was available on stand-by to supplicate assessment of participants' depression state.

Randomization of eligible patients took place following baseline assessment and obtained informed consent. Persons not involved in the studies executed the randomization procedures.

Monetary compensation or any other type of reimbursement was not offered in exchange for participation in the studies.

Ethical permission was granted by the regional ethics committee in Linköping, Sweden. 


\section{Interventions}

\section{Study I}

The full survey comprised 40 questions that assessed views on standard and internet-assisted treatments (pure online treatment and blended treatment) in treatment of adult depression. The survey covered four thematic areas: a) knowledge of treatments, b) attitudes toward treatments, c) acceptability of treatments and d) expectations of treatments in near future. Internet-assisted treatments were introduced in explanatory terms. Respondents were asked to complete the survey on behalf of their organization. Table 3 presents the survey items that were selected for analysis in Study I. 
Table 3. Overview of analyzed survey items

\begin{tabular}{|c|c|c|}
\hline $\begin{array}{l}\text { Survey } \\
\text { theme }\end{array}$ & Presented item & Item design \\
\hline Knowledge & $\begin{array}{l}\text { "To what extent does your organization } \\
\text { have knowledge about internet-based } \\
\text { psychotherapy (referred to as online } \\
\text { therapy and web-based treatment) as a } \\
\text { treatment tool for adult depression?” }\end{array}$ & $\begin{array}{l}\text { Six-point scale: o } \\
=\text { no knowledge } \\
\text { at all, to } 5 \text { = very } \\
\text { good knowledge } \\
\text { Opt out option: } \\
\text { "does not apply" }\end{array}$ \\
\hline Attitude & $\begin{array}{l}\text { "Is your organization discussing and/or } \\
\text { proclaiming internet-based psychotherapy } \\
\text { as a future enhancement in mental health } \\
\text { care?" }\end{array}$ & $\begin{array}{l}\text { Single-choice } \\
\text { question with } \\
\text { alternatives: "yes, } \\
\text { "partly", "no", } \\
\text { "does not apply" }\end{array}$ \\
\hline Acceptance & $\begin{array}{l}\text { "Would your organization recommend: } \\
\text { 1) stand-alone treatment full } \\
\text { psychotherapy program for } \\
\text { computer/tablet/smartphone, with online } \\
\text { educational material and communication } \\
\text { with health care professional?" } \\
\text { (= pure online treatment, e.g. ICBT) } \\
\text { 2) "Traditional face-to-face treatment } \\
\text { with the addition of a web-based platform } \\
\text { and digital tools for support, with the aim } \\
\text { of reducing the number of face-to-face } \\
\text { sessions while maintaining the same } \\
\text { treatment quality" (= blended treatment) }\end{array}$ & $\begin{array}{l}\text { Single-choice } \\
\text { question with } \\
\text { alternatives: } \\
\text { "yes, "no", "does } \\
\text { not apply" }\end{array}$ \\
\hline Expectation & $\begin{array}{l}\text { "What does your organization expect to be } \\
\text { the most important incentive for/barrier } \\
\text { to integrating internet-based } \\
\text { psychotherapy as a stand-alone treatment } \\
\text { for adult depression in your country's } \\
\text { health care system?" }\end{array}$ & $\begin{array}{l}\text { Choose } \\
\text { alternative from } \\
\text { presented list }\end{array}$ \\
\hline
\end{tabular}




\section{Study II}

The blended treatment was developed especially for the study and was based on behavioral activation, in agreement with Martell and co-workers' treatment manual (Martell, Dimidjian \& HermannDunn, 2013). The treatment was delivered in individual format over the course of nine weeks and consisted of four face-to-face sessions and a between-session smartphone application. Standard sessions ranged from 45 to 60 min and were conducted every second or third week with a CBT therapist in training. The smartphone application (downloaded to participants' phones) assisted in participants' management of non-depressed behavioral activities: selecting, scheduling and evaluating completed activities. Participants could set reminders for activities and view summaries of their own progress in the application. Therapist sent encouraging messages in the application every second or third day (one-way communications). Table 4 presents an overview of the blended treatment.

The comparison condition consisted of full standard BA treatment. The treatment was delivered in individual format over the course of ten weeks and consisted of ten face-to-face sessions conducted with a CBT therapist in training. Between the sessions, the participants received homework as well as an activity schedule and activity plan in paper format. 
Table 4. Blended treatment overview, Study II

\begin{tabular}{|c|c|c|c|}
\hline Week & $\begin{array}{l}\text { Face-to-face } \\
\text { session }\end{array}$ & $\begin{array}{l}\text { Smartphone } \\
\text { support }\end{array}$ & Exercise \\
\hline 1 & $\begin{array}{l}\text { Psychoeducation, } \\
\text { rationale for BA }\end{array}$ & $\mathrm{X}$ & Create activity plan \\
\hline 2 & & $\mathrm{X}$ & $\begin{array}{l}\text { Activation according } \\
\text { to activity plan }\end{array}$ \\
\hline 3 & $\begin{array}{l}\text { Follow-up on and } \\
\text { modify activity plan }\end{array}$ & $\mathrm{X}$ & $\begin{array}{l}\text { Activation according } \\
\text { to activity plan }\end{array}$ \\
\hline 4 & & $\mathrm{X}$ & $\begin{array}{l}\text { Activation according } \\
\text { to activity plan }\end{array}$ \\
\hline 5 & $\begin{array}{l}\text { Follow-up on and } \\
\text { modify activity plan }\end{array}$ & $\mathrm{X}$ & $\begin{array}{l}\text { Activation according } \\
\text { to activity plan }\end{array}$ \\
\hline 6 & & $\mathrm{X}$ & $\begin{array}{l}\text { Activation according } \\
\text { to activity plan }\end{array}$ \\
\hline 7 & & $\mathrm{X}$ & $\begin{array}{l}\text { Activation according } \\
\text { to activity plan }\end{array}$ \\
\hline 8 & $\begin{array}{l}\text { Follow-up on and } \\
\text { modify activity plan, } \\
\text { maintenance and } \\
\text { prevent relapse plan }\end{array}$ & $\mathrm{X}$ & $\begin{array}{l}\text { Activation according } \\
\text { to activity plan }\end{array}$ \\
\hline 9 & & $\mathrm{X}$ & $\begin{array}{l}\text { Activation according } \\
\text { to activity plan }\end{array}$ \\
\hline
\end{tabular}




\section{Study III}

The blended treatment was delivered in individual format over the course of ten weeks and consisted of four face-to-face sessions and six online sessions. Standard sessions ranged from 45 to 60 min and were conducted every second or third week with a CBT therapist in training. Online sessions were delivered on a secured website and comprised reading material, educational videos, and homework assignments. Online sessions included brief therapist support in the form of feedback messages on completed homework assignments and questions. Table 5 presents an overview of the blended treatment.

The comparison consisted of treatment as usual (TAU). TAU was defined as the treatment an individual receives when seeking treatment for depression in a Swedish primary care setting, and participants allocated to TAU continued without any involvement of the study. The interventions thus varied and could involve a waitand-see approach, antidepressants, counseling/psychotherapy, GP visits, waiting-list to therapy or combinations thereof. 
Table 5. Blended treatment overview, Study III

\begin{tabular}{|c|c|c|c|}
\hline Week & Face-to-face & Online & Exercise \\
\hline 1 & $\begin{array}{l}\text { Introduction, } \\
\text { Psychoeducation, } \\
\text { treatment goals }\end{array}$ & Repeated & Mood-activity diary \\
\hline 2 & & $\begin{array}{l}\text { Analysis of } \\
\text { behavior }\end{array}$ & $\begin{array}{l}\text { Mood-activity diary, } \\
\text { Treatment goals }\end{array}$ \\
\hline 3 & $\begin{array}{l}\text { Behavioral activation: } \\
\text { introduction, rationale } \\
\text { for coming weeks }\end{array}$ & Repeated & $\begin{array}{l}\text { Mood-activity diary, BA- } \\
\text { activities }\end{array}$ \\
\hline 4 & & $\begin{array}{l}\text { Behavioral } \\
\text { activation }\end{array}$ & $\begin{array}{l}\text { Mood-activity diary, BA- } \\
\text { activities }\end{array}$ \\
\hline 5 & & $\begin{array}{l}\text { Behavioral } \\
\text { activation, } \\
\text { cope with } \\
\text { avoidance }\end{array}$ & $\begin{array}{l}\text { Mood-activity diary, BA- } \\
\text { activities, BA-analysis }\end{array}$ \\
\hline 6 & $\begin{array}{l}\text { Cognitive reframing: } \\
\text { introduction, rationale } \\
\text { for coming weeks }\end{array}$ & Repeated & $\begin{array}{l}\text { Identify and evaluate } \\
\text { thoughts } \\
\text { (Mood-activity diary, BA- } \\
\text { activities) }\end{array}$ \\
\hline 7 & & $\begin{array}{l}\text { Cognitive } \\
\text { restructuring }\end{array}$ & $\begin{array}{l}\text { Identify and challenge } \\
\text { thoughts } \\
\text { (Mood-activity diary, BA- } \\
\text { activities) }\end{array}$ \\
\hline 8 & & $\begin{array}{l}\text { Cognitive } \\
\text { restructuring }\end{array}$ & $\begin{array}{l}\text { Identify and challenge } \\
\text { thoughts, problem-solving } \\
\text { (Mood-activity diary, BA- } \\
\text { activities) }\end{array}$ \\
\hline 9 & & $\begin{array}{l}\text { Treatment } \\
\text { goals \& life } \\
\text { values }\end{array}$ & $\begin{array}{l}\text { Revisit treatment goals, } \\
\text { identify values (Cognitive } \\
\text { reframing, BA-activities) }\end{array}$ \\
\hline 10 & $\begin{array}{l}\text { Treatment summary, } \\
\text { maintenance }\end{array}$ & Repeated & $\begin{array}{l}\text { Relapse prevention, write } \\
\text { treatment maintenance plan }\end{array}$ \\
\hline
\end{tabular}




\section{Study IV}

The blended treatment was delivered in individual format over the course of eight weeks and consisted of online sessions and weekly chat sessions with a therapist. Online sessions comprised reading material, educational videos and homework assignments, and included brief therapist support (feedback messages on completed homework assignments and questions). One online session targeted anxiety. Weekly 30 min chat-sessions, conducted with a CBT therapist in training, referred to the content in online sessions, and assisted with individual process-related treatment aspects. All treatment and communication took place on the secured treatment platform. Table 6 presents an overview of the treatment program.

The control condition consisted of attention control. Participants were assigned to a therapist, given restricted access to the treatment platform and instructed to complete a depression questionnaire on a weekly basis. Platform access included that participants could view their depression score and message their therapist. They were informed that their assessments would be monitored by their therapist and instructed to contact the therapist in the event that their symptoms deteriorated. Participants that contacted their therapist due to deterioration received non-specific support while being monitored. Therapists received instructions not to use specific CBT techniques. 
Table 6. Treatment overview, Study IV and Study V

\begin{tabular}{cll}
\hline Week & Online session & Assignment/exercise \\
\hline 1 & Psychoeducation & Write history, set goals \\
& depression & \\
2 & Analysis of behavior & Identify dysfunctional and functional schemas \\
3 & Behavioral activation & Mood-activity diary \\
4 & Behavioral activation & Mood-activity diary \\
5 & Cognitive restructuring & Identify and challenge thoughts \\
6 & Psychoeducation anxiety & Anxiety management, graded exposure \\
7 & Emotional recognition & Coping strategies, self-esteem, affect \\
& & regulation \\
8 & Maintenance & Relapse prevention, treatment summary \\
\hline
\end{tabular}




\section{Study V}

The blended treatment used in Study IV was revised in accordance with study participants' feedback: i) chat sessions were prolonged from 30 to 45 minutes, ii) the administration of online sessions every week was made more structured to better inform participants about what was expected each week, iii) text material in online sessions was revised to present more clearly, and the session targeting anxiety was revised, iiii) the design of the study website was altered so as to attract more male adolescents. The delivery of treatment followed the same procedure as described in Study IV.

The control condition consisted of minimal attention control. At the start of the control period, participants received an introductory message from their therapist on the treatment platform, with instructions fill out a weekly assessment and to message their therapist for assistance in the event they felt worse. Standby support was available for participants that contacted their therapist, no active treatment was implemented. Participants were informed that they would get a full treatment after the monitoring period. 


\section{Analyses}

In Study I, survey data were analyzed using descriptive statistics, Kruskal-Wallis-, $\chi^{2}$-and ANOVA tests.

Study II and Study III aimed to determine whether blended treatment was non-inferior to comparison conditions; they were thus non-inferiority studies (Piaggio, Elbourne, Altman, Pocock, Evans \& Altman, 2012). For Study II, the margin of non-inferiority $\Delta$ for difference in treatment effect between the blended treatment and the comparison treatment was preset to 2.50 points on the primary outcome (BDI-II) at post-treatment, and the confidence interval approach to non-inferiority was used. The 2.50 points margin has been used in previous non-inferiority trials and is considered to distinguish a clinically important treatment difference from a clinically negligible difference (Montgomery, 1994; Szegedi, Kohnen, Dienel \& Kieser, 2005). Mixed-effect regression models were used to examine the effects of blended treatment compared to full standard treatment (Gueorgiuvera \& Krystal, 2004). Differences between the treatment conditions were investigated by modelling interactions effects between group and over time. Models were estimated by means of full information maximum likelihood estimation (Little \& Rubin, 2002). For Study III, the non-inferiority margin was predefined in line with the larger multi-national trial the study was part of (Kleiboer et al, 2016). Here, $\Delta$ Cohen's $d=-0.20$ for the primary outcome (PHQ-9) at post-treatment was used. Blended treatment was considered non-inferior to the comparison condition (TAU) when the lower limit of the two-sided 95\% confidence interval was above the non-inferiority limit Cohen's $d$ $=-0.20$. The margin is considered a conservative estimate of the subjective minimal important difference noticeable by patients (Cuijpers, Turner et al., 2014). Analysis of covariance (ANCOVA) was used for the primary outcome, including pre-treatment score on the primary outcome as covariate.

Study IV and Study V were superiority trials, aimed to determine whether blended treatment led to therapeutic improvement in comparison to attention controls. The primary outcome in both trials was BDI-II depression score at post-treatment. Between-group 
differences were evaluated by analysis of covariance, using pretreatment score on the primary outcome as a covariate at the $p<$ 0.05 level (Vickers \& Altman, 2001). For more details, please see each study.

To determine participants' improvement and response following treatment, several approaches were investigated. In these analyzes, missing cases were consistently categorized as not having improved. The proportion of participants showing a symptom decrease of $\geq 30 \%$ and $\geq 50 \%$ in the primary outcome from baseline to posttreatment was investigated, as these cut-offs have previously been used to determine treatment response (e.g., Nobler et al., 1997; Möller, Muller \& Volz, 1996; Richards et al., 2016; Richardson et al., 2014; Schmidt et al., 2017). In line with Jacobson and Truax, clinically significant change was determined, i.e. the number of participants who at post-treatment scored $2 S D$ below the pre-treatment mean for both conditions on the primary outcome (Jacobson \& Truax, 1991), while fulfilling the Reliable Change Index criteria (Evans, Margison \& Barkham, 1998). For the studies that used BDI-II as the primary outcome, the number of participants who scored $\leq 13$ and $\leq 10$ at post-treatment was investigated, given that these scores are used as cut-offs for mild and clinical depression (Beck et al., 1996; Kessler, Lewis et al., 2009). For the study that used PHQ-9 as the primary outcome, the number of participants who scored $<5$ at posttreatment was investigated, given that this score is used as cut-off for mild depression (Kroenke et al., 2001).

Deterioration associated with treatment was investigated using worsening depression symptoms following treatment (Bergin, 1966; Rozental, 2016) and subjective negative experience in connection with treatment (Dimidjian \& Hollon, 2010). For deterioration, an increase of $\geq 30 \%$ or more on the primary outcome score from baseline to post-treatment was used, in agreement with methods used in previous trials on depression treatment (Titov et al., 2016). Negative experiences were collected by means of participant report in the post-treatment assessments (free text responses), in line with recommendations (Rozental et al., 2014). 


\section{Sample calculation}

Non-inferiority trials usually require large samples to allow reliable detection of small differences in effects between evaluated treatments (Piaggio et al., 2012). In Study II, there were no means to treat as many patients as would have been required to reliably detect small differences in effects between evaluated treatments. The sample size for Study III was calculated based on the larger multinational trial that the study was part of. Based on the set noninferiority margin (Cohen's $d=-0.20$ ), it was calculated that $n=1052$ participants were required to obtain the desired certainty level of $90 \%$ (power .90). The total number of patients was set to $n=1200$ for the larger trial, and to $n=150$ for Study III. The final enrollment in Study III $(n=141)$ was about 6\% below this goal.

For Study IV and Study V, a meta-analysis on youth depression was used as a reference to estimate between-group effects (Ebert, Zarski et al., 2015). Here, the overall between-group effect reported for guided ICBT compared to non-active control was $g=0.72$. To detect a similar between-group effect size (Cohen's $d=0.70$ ) at posttreatment, with a two-tailed $5 \%$ significance level and a power of $80 \%$, a sample size of $n=72$ was required. The final enrollment in Study IV and Study V (each, $n=70$ ), respectively, was about 3\% below this goal.

Data in all trials were handled according to the intention-to-treat principle (ITT). To account for the impact of participant dropout, missing data were addressed with last observation carried forward (Study II) or multiple imputations (Little \& Rubin, 2002). 


\section{RESULTS}

\section{Study I}

The survey response-rate was $23 \%$. All stakeholder categories and countries were represented. The knowledge of internet-assisted treatments among stakeholders was moderate. Cost-advantage was considered the primary incentive for and care systems not being ready the primary barrier to integration of internet-assisted psychological treatment into standard care settings. The majority considered blended treatment an acceptable treatment approach for management of mild (70\%) and moderate depression (57\%) in adults (Figure 1). Pure online treatment was not accepted by the majority for any level of depression. The relatively more favorable views on blended treatment were consistent on the stakeholder and country subgroup level (for the management of mild depression, both approaches were equally accepted among technology providers and funders, and among stakeholders from the United Kingdom). In several countries (Switzerland, England, Spain, the Netherlands, Sweden) and stakeholder groups (funder, research, technology), the majority also accepted pure online treatment for the management of mild depression. An investigation of survey free-text comments indicated that the lower acceptance rates for pure online treatment for depression related to perceived risks and limitations in effect and in building rapport and alliance. 


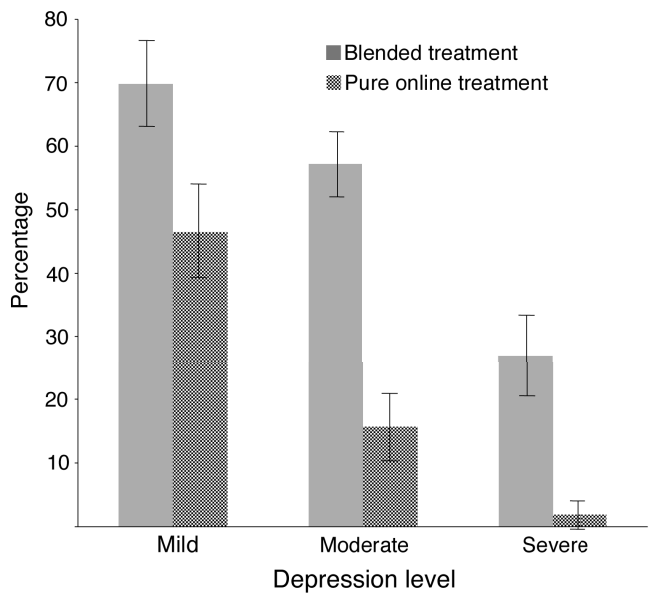

Figure 1. Comparative overview of stakeholder acceptance rates for blended treatment and pure online treatment, in management of mild, moderate and severe adult depression (yes responses, \%) 


\section{Study II}

In the study, $n=46$ participants were randomized to blended treatment and $n=47$ to full standard treatment. The attrition rate for the primary outcome was $9 \%$ at post-treatment and $26 \%$ at six months. There were no significant differences in baseline characteristics between groups.

For the primary outcome, no significant interaction of group and time was found at post-treatment $(p=0.76)$ or at six months $(p=$ 0.72). The estimated mean differences on the BDI-II between conditions were 2.42 points (CI: -2.19 to 7.03 ) at post-treatment, and 0.50 points (CI: -4.93 to 5.92 ) at six months. These included the noninferiority limit; thus, non-inferiority could not be statistically established. Within-group effects for the blended group and the comparison group were similar between conditions at posttreatment and after six months, ranging Cohen's $d=1.35$ to 1.47. Similar results on between-group and within-group effects were found for the secondary depression outcome. Results for the primary outcome are further presented in Table 7.

There were no significant differences between groups posttreatment or at six months follow-up, in terms of remission from depression diagnosis, or in investigated response or recovery rates (all $p$-values $>0.05$ ). No study participant showed $\geq 30 \%$ deterioration on the primary outcome from baseline to posttreatment, or from baseline to six months. Results for the blended treatment are further presented in Table 8.

The proportion of participants that completed all of scheduled faceto-face sessions were similar across allocation (91\% and 93\%).

Treatment credibility ratings (CEQ; 5 items x 10-point scale) showed that the average scores were $33.0(S D=8.0)$ out of a maximum of 50 . Working alliance ratings showed that the average total score was 63.5 $(S D=9.6)$ out of a maximum of 84 (highest satisfaction). There were no significant differences between groups in ratings on credibility or alliance (all $p$-values $>0.05$ ). 


\section{Study III}

In the study, $n=73$ participants were randomized to blended treatment and $n=68$ to TAU. The attrition rate for the primary outcome was $11 \%$ at post-treatment, $31 \%$ at 6 months, and $27 \%$ at 12 months. There were no significant differences in baseline characteristics between groups, or between completers and dropouts.

For the primary outcome, superiority was indicated for the blended treatment at post-treatment $(p<0.05)$. The correspondent betweengroup effect was Cohen's $d=0.32$ (CI 95\% = 0.00 to 0.66), which was above the preset non-inferiority margin (Cohen's $d=-0.20$ ). The results at 6 months and 12 months were at, or below, the inferiority margin, thus non-inferiority for the blended treatment could not be established at these time points. Significant differences between conditions in favor of the blended treatment were found for the secondary depression outcome (QIDS-16) at post-treatment and at 6 months ( $p$-values $<0.05$ ). Within-group effects were initially larger for blended treatment and evened out gradually over time. Results for the primary outcome are further presented in Table 7 .

At post-treatment there were no differences between groups in terms of response and recovery rates. A higher proportion of participants in the blended group than in the TAU group no longer fulfilled depression diagnosis criteria $(p<0.01)$. Among participants who had remitted and completed the 12-month follow-up, $n=4$ in the blended group and $n=3$ in the TAU group showed relapse at 12 months. Results for the blended treatment are presented in Table 8.

The blended treatment group completed an average of $7.9(S D=2.8)$ sessions of the ten available (79\%). Treatment credibility ratings (Cscale) showed an average rating of $21.96(S D=3.39)$ out of a maximum total 27 (highest credibility). The average score on Working Alliance Inventory items was $3.86(S D=0.60)$ out of a maximum of 5 (highest satisfaction). TAU participants were not assessed. In the blended group, $n=8$ reported negative experiences related to treatment (pressure, negative feelings) and $n=4$ showed $\geq 30 \%$ deterioration on the primary outcome from baseline to posttreatment. The correspondent number in the TAU group was $n=5$ (deterioration). 


\section{Study IV}

In the study, $n=33$ participants were randomized to blended treatment and $n=37$ to attention control. The attrition rate for the primary outcome was $6 \%$ at post-treatment and $34 \%$ at six months. There were no significant differences in baseline characteristics between groups, or between completers and dropouts.

For the primary outcome, there was a significant effect between groups at post-treatment, favoring blended treatment over the control condition $(p<0.05)$. The correspondent between-group effect was moderate (Cohen's $d=0.71$ ). The treatment effect appeared to be maintained for the blended group from posttreatment to six months $(p=0.310)$. Within-group effects for the blended treatment as well as the control group were significant at post-treatment (all $p$-values $<0.001$ ). Results are further presented in Table 7. No significant differences between conditions in favor of the blended treatment were found for the secondary depression outcome (PHQ-9) or anxiety outcome (BAI) at post-treatment (all $p$ values $>0.05$ ), within-group effects were significant in both groups (all $p$-values $<0.001$ ).

At post-treatment, a higher proportion of participants in the blended group (71\%) than in the control group (16\%) no longer met depression diagnosis criteria $(p<0.001)$. A higher proportion in the blended group than controls improved $\geq 30 \%$ and $\geq 50 \%$ in BDI-II score from baseline to post-treatment $(p<0.05, p<0.01)$. Results are further presented in Table 8.

The blended group completed an average of 6.2 chat sessions of eight available and 6.5 online sessions of eight available. The average total completion was 12.8 sessions $(S D=5.0)$ of the 16 available sessions (79\%). Treatment credibility ratings (C-scale) showed an average rating of $22.07(S D=2.23)$ out of 27 (highest credibility). The average score on Working Alliance Inventory items was $5.61(S D=$ o.91) out of 7 (highest satisfaction). Five participants (15\%) reported negative experiences related to treatment (stress, at times feeling worse). One participant in the blended group, and three in the control group, showed $\geq 30 \%$ deterioration on the primary outcome from baseline to post-treatment. 


\section{Study V}

In the study, $n=35$ were allocated to blended treatment and $n=35$ to attention control. The attrition rate for the primary outcome was $6 \%$ at post-treatment. There were no significant differences in baseline characteristics between groups, or between completers and dropouts at post-treatment.

For the primary outcome, there was a significant effect between groups at post-treatment, favoring blended treatment over the control condition $(p<0.001$.). The corresponding between-group effect size was large (Cohen's $d=0.86$ ). Effects for the primary outcome are further presented in Table 7. Significant differences between groups were found for the secondary outcome depression measure (MFQ) at post-treatment, corresponding to a moderate between-group effect $(p<0.01)$.

All response and recovery rates investigated showed significant differences between groups a post-treatment, including a significantly higher proportion of participants in the blended group (46\%) than controls (11\%) fulfilling Jacobson and Truax's criteria for improvement $(p=0.001$.). A significantly higher proportion in the blended group (56\%) than in the control group (27\%) no longer met depression diagnosis criteria at post-treatment $(p<0.05)$. Results for the blended treatment are further presented in Table 8 .

The blended group completed an average of $5.6(70 \%)$ chat sessions of the eight available, and $6.2(78 \%)$ online sessions of the eight available. The average total completion was 11.4 sessions $(S D=5.2)$ of the 16 available sessions (71\%). Treatment credibility ratings (Cscale) showed an average rating of $18.50(S D=4.17)$ out of 27 (highest credibility). The average score on Working Alliance Inventory items was $4.95(S D=0.63)$ out of 7 (highest satisfaction). Four participants (11\%) reported negative experiences related to treatment (stress, or at times feeling deeply affected). No study participant showed $\geq 30 \%$ deterioration on the primary outcome from baseline to posttreatment. 


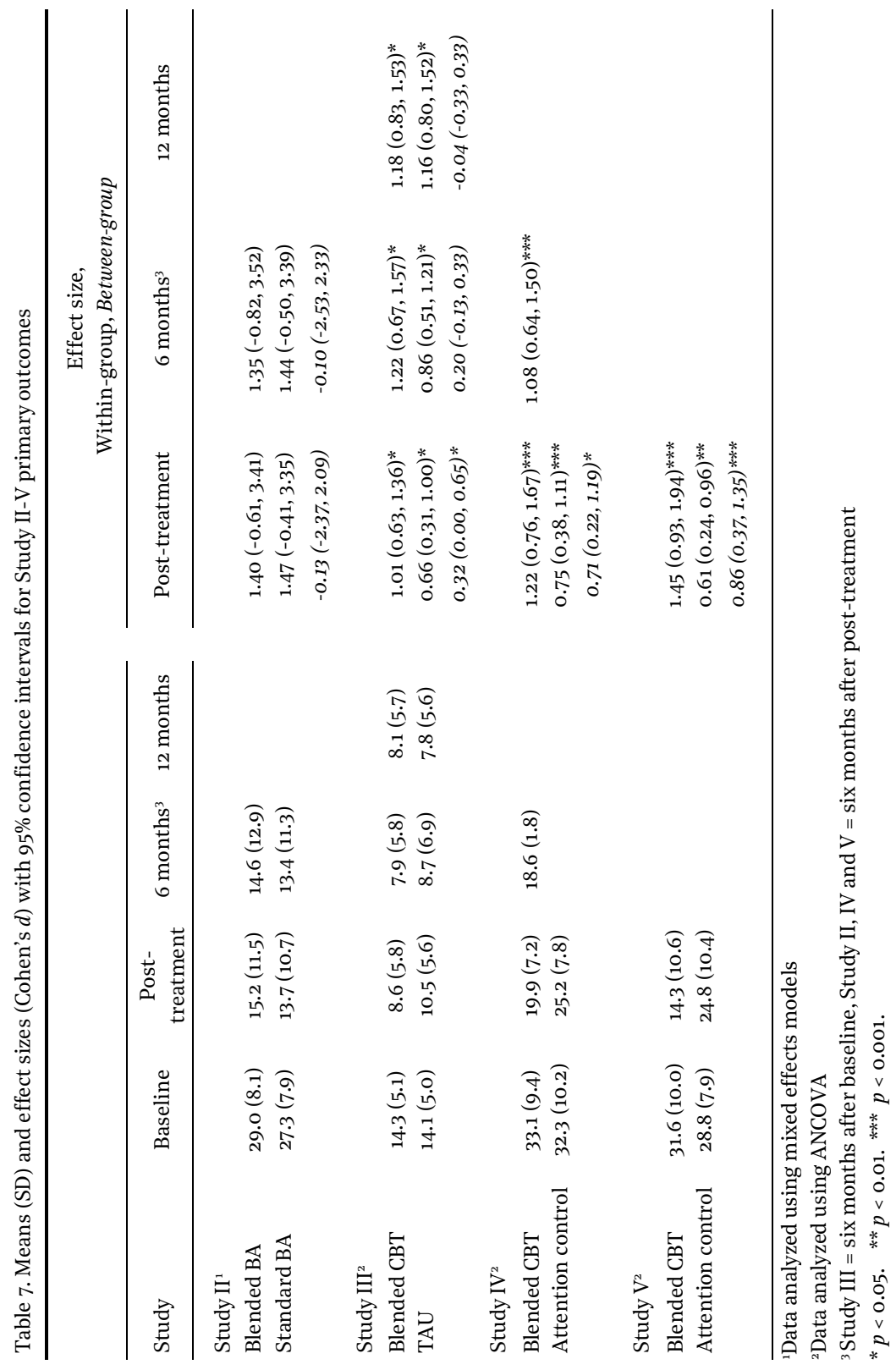


Table 8. Comparative overview of post-treatment results for the blended treatments, Study II-V

\begin{tabular}{|c|c|c|c|c|}
\hline & Study II & Study III & Study IV & Study V \\
\hline $\begin{array}{l}\text { Average improvement } \\
(\%)\end{array}$ & $47 \%$ & $40 \%$ & $40 \%$ & $55 \%$ \\
\hline \multicolumn{5}{|l|}{ Responders (\%) } \\
\hline a) Jacobson \& Truax & $45 \cdot 7$ & 13.7 & 30.3 & $45 \cdot 7^{* *}$ \\
\hline b) $30 \%$ improv. & b) 60.9 & b) 56.2 & b) $60.6^{*}$ & b) $68.6^{* *}$ \\
\hline c) $50 \%$ improv. & c) 52.2 & c) 35.6 & c) $42.4^{* *}$ & c) $45 \cdot 7^{* *}$ \\
\hline d) score $<$ inclusion & d) $\quad 51.1$ & d) 21.9 & d) 30.3 & d) $45 \cdot 7^{* *}$ \\
\hline $\begin{array}{l}\text { cut-off } \\
\text { e) Score } \leq 10\end{array}$ & e) 43.5 & e) - & e) 15.2 & e) $37.1^{* * * *}$ \\
\hline $\begin{array}{l}\text { Remission, Major } \\
\text { Depressive Episode }^{1}\end{array}$ & $76 \%$ & $73 \% * *$ & $71 \%^{* * *}$ & $56 \% *$ \\
\hline $\begin{array}{l}\text { Significant } \\
\text { deterioration }^{2}\end{array}$ & o\% & $5 \%$ & $3 \%$ & o\% \\
\hline $\begin{array}{l}\text { Participant report of } \\
\text { negative treatment } \\
\text { effects }^{3}\end{array}$ & Missing & $11 \%$ & $15 \%$ & $11 \%$ \\
\hline Treatment completion & $\begin{array}{l}\text { Missing } \\
\text { Full 93\% }\end{array}$ & $\begin{array}{l}\text { Average } 79 \% \\
\text { Full } 48 \%\end{array}$ & $\begin{array}{l}\text { Average } 79 \% \\
\text { Full 36\% }\end{array}$ & $\begin{array}{l}\text { Average } 71 \% \\
\text { Full } 31 \%\end{array}$ \\
\hline Therapist sessions ${ }^{4}$ & 4 of 9 weeks & 4 of 10 weeks & 8 of 8 weeks & 8 of 8 weeks \\
\hline $\begin{array}{l}\text { Therapist time, } \\
\text { weekly average } 5\end{array}$ & $36 \mathrm{~min}$ & $35 \min$ & $47 \mathrm{~min}$ & $56 \min$ \\
\hline $\begin{array}{l}\text { Therapist time } \\
\text { vs. } 60 \text { min face-to-face } \\
\text { session }{ }^{5}\end{array}$ & $\begin{array}{l}41 \% \text { reduction } \\
\text { (comparison) }\end{array}$ & $\begin{array}{l}\text { 44\% reduction } \\
\text { (estimated) }\end{array}$ & $\begin{aligned} \geq & 47 \% \text { reduction } \\
& (\text { estimated })\end{aligned}$ & $\begin{aligned} \geq & 45 \% \text { reduction } \\
& (\text { estimated })\end{aligned}$ \\
\hline Adverse event & None & None & None & None \\
\hline
\end{tabular}

${ }^{1}$ Confirmed in The Mini- International Neuropsychiatric Interview

${ }^{2}$ Defined as $30 \%$ increase in primary outcome from baseline to post-treatment

${ }^{3}$ Participant-reported negative experiences

${ }^{4}$ Refers to individual therapist-patient sessions, conducted face-to-face (Study II, III) or using chat communication (Study IV, V)

${ }^{5}$ Estimates are further described on the following page.

Level of significance for between-group difference, ${ }^{*} p<0.05 .{ }^{* *} p<0.01 .{ }^{* * *} p<0.001$. 


\section{Therapist time}

Study II The maximum therapist time for standard sessions was 60 min (both conditions), therapists did not record times. In the blended group, therapists spent on average $81 \mathrm{~min}$ in total on the smartphone application per participant. Calculating standard sessions to $60 \mathrm{~min}$, blended treatment consumed $47 \%$ less therapist time in a direct comparison. Adjusting for the blended treatment being one week shorter, the saving was $41 \%$.

Study III In the blended condition, therapists spent on average 63.1 min on face-to-face sessions and $17 \mathrm{~min}$ on online sessions corresponding an average of 35.4 min per week (total $354.4 \mathrm{~min}$ ). Based on these numbers, it was estimated that the blended treatment saved $44 \%$ of therapist time - compared to if all sessions had been delivered face-to-face $(63 \mathrm{~min} \times 10$ weeks $=630 \mathrm{~min})$.

Study IV Therapists spent on average 47.3 min on each participant every week. The total time correspond well to a $30 \mathrm{~min}$ chat-session, plus clinician administration time in guided ICBT treatment (about 15 min per week and patient). Two parallel chat-session were tested. Based on the recorded time, estimates for two, three and four parallel $30 \mathrm{~min}$ chat sessions $(+17.3 \mathrm{~min}$ in additional time for each participant) resulted in 32, 27, and 25 min per participant every week. This corresponds to $47-59 \%$ less time compared to a $60 \mathrm{~min}$ session, and $28-45 \%$ less time compared to a 45 min session.

Study $\mathbf{V}$ Excluding weekly time recordings that indicated no session had been conducted (recordings $<15 \mathrm{~min}$ ), therapists spent on average $55.8 \mathrm{~min}$ on each participant each week. The total time corresponds to a $45 \mathrm{~min}$ chat-session plus clinician administration similar to time in guided ICBT treatment (10.8 min). Based on the recorded time, estimates for two, three and four parallel $45 \mathrm{~min}$ sessions (+ $10.8 \mathrm{~min}$ in additional time for each participant) resulted in weekly 33, 26, and 22 min per participant every week. This corresponds to a saving of $45-62 \%$ compared to a 60 min session, and a saving of $26-51 \%$, saving compared to a 45 min session.

Best practice guidelines estimate that chat agents can handle up to four simultaneous chat sessions of a complex nature (Jacobs, 2014). 


\section{GENERAL DISCUSSION}

\section{Main findings}

The aim of the thesis was to evaluate the acceptance and clinical effect of blended cognitive behavior therapy in the treatment of depression. A survey and a series of controlled trials show that blended treatment is acceptable and could be an effective treatment approach in the adult and adolescent population.

\section{Acceptance of blended treatment}

In the development of interventions intended for health care systems, the preferences of and input from key stakeholders should early be acknowledged to ensure optimal design and feasibility of implementation (Mohr, Weingardt, Reddy \& Schueller, 2017).

In Study I, attitudes towards technology-assisted treatments among mental health care stakeholders were explored in a European survey, and support for the blended treatment approach was found. Blended treatment was strongly preferred when compared to pure online treatment in the management of adult depression. While acceptance was based solely on descriptive measurements and thus tentative, the respondents were representative of the health care infrastructure and different levels of e-mental health implementation in Europe, and the result of more favorable attitudes toward blended treatment were consistent over country and stakeholder subgroups. The results are in line with early investigations of blended approaches (van der Vaart et al., 2014). While the underlying reasons for preferring blended treatment were not thoroughly assessed, respondents' free texts indicated that hesitance regarding online treatment is tied to depression being a serious disorder and face-toface contact being perceived as necessary to identify and adequately react to patient needs, and to adequately monitor deterioration, including crisis situations.

In Study II-V, acceptance based on participants' first-hand experiences included high treatment completion rates among study participants and their rating of treatment as credible. Ratings of 
therapist working alliance (WAI-S) across studies were in line with those seen for face-to-face CBT in treatment of adults (Munder, Wilmers, Leonhart, Linster \& Barth, 2010) and adolescents (Webb, Auerbach \& Derubeis, 2012). In Study II, no difference in alliance or credibility ratings between blended treatment and full standard treatment was found, and in Study III, participants satisfactionratings of the blended treatment were positive. The findings for the blended treatment evaluated in Study IV and Study V are interesting. This blended approach with chat-sessions was not evaluated in Study I, but could be expected to be less accepted given that it did not include face-to-face contact. Participants receiving this treatment, however, indicated that it did not perform less well than blended treatment including face-to-face contact, as measured in dropout, credibility as well as in alliance. Thus, a completely text-based blended approach seemed to be meaningful and generated a stable and positive therapeutic relationship for young individuals. The result is in line with experiences reported by young users of chatsupport helplines (Sindahl, 2013).

In summary, the findings on attitudes towards blended treatment among stakeholders and patients' first-hand experiences are positive, but need to be further investigated. Qualitative investigation will help to ensure that components perceived to be essential in blended treatment are not lost, but enhanced in further developments.

\section{Clinical effect of blended treatment}

In a series of randomized controlled trials, conducted in a variety of settings and with different comparatives, blended treatment was found to produce moderate to large effects in treatment of adult and adolescent depression from baseline to post-treatment, as measured by Cohen's $d$. Across studies, 56-76\% participants allocated to blended treatment no longer met criteria for major depressive episode at post-treatment.

Study II demonstrated tentative support for the efficacy of blended treatment in managing adult depression. Here an early form of blended treatment, based on behavioral activation, using a 
smartphone application for support between a reduced number of face-to-face sessions, was compared to a full standard face-to-face behavioral activation protocol. The study was insufficiently powered to statistically establish that the blended treatment was noninferior. However, there were other findings in data indicating that blended treatment was effective in reducing depression, and similar to the comparison treatment: there were no major differences between conditions for any of the outcome variables and MDD remission rates - including at six months follow-up, and response rates were observed for both conditions were in line with response rates face-to-face therapies including $\mathrm{CBT}$ and $\mathrm{BT}$, reported in a meta-analysis (Cuijpers, Karyotaki et al., 2014).

Study III aimed for evaluation under real-world conditions (Flay et al., 2005). The study recruited participants mainly from primary care settings and evaluated blended CBT treatment for adult depression compared to treatment as usual (TAU). Blended treatment also outperformed TAU at post-treatment in selfreported as well as clinician-reported outcomes. This result, however, can be attributed to the relatively brief and heterogeneous interventions seen in the control condition (TAU) at post-treatment as opposed to blended treatment. The superiority of blended treatment was partly retained at 6 months, and at 12 months outcomes in the two conditions were similar and non-inferiority could not be statistically established. In line with observations that evaluations in routine care settings are associated with lower effect sizes (Gilbody, Bower \& Whitty, 2006; van der Lem, van der Wee, van Veen \& Zitman, 2012), within-group effect sizes were moderate to large for both conditions at post-treatment and follow-ups. Response-rates were lower than in Study II, which could relate to baseline depression scores being comparably less severe, leaving less room for improvement. The evaluation in Study III indicate that blended treatment may be similarly effective, or possibly better compared to those usual care alternatives that are readily available in Swedish primary care settings.

Study IV investigated a completely online and text-based blended treatment approach, comprising of individual chat-sessions and 
online self-help sessions. The results demonstrated significantly reduced depressive symptoms in adolescents 15-19 years of age as compared to attention control. A six-month follow-up was conducted, and although no control group was available at this point, treatment effects seemed to persist based on scores on the primary outcome and within-group effect. The goal of Study $\mathbf{V}$ was to further develop and examine the blended treatment used in Study IV to similar methods and in a similar population. Compared to minimal attention control, a large between-group effect size was found in favor of the blended treatment at post-treatment.

The obtained effect sizes at post- treatment in Study IV were in line with, and in Study V larger than, overall effects reported in metaanalyses on standard CBT treatment compared to active and nonactive control conditions, e.g. psychological placebo, treatment-asusual and waitlist (Klein, Jacobs \& Reinecke, 2007; Weisz, McCarty \& Valeri, 2006; Zhou et al., 2015), and effect sizes reported for guided ICBT compared to waitlist (Ebert, Zarski et al., 2015). The depression remission rates observed following the blended treatment were in line with rates reported for standard CBT treatment; 50\% to 87\% (Shirk, DePrince, Crisostomo \& Labus, 2014; Vostanis, Feehan, Grattan \& Bickerton, 1996; Weisz et al, 2009). Study IV demonstrated that the text-based blended approach was feasible and could achieve clinically meaningful effect, and the findings in Study V helped confirm the results - further demonstrating the potential of a textbased blended treatment to reduce symptoms of depression and major depressive episode in young people.

The findings from Study II-V are promising and support the notion that blended treatment is efficacious in management of clinically significant depression in adults as well as in adolescents. In addition, Study II-IV suggest long-term effects of psychological treatment (i.e., beyond post-treatment) - effects that have been relatively under-studied for psychological (Cuijpers, 1998) as well as pharmacological (Ioannidis, 2008) depression treatment. 


\section{Therapist time in blended treatment}

The blended treatments were developed with the current treatment shortages and need for scalability of psychological treatment in mind (Holmes et al., 2018).

In Study II and Study III, data from more than 1400 weeks of treatment indicate that the simple approach of reducing therapist sessions in blended treatment can save a substantial amount of therapist time compared to standard delivery, while maintaining similar treatment effects. Specifically, scaling down from ten to four therapist sessions in a 10-week treatment (60\% decrease) was found to save about $40 \%$ of the total therapist time in treatment. These figures are based on direct comparison to standard delivery (Study II), and on therapists' time-recordings for face-to-face sessions versus online sessions (Study III).

For Study IV and Study V, it was indicated that a similar amount of time could be saved if conducting parallel chat sessions. Multiple chat-sessions is an established practice in business customer-care settings, including complex conversation topics, and guidelines estimate that web chat agents can handle four simultaneous chat sessions of complex nature (Jacobs, 2014). Parallel sessions are also used in some online counseling services for youth (Sindahl, 2013). Parallel chat sessions were only occasionally conducted, but two parallel sessions were tested and deemed feasible.

The results were in line with expectations, indicating that blended treatment falls between minimally guided ICBT, which has been reported to save up to $85 \%$ of therapist time (Hedman et al, 2012), and standard treatment. Meanwhile blended treatment provides strong therapist support, and in the text-based blended approach, the patients receive as much therapist time as in standard treatment. These findings indicate the potential of the blended treatment approach to deliver treatment in accordance with the urgent need to improve reach and access of psychological treatment. 


\section{Negative effects of blended treatment}

Negative effects of CBT, such as significant deterioration following treatment or other perceived negative experiences, are increasingly being acknowledged as important to the scientific evaluation of psychological treatment (Rozental et al., 2014). To establish that the developed blended formats did not carry potential serious or nonproportional negative effects, Study II-V included investigation of negative effects.

Significant deterioration, defined as $30 \%$ or more increase on the primary outcome from baseline to post-treatment, showed rates no higher than $5 \%$ across Study II-V. This compares favorably to deterioration rates reported for adult populations: e.g., 5.8\% for ICBT self-help (Karyotaki et al., 2018), 6.6\% for standard psychotherapies within the IAPT initiative in England (Gyani, Shafran, Layard \& Clark, 2013), and 10\% among patients receiving guided ICBT in Swedish routine care settings (Kivi et al., 2014). The studies with adolescents are particularly promising, given previous reports of $14-24 \%$ of children and adolescents experiencing symptom elevation/distress during standard psychosocial treatment (Warren, Nelson, Mondragon, Baldwin \& Burlingame, 2010).

Study III-V also assessed participants' reports of negative experiences. Depending on the study, 11-15\% of participants reported some kind of negative experience related to treatment. Reports were similar among adolescents and adults and most often related to the tempo and workload in treatment. Participants described putting pressure on themselves to complete treatment, , or having too little time for treatment in addition to school or work commitments. Several dropouts gave stress as a reason for discontinuation. CBT is known for its structured approach, where patients' own effort is considered essential to improvement, and similar complaints about tempo have been found for ICBT studies (Carlbring et al., 2013; Holst et al., 2017). Here, prolonging the time to complete treatment has positively affected completion rates (Kivi et al., 2014), suggesting this may be appropriate for blended treatment approaches as well. 
In conclusion, the results on negative effects suggest that blended treatment is no more harmful than other psychological treatments. Even in a worst-case scenario - all missing cases considered to have deteriorated ( $\leq 12 \%)$, rates would be acceptable as regards comparison to the existing literature (Rozental, 2016).

\section{Generalizability of findings}

A common criticism of controlled trials is that study samples are too strict to represent the true clinical population. Rigid inclusion criteria (e.g., not allowing comorbidity and/or suicidal ideation), strict treatment protocol, highly trained therapists (Beard et al., 2016), study participants being in favor of the method investigated (Mohr et al., 2017), highly motivated and more educated than the target population are factors that are considered to limit the generalizability of findings (Andersson \& Cuijpers, 2009).

Thus, the wide inclusion criteria used in all studies should be considered a strength. For example, having a history of psychotherapy, current medication with antidepressants, moderate suicidal ideation, comorbid anxiety, or attention deficit disorder were not exclusion criteria in any trial. Moreover, study therapists, although highly trained, did not have a great deal of experience in conducting CBT treatment. In comparison, other CBT studies that have used expert level therapists have discussed that it limits the generalizability of results - therapists with similar expertise may not be available in many settings (e.g. Thase et al., 2018). The blended approaches in Study II-V also to a high degree include standardized components. This means that they are likely less sensitive than face-to-face treatment, to variations in therapist characteristics, e.g., competence and training level, or to therapist drift. This is promising in terms of the generalizability of obtained treatment effects.

In terms of generalization to a clinical population, major depressive episode was inclusion criteria in the studies with adults (Study II, Study III), why depression severity is considered no lower than that seen in Swedish primary care settings. The proportion of females in the study samples were in line with the gender ratio seen for MDD in 
Swedish primary care setting (Sundquist, Ohlsson, Sundquist \& Kendler, 2017), as well as the rates of comorbid anxiety (Nordstrom \& Bodlund, 2008). However, participants were younger compared to other primary care studies on depression (e.g. Hallgren et al., 2015; Richards et al., 2016; Sobocki et al, 2007) and had higher educational level compared to the general population (Statistics Sweden, 2018). While the study populations are in line with findings on treatmentseeking in general (Vessey \& Howard, 1993) it cannot be ruled out that these sample characteristics (as well as other not identified) affected treatment outcome. For example, participants could possess greater IT experience than the general clinical population, and this might interact with treatment effect. In particular, Study II may have attracted individuals with interest in a technologyassisted treatment approach. At the time the study was conducted smartphone-supported treatment was rather novel, and the study recruited via self-referral from community setting. However, there are findings showing that the method of self-referral is not necessarily unrepresentative in terms of treatment outcome. In a study conducted with over 19.000 patients in England, no differences in recovery between patients that had self-referred to psychological treatment compared to patients that were referred by their GP were found (Gyani et al, 2013). Similarly, it is at this time unclear whether educational level affect treatment outcome (Button, Wiles, Lewis, Peters \& Kessler, 2012; Donker et al., 2013; Hamilton \& Dobson, 2002; Stiles-Shields, Corden, Kwasny, Schueller $\&$ Mohr, 2015). While Study III aimed to be representative for a clinical population, and recruited in primary care setting, the study methods did not rule out that participants may have self-referred. Also, some of the methods used (e.g. the randomization and the controlled treatment delivery) are more representative for controlled setting than real-world circumstances. It has previously been discussed that it is likely impossible to perform research with conditions that represent true real-world conditions, i.e. effectiveness research (Fritz \& Cleland, 2003). Rather, the distinction between evaluations in highly controlled settings (efficacy research) and effectiveness research is better understood as a continuum (Singal, Higgins \& Wajlee, 2014). In this perspective, Study III falls 
somewhere between efficacy and effectiveness research (Flay et al, 2015).

For the adolescent population, it can be discussed whether the true clinical population can be properly approximated. In addition to the shortage in care capacity, adolescents under-represent in standard care settings for reasons of stigma, limited mental health literacy, and a preference for seeking help from friends and family rather than professionals (e.g. Bradley et al, 2012; Gulliver, Griffiths \& Christensen, 2010; Melas et al, 2013). Study IV and Study V acknowledged this and allowed adolescents to autonomously enroll and conduct treatment if they were deemed to possess adequate maturity to make informed decisions about their treatment. The studies helped reveal what kind of population is to be expected when providing an alternative pathway to care, aimed at reducing stigma and lowering the threshold to care. The demographics were strikingly similar across studies, thus reviewed as one sample. Both individuals with (37\%) and without previous mental health care history or contact with standard care or school counseling services were represented, indicating that the treatment had a broad appeal. About 37\% lived with both of their parents, which is lower than the population average of 60\% (Statistics Sweden, 2016). This is likely not explained by participants already living on their own, given that the mean age for moving from home in Sweden is 19.6 years (Eurostat, 2015), the mean age in the sample was about 17 years. The majority reported living in a rural area or a small town $(72 \%)$. This is interesting and may indicate increased accessibility to treatment via elimination of geographical barriers, as well as the possible barriers caused by stigma. Seeking help in a rural setting could be more challenging for adolescents, both regarding resources and discretion, compared to seeking help in municipal areas, where youth mental health resources are more readily available as well as possible to seek more anonymously. In this connection, 30\% had not told their parents about their depression. How this compares to the general population is unknown, but it is not representative of the population seen in Swedish child and adolescent mental health services as these settings in general require guardians to be 
informed about treatment (Swedish Child and Adolescent Mental Health Services, 2016). A striking finding in the sample was the female preponderance (95\%). Similarly, skewed population are observed in chat-based help lines and counseling services for youth in Sweden (Children's Rights in Society, 2017), Denmark (Sindahl, 2013), Canada (Haner \& Pepler, 2016) and Australia (Rickwood, Webb, Kennedy \& Telford, 2016), which indicate that the result may relate to the online-medium. The difference in help-seeking patterns seen among girls and boys has been suggested to be an underlying reason. More specifically, as discussed by Rickwood and colleagues, young boys are more likely than girls to seek help as a consequence of being influenced by others and this may act against boys' enrollment in online interventions, given that such enrollment is more dependent on self-motivation (Rickwood et al., 2016). However, also within Swedish standard care settings, the large majority (73\%) of adolescents treated for depression are girls (The National Board of Health and Welfare, 2017b), reflecting the excess of affected girls seen clinical as well as in epidemiological samples (Thapar et al., 2012). Thus, the populations in Study IV and Study V are unlikely to be merely due to differences in help-seeking. In conclusion, the adolescents who sought out treatment in Study IV and Study V were in many respects similar to the general population, but also showed important difference in characteristics.

\section{Limitations}

The survey had a limited response rate (23\%) and reflects the attitudes of a convenience sample. Written questions for data provide limited in-depth understanding of contributed views (Feijt et al., 2018). The results are preliminary and need to be replicated and extended. In particular, the underlying reasons for the preference for blended treatment were not sufficiently assessed. Given these limitations, the unambiguous result for blended treatment, with more positive attitudes consistent over stakeholder and country sub-groups, is a strength. Likewise, that respondents were representative of different health care infrastructures and levels of e-mental health implementation in Europe. 
Study II and Study III were not powered to establish statistical noninferiority for the blended treatments. In Study II this was for reason of resources. Study III was part of a larger multinational trial and the sample size and non-inferiority criteria was set accordingly (Kleiboer et al., 2016). There is no universally agreed criteria for noninferiority, and variations are seen, including studies on blended depression treatment (e.g. Kemmeren et al., 2016; Mathiasen, Andersen, Riper, Kleiboer \& Roessler, 2016; Thase et al, 2018). The criteria for non-inferiority used in Study II and Study III can be questioned. While the lack of power is certainly essential limitation in Study II and III, the trials still make relevant contributions to the literature as results can be included in larger systematic reviews (Guyatt, Mills \& Elbourne, 2008; Schulz \& Grimes, 2005).

In Study III it is unfortunate that information of care utilization was not gathered in interviews beyond post-treatment assessment. This limits the conclusions that can be made in terms of long-term effects.

In Study III-V, therapists conducting clinical interviews were not blind to participants' group assignment. For interviews conducted post-treatment and at follow-ups, the non-blinded procedure introduces a risk of systematic bias in answers, such as socially desirable response from participants and interpretation of symptoms by clinicians (for example highlighted by Baumeister et al., 2014). Remission from diagnosis was not the primary outcome, and in relation to the limitations of methodology in the interviews, the use of self-report outcome measures (BDI-II, PHQ-9) that were automatically assigned to participants, without any interaction with assessors, should be considered a strength.

As regards to assessment, Study II-V would have benefited from the inclusion of behavioral change measures. In Study IV and Study V, additional sources from parents or teachers would moreover have been beneficial.

Studies included only limited (Study II) or no evaluation of therapist's adherence and competence. However, the delivery of treatments where to a large extent supported by standardized online 
components, which may reduce potential effects related to therapist's adherence and competence. It is indicated that adherence and competence aspects may play only a small role for patient treatment improvement (Webb, DeRubeis \& Barber, 2010).

Given the novelty of the blended treatment, it is unfortunate that qualitative treatment aspects were not more thoroughly assessed. Similarly, given that treatments aim to be relevant in a scalability perspective economic evaluation is highly relevant but this data collection was only included in Study III. This evaluation will be reported on separately, as part of a broader collaborative European research project).

The blended treatments were based on evidence-based treatments (e.g., Butler et al., 2006; Cristea et al., 2017; Cuijpers et al., 2013). While the results supported that treatments improved depression, the studies contributed limited information on how effects were achieved. Especially, the CBT blended treatments are packages that include a range of components. It is not certain that mechanisms of change are the same in traditional treatment and technologyassisted psychological treatment (Mogoase, Cobeanu, David, Giosan \& Szentagotai, 2017).

\section{Clinical implications}

Clearly, there is a need among professionals and other mental health care stakeholders to maintain therapist-patient contact. It has become increasingly evident that the cautious attitudes seen towards ICBT are often related to perceived risks. Depression is a serious disorder and therapist-patient contact is thought to be necessary for reasons of safety monitoring, to allow treatment to be tailored to individual patient needs (Titzler, Saruhanjan, Berking, Riper \& Ebert, 2018; van der Vaart et al., 2014) as well as to achieve therapist-patient collaboration and therapeutic alliance (e.g., Horvath \& Bedi, 2011). Moreover, therapist-patient contact seems essential for clinicians to perceive their work as meaningful (Folker et al., 2018). The blended treatment approach that reduces but still includes face-to-face sessions was found to be promising in addressing these needs, as well as the need to design psychological 
treatment that is scalable. The approach represents a gradual integration of technology into treatment practice that can be highly relevant in stepped care public health models, falling between universal health promotion and intensive treatments for more severe depression states.

In addition to treatment shortages, especially young populations present the additional challenges of drop-out, stigma and low clinical effect. The online blended treatment with chat sessions was designed with this in mind - it was a concurrent goal for treatment to overcome individual as well as structural barriers to treatment. The literature on adolescents' online behavior, and preferences and experiences of online help-seeking and treatment formed the basis for development. The findings on improvement, recruitment, and treatment engagement indicate that this kind of treatment and/or direct pathway to care is needed and appreciated. The studies make an important contribution by revealing which population can be expected to respond if similar treatments are made available to youth. If the aim is to reach individuals in need, at an early stage of the disorder, the conditions for young people to receive treatment may need to become more inclusive. The individual and societal benefits of timely intervention cannot be overstated.

\section{Conclusion and future research directions}

The blended treatment models developed and investigated in the thesis build on the large body of accumulated evidence supporting the clinical effect of standard as well as internet-based cognitive behavioral therapy. The findings presented show that the blended treatment approach can achieve acceptance among key mental health stakeholders and obtain clinically relevant effects, including long-term effects, in treatment of depression in the adult and adolescent populations. In conclusion, the blended treatment approaches seem to be viable in efforts to scale up and enhance the delivery of psychological treatment.

Future research could further investigate how blended approaches, such as those evaluated in this thesis, can complement each otheror be combined - in addressing different needs related to cultural 
contexts, regulations and populations. The possibility of blended treatments to be configured to varying organizational demands and populations may be a critical feature to allow further implementation and application of psychological treatment that integrate technologies, for example in routine care settings. It is of interest to further evaluate blended treatment in representative populations and contexts, including the potentials in stepped public health care models. As for conditions in countries with less developed mental health infrastructures, text-based blended treatment may prove to be particularly promising and readily feasible, given no geographical boundary and that it uses simple device-independent technology. Future research could investigate the potentials of blended CBT treatment approaches delivered by mental health workers with little training in psychological treatment delivery due to increased automation.

While the blended treatments evaluated in this thesis show promising results, they still present designs that highly relate to standard delivery of psychological treatment - in their respective outline, components, therapist contact, content and timing. Newer technologies and methods, such as artificial intelligence, virtual reality and non-intrusive collection of data, open up new perspectives on the delivery of psychological treatment, and the possibility to enhance treatment effect and precision in treatment.

Evidence for psychological treatment is mostly based on limited time frames, and treatment effect during the acute treatment of depression. Future studies should further establish the longitudinal effects of blended CBT treatment to learn about the on the longterm disease course compared to other, or no treatment. Finally, to include phases of low-intensive continuation treatment in technology-assisted interventions is a potential that could be further explored. 


\section{REFERENCES}

American Psychiatric Association. (2010). Practice guideline for the treatment of patients with major depressive episode. American Psychiatric Association: Arlington.

American Psychiatric Association. (2013). Diagnostic and statistical manual of mental disorders: DSM-5. American Psychiatric Association: Arlington.

Amick, H. R., Gartlehner, G., Gaynes, B. N., Forneris, C., Asher, G. N., Morgan, L. C., ... Lohr, K. N. (2015). Comparative benefits and harms of second generation antidepressants and cognitive behavioral therapies in initial treatment of major depressive disorder: systematic review and metaanalysis. British Medical Journal (Clinical research ed.), 351, h6019.

Andersson, G. (2009). Using the internet to provide cognitive behaviour therapy. Behaviour Research and Therapy, 47, 175-180.

Andersson, G. (2016). Internet-delivered psychological treatments. Annual Review of Clinical Psychology, (12), 157-179.

Andersson, G., \& Carlbring, P. (2017). Internet-Assisted Cognitive Behavioral Therapy. Psychiatric Clinics of North America, 40(4), 689-700.

Andersson, G., Carlbring, P., Berger, T., Almlöv, J., \& Cuijpers, P. (2009). What makes Internet therapy work? Cognitive Behaviour Therapy, 38(S1), 55-60.

Andersson, G., \& Cuijpers, P. (2009). Internet-based and other computerized psychological treatments for adult depression: A meta-analysis. Cognitive Behaviour Therapy, 38, 196-205.

Andersson, G., Cuijpers, P., Carlbring, P., Riper, H., \& Hedman, E. (2014). Guided Internet-based vs. face-to-face cognitive behavior therapy for psychiatric and somatic disorders: a systematic review and metaanalysis. World Psychiatry, 13(3), 288-295.

Andersson, G. \& Titov, N. (2014). Advantages and limitations of Internet-based interventions for common mental disorders. World Psychiatry, 13(1), 4-11.

Andersson, G., Topooco, N., Havik, O., \& Nordgreen, T. (2016). Internetsupported versus face-to-face cognitive behavior therapy for depression. Expert Review of Neurotherapeutics, 16(1), 55-60.

Andrews, G., Basu, A., Cuijpers, P., Craske, M. G., McEvoy, P., English, C. L., \& Newby, J. M. (2018). Computer therapy for the anxiety and depression disorders is effective, acceptable and practical health care: An updated meta-analysis. Journal of Anxiety Disorders, 55, 70-78. 
Angold, A., Weissman, M. M., John, K., Merikangas, K. R., Prusoff, B. A., Wickramaratne, P., Gammon, G. D., \& Warner, V. (1987). Parent and child reports of depressive symptoms in children at low and high risk of depression. Journal of Child Psychology and Psychiatry, and Allied Disciplines, 28, 901-15.

Avenevoli, S., Knight, E., Kessler, R. C., \& Merikangas, K. R. (2008). Epidemiology of depression in children and adolescents. In: J. R. Z. Abela, \& B. L. Hankin (Eds.), Handbook of depression in children and adolescents (pp. 6-32). New York: Guilford Press.

Avenevoli, S., Stolar, M., Li, J., Dierker, L., \& Ries Merikangas, K. (2001). Comorbidity of depression in children and adolescents: models and evidence from a prospective high-risk family study. Biological Psychiatry, 49(12), 1071-1081.

Balazs, J., Miklosi, M., Kereszteny, A., Hoven, C. W., Carli, V., Wasserman, C., . . . Wasserman, D. (2013). Adolescent subthreshold-depression and anxiety: psychopathology, functional impairment and increased suicide risk. Journal of Child Psychology and Psychiatry and Allied Disciplines, 54(6), 670-677.

Bardone, A. M., Moffitt, T. E., Caspi, A., Dickson, N., Stanton, W. R., \& Silva, P. A. (1998). Adult physical health outcomes of adolescent girls with conduct disorder, depression, and anxiety. Journal of the American Academy of Child and Adolescent Psychiatry, 37(6), 594-601.

Batterham, P. J., Neil, A. L., Bennett, K., Griffiths, K. M., \& Christensen, H. (2008). Predictors of adherence among community users of a cognitive behavior therapy website. Patient Preference and Adherence, 2, 97-105.

Bauer, M., Monz, B.U, Montejo, A. L., Quail, D., Dantchev, N., Demyttenaere, K., Garcia-Cebrian, A.,... Tylee, A. (2008). Prescribing patterns of antidepressants in Europe: results from the Factors Influencing Depression Endpoints Research (FINDER) study. European Psychiatry, 23(1), 66-73.

Baumeister, H., Reichler, L., Munzinger, M., \& Lin, J. (2014). The impact of guidance on Internet-based mental health interventions - A systematic review. Internet Interventions, 1(4), 205-215.

Baumel, A., Tinkelman, A., Mathur, N., \& Kane, J. M. (2018). Digital peersupport platform (7Cups) as an adjunct treatment for women with postpartum depression: feasibility, acceptability, and preliminary efficacy study. JMIR mHealth and uHealth, 6(2), e38.

Beard, C., Stein, A. T., Hearon, B. A., Lee, J., Hsu, K. J., \& Bjorgvinsson, T. (2016). Predictors of depression treatment response in an intensive cbt partial hospital. Journal of Clinical Psychology, 72(4), 297-310. 
Beck, A. T., Steer, R. A., \& Brown, G. K. (1996). Manual for the Beck Depression Inventory-II. San Antonio, TX: Psychological Corporation.

Becker, E. M., \& Jensen-Doss, A. (2013). Computer-assisted therapies: Examination of therapist-level barriers to their use. Behavior Therapy, 44(4), 614-624.

Belmaker, R. H., \& Agam , G. (2008). Major Depressive Disorder. New England Journal of Medicine, 358(1), 55-68.

Belsher, G. \& Costello, C. G. (1988). Relapse after recovery from unipolar depression: a critical review. Psychological Bulletin, 104(1), 84-96.

Bergin, A. E. (1966). Some implications of psychotherapy research for therapeutic practice. Journal of Abnormal Psychology, 71(4), 235- 246.

Birmaher, B., Brent, D., Bernet, W., Bukstein, O., Walter, H., Benson, R. S., . . . Medicus, J. (2007). Practice parameter for the assessment and treatment of children and adolescents with depressive disorders. Journal of the American Academy of Child and Adolescent Psychiatry, 46(11), 1503-1526.

Bloom D.E, Cafiero E, Jané-Llopis, E., Abrahams-Gessel, S., Bloom, L. R., Fathima, S., ... Weinstein, C. (2011). The global economic burden of noncommunicable diseases. Geneva: World Economic Forum.

Bogren, M., Bradvik, L., Holmstrand, C., Nobbelin, L., \& Mattisson, C. (2018). Gender differences in subtypes of depression by first incidence and age of onset: a follow-up of the Lundby population. European Archives of Psychiatry and Clinical Neuroscience, 268(2), 179-189.

Bower, P., Kontopantelis, E., Sutton, A., Kendrick, T., Richards, D. A., Gilbody, S., . . Liu, E. T. (2013). Influence of initial severity of depression on effectiveness of low intensity interventions: meta-analysis of individual patient data. British Medical Journal, 346, f540.

Bradley, K. L., Robinson, L. M., \& Brannen, C. L. (2012). Adolescent help-seeking for psychological distress, depression, and anxiety using an internet program. International Journal of Mental Health Promotion, 14 (1), 23-34.

Brent, D., Emslie, G., Clarke, G., Wagner, K. D., Asarnow, J. R., Keller, M., ... Zelazny, J. (2008). Switching to another SSRI or to venlafaxine with or without cognitive behavioral therapy for adolescents with SSRIresistant depression: the TORDIA randomized controlled trial. JAMA, 299(8), 901-913.

Bromet, E., Andrade, L. H., Hwang, I., Sampson, N. A., Alonso, J., de Girolamo, G., ... Kessler, R. C. (2011). Cross-national epidemiology of DSM-IV major depressive episode. BMC Medicine, 9, 90.

Butler, A. C., Chapman, J. E., Forman, E. M., \& Beck, A. T. (2006). The empirical status of cognitive-behavioral therapy: A review of meta-analyses. Clinical Psychological Review, 26(1), 17-31. 
Button, K. S., Wiles, N. J., Lewis, G., Peters, T. J., \& Kessler, D. (2012). Factors associated with differential response to online cognitive behavioural therapy. Social Psychiatry and Psychiatric Epidemiology, 47(5), 827-833.

Calear, A. L., Christensen, H., Mackinnon, A., Griffiths, K. M., \& O'Kearney, R. (2009). The YouthMood Project: a cluster randomized controlled trial of an online cognitive behavioral program with adolescents. Journal of Consulting and Clinical Psychology, 77,(6), 1021-1032.

Cassano, P., \& Fava, M. (2004). Tolerability issues during long-term treatment with antidepressants. Annals of Clinical Psychiatry, 16(1), 15-25.

Cheung, A. H., Zuckerbrot, R. A., Jensen, P. S., Ghalib, K., Laraque, D., \& Stein, R. E. (2007). Guidelines for adolescent depression in primary care (GLADPC): II. Treatment and ongoing management. Pediatrics, 120(5), e13131326.

Children's rights in Society. (2013). 2013 Report. (BRIS-rapporten 2013). Accessed from www.mynewsdesk.com/se/documents/bris-rapporten-2013-25340

Children's rights in Society. (2017). Children's mental health. Report 2017:1. (Barns psykiska ohälsa - det är dags att bryta trenden. Rapport 2017:1). Accessed from http://www.sfbup.se/wp-content/uploads/2017/o3/bris-rapport2017_1.pdf

Chisholm, D., Sweeny, K., Sheehan, P., Rasmussen, B., Smit, F., Cuijpers, P., \& Saxena, S. (2016). Scaling-up treatment of depression and anxiety: a global return on investment analysis. Lancet Psychiatry, 3(5), 415-424.

Cipriani, A., Zhou, X., Del Giovane, C., Hetrick, S. E., Qin, B., Whittington, C., .. . Xie, P. (2016).Comparative efficacy and tolerability of antidepressants for major depressive disorder in children and adolescents: a network meta-analysis. Lancet, 388(10047), 881-890.

Cipriani, A., Furukawa, T. A., Salanti, G., Chaimani, A., Atkinson, L. Z., Ogawa, Y., ... Geddes, J. R. (2018). Comparative efficacy and acceptability of 21 antidepressant drugs for the acute treatment of adults with major depressive disorder: a systematic review and network meta-analysis. Lancet, 7, 391(10128), 1357-1366.

Coles, M. E., Ravid, A., Gibb, B., George-Denn, D., Bronstein, L. R., \& McLeod, S. (2016). Adolescent mental health literacy: young people's knowledge of depression and social anxiety disorder. Journal of Adolescent Health, 58(1), 57-62.

Colón-Semenza, C., Latham, N. K., Quintiliani, L. M., \& Ellis, T. D. (2018). Peer coaching through mhealth targeting physical activity in people with parkinson disease: feasibility study. JMIR Mhealth Uhealth, 6(2), e42.

Copeland, W. E., Shanahan, L., Costello, E. J., \& Angold, A. (2009). Childhood and adolescent psychiatric disorders as predictors of young adult disorders. Archives of General Psychiatry, 66(7), 764-772. 
Costello, E. J., Egger, H., \& Angold, A. (2005). 10-year research update review: the epidemiology of child and adolescent psychiatric disorders: I. Methods and public health burden. Journal of the American Academy of Child and Adolescent Psychiatry, 44(10), 972-986.

Cox, G. R., Callahan, P., Churchill, R., Hunot, V., Merry, S. N., Parker, A. G., \& Hetrick, S. E. (2014). Psychological therapies versus antidepressant medication, alone and in combination for depression in children and adolescents. The Cochrane database of systematic reviews, 14, 11, Cdoo8324.

Cristea, I. A., Stefan, S., Karyotaki, E., David, D., Hollon, S. D., \& Cuijpers, P. (2017). The effects of cognitive behavioral therapy are not systematically falling: A revision of Johnsen and Friborg (2015). Psychological Bulletin, 143(3), 326-340.

Crutzen, R., Bosma, H., Havas, J., \& Feron, F. (2014). What can we learn from a failed trial: insight into non-participation in a chat-based intervention trial for adolescents with psychosocial problems. BMC Research Notes, 7,824 .

Cuijpers, P. (1998). Minimizing interventions in the treatment and prevention of depression: Taking the consequences of the "Dodo Bird Verdict." Journal of Mental Health, 7, 355-365.

Cuijpers, P., \& Cristea, I. A. (2015). What if a placebo effect explained all the activity of depression treatments? World Psychiatry, 14(3), 310-311.

Cuijpers, P., de Wit, L., Weitz, E., Andersson, G., \& Huibers, M. J. H. (2015). The combination of psychotherapy and pharmacotherapy in the treatment of adult depression: A comprehensive meta-analysis. Journal of Evidence-Based Psychotherapies, 15, 147-168.

Cuijpers, P., Dekker, J., Hollon, S. D., \& Andersson, G. (2009). Adding psychotherapy to pharmacotherapy in the treatment of depressive disorders in adults: A meta-analysis. Journal of Clinical Psychiatry, 7o, 1219-1229.

Cuijpers, P., Donker, T., van Straten, A., \& Andersson, G. (2010). Is guided selfhelp as effective as face-to-face psychotherapy for depression and anxiety disorders? A meta-analysis of comparative outcome studies. Psychological Medicine, 40, 1943-1957.

Cuijpers, P., Karyotaki, E., Weitz, E., Andersson, G., Hollon, S. D., \& van Straten, A. (2014). The effects of psychotherapies for major depression in adults on remission, recovery and improvement: a meta-analysis. Journal of Affective Disorders, 159, 118-126. 
Cuijpers, P., Sijbrandij, M., Koole, S. L., Andersson, G., Beekman, A. T., \& Reynolds, III, C. F. (2013). The efficacy of psychotherapy and pharmacotherapy in treating depressive and anxiety disorders: a metaanalysis of direct comparisons. World Psychiatry, 12(2), 137-148.

Cuijpers, P., Sijbrandij, M., Koole, S. L., Andersson, G., Beekman, A. T., \& Reynolds III, C. F. (2014). Adding psychotherapy to antidepressive medication in depression and anxiety disorders: A meta-analysis. World Psychiatry, 13, 56-67.

Cuijpers, P., Turner, E. H., Koole, S. L., van Dijke, A., \& Smit, F. (2014). What is the threshold for a clinically relevant effect? The case of major depressive disorders. Depression and Anxiety, 31(5), 374-378.

Cuijpers, P., van Straten, A. M., \& Andersson, G. (2008). Internet-administered cognitive behavior therapy for health problems: A systematic review. Journal of Behavioral Medicine, 31, 169-177.

Cuijpers, P., van Straten, A., Warmerdam, L. \& Andersson, G. (2009). Psychotherapy versus the combination of psychotherapy and pharmacotherapy in the treatment of depression: A meta-analysis. Depression and Anxiety, 26, 279-288.

Cuijpers, P., Vogelzangs, N., Twisk, J., Kleiboer, A., Juan, L., \& Penninx, B. W. (2014). Comprehensive meta-analysis of excess mortality in depression in the general community versus patients with specific illnesses. The American Journal of Psychiatry, 171 (4), 453-62.

Davidson, J. R. (2010). Major depressive disorder treatment guidelines in America and Europe. Journal of Clinical Psychiatry, 71 Suppl E1, eo4.

Daviss, W. B., Birmsher, B., Melhem, N. A. (2006). Criterion validity of the Mood and Feelings Questionnaire for depressive episodes in clinic and nonclinic subjects. Journal of Child Psychology and Psychiatry, 47, 927-34.

Dimidjian, S., Barrera M. Jr, Martell, C., Muñoz, R. F., \& Lewinsohn, P. M. (2011). The origins and current status of behavioral activation treatments for depression. Annual review of clinical psychology, 7, 1-38.

Dimidjian, S., \& Hollon, S. D. (2010). How would we know if psychotherapy were harmful? American Psychologist, 65(1), 21-33.

Donker, T., Batterham, P. J., Warmerdam, L., Bennett, K., Bennett, A., Cuijpers, P., ... Christensen, H. (2013). Predictors and moderators of response to internet-delivered interpersonal psychotherapy and cognitive behavior therapy for depression. Journal of Affective Disorders, 151(1), 343-351.

Driessen, E., \& Hollon, S. D. (2010). Cognitive behavioral therapy for mood disorders: efficacy, moderators and mediators. Psychiatric Clinics of North America, 33(3), 537-555.

Duggal, R., Brindle, I. \& Bagenal, J. (2018). Digital healthcare: regulating the revolution. British Medical Journal, (Clinical research ed.), 36o, k6. 
Dunn, V. \& Goodyer, I. M. (2006). Longitudinal investigation into childhoodand adolescence-onset depression: psychiatric outcome in early adulthood. British Journal of Psychiatry, 188, 3.

Ebert, D. D., \& Baumeister, H. (2017). Internet-based self-help interventions for depression in routine care. JAMA Psychiatry, 74(8), 852-853.

Ebert, D. D., Berking, M., Cuijpers, P., Lehr, D., Portner, M., \& Baumeister, H., (2015). Increasing the acceptance of internet-based mental health interventions in primary care patients with depressive symptoms. A randomized controlled trial. Journal of Affective Disorders, 176, 9-17.

Ebert, D. D., Zarski, A. C., Christensen, H., Stikkelbroek, Y., Cuijpers, P., Berking, M., \& Riper, H. (2015). Internet and computer-based cognitive behavioral therapy for anxiety and depression in youth: a meta-analysis of randomized controlled outcome trials. PLoS One, 10(3), e0119895.

Emslie, G. J., Mayes, T. L., \& Ruberu, M. (2005). Continuation and maintenance therapy of early-onset major depressive disorder. Paediatric Drugs, 7(4), 203-217.

Eonta, A. M., Christon, L. M., Hourigan, S. E., Ravindran, N., Vrana, S. R., \& Southam-Gerow, M. A. (2011). Using everyday technology to enhance evidence-based treatments. Professional Psychology: Research and Practice, 42(6), 513-520.

Erbe, D., Eichert, H. C., Riper, H., \& Ebert, D. D. (2017). Blending Face-to-Face and Internet-Based Interventions for the Treatment of Mental Disorders in Adults: Systematic Review. Journal of Medical Internet Research, 19(9), e306.

Etkin, A., Buchel, C., \& Gross, J. J. (2015). The neural bases of emotion regulation. Nature Reviews Neuroscience, 16(11), 693-700.

Evans, C., Margison, F., \& Barkham, M. (1998). The contribution of reliable and clinically significant change methods to evidence-based mental health. Evidence-based Mental Health, 1(3), 70-72.

Eurostat. (2015). Being young in Europe today. European Union: Luxembourg: Publications.

Feijt, M. A., de Kort, Y. A., Bongers, I. M., \& IJsselsteijn, W. A. (2018). Perceived drivers and barriers to the adoption of emental health by psychologists: the construction of the levels of adoption of emental health model. Journal of Medical Internet Research, 20(4), e153.

Ferrari, A. J., Somerville, A. J., Baxter, A. J., Norman, R., Patten, S. B., Vos, T., \& Whiteford, H. A. (2013). Global variation in the prevalence and incidence of major depressive disorder: a systematic review of the epidemiological literature. Psychological Medicine, 43(3), 471-481. 
Fischer, A. S., Camacho, M., Ho, T. C., Whitfield-Gabrieli, S., \& Gotlib, I. H. (2018). Neural markers of resilience in adolescent females at familial risk for major depressive disorder. JAMA Psychiatry, 75(5), 493-502.

Fitzpatrick, K. K., Darcy, A., \& Vierhile, M. (2017). Delivering cognitive behavior therapy to young adults with symptoms of depression and anxiety using a fully automated conversational agent (woebot): a randomized controlled trial. Journal of Medical Internet Research, 4(2), e19.

Flay, B. R., Biglan, A., Boruch, R. F., Castro, F. G., Gottfredson, D., Kellam, S., . . . Ji, P. (2005). Standards of evidence: criteria for efficacy, effectiveness and dissemination. Prevention Science, 6(3), 151-175.

Flint, J., \& Kendler, K. S. (2014). The Genetics of Major Depression. Neuron, 81(5), 1214.

Folker, A. P., Mathiasen, K., Lauridsen, S. M., Stenderup, E., Dozeman, E., \& Folker, M. P. (2018). Implementing internet-delivered cognitive behavior therapy for common mental health disorders: A comparative case study of implementation challenges perceived by therapists and managers in five European internet services. Internet Interventions, 11, 60-70.

Friedman , R. A., \& Leon, A. C. (2007). Expanding the Black Box - Depression, Antidepressants, and the Risk of Suicide. New England Journal of Medicine, 356(23), 2343-2346.

Fritz, J. M., \& Cleland, J. (2003). Effectiveness versus efficacy: more than a debate over language. The Journal of Orthopaedic and Sports Physical Therapy, 33(4), 163-165.

Gartlehner, G., Hansen, R. A., Morgan, L. C., Thaler, K., Lux, L., Van Noord, M., . .. Lohr, K. N. (2011). Comparative benefits and harms of secondgeneration antidepressants for treating major depressive disorder: an updated meta-analysis. Annals of Internal Medicine, 155(11), 772-785.

Gerrits, R. S., van der Zanden, R. A. P., Visscher, R. F. M., \& Conijn, B. P. (2007). Master your mood online: A preventive chat group intervention for adolescents. Advances in Mental Health, 6(3), 152-162.

Gilbody, S., Bower, P., \& Whitty, P. (2006). Costs and consequences of enhanced primary care for depression: systematic review of randomised economic evaluations. British Journal of Psychiatry, 189, 297-308.

Gilbody, S., Richards, D., Brealey, S., \& Hewitt, C. (2007). Screening for depression in medical settings with the Patient Health Questionnaire (PHQ): A diagnostic meta-analysis. Journal of General Internal Medicine, 22, 1596-602. 
Gros, D. F., Morland, L. A., Greene, C. J., Acierno, R., Strachan, M., Egede, L. E., . .. Frueh, B. C. (2013). Delivery of Evidence-Based Psychotherapy via Video Telehealth. Journal of Psychopathology and Behavioral Assessment, 35(4), 506-521.

Gueorguieva, R., \& Krystal, J. H. (2004). Move over ANOVA: progress in analyzing repeated-measures data and its reflection in papers published in the Archives of General Psychiatry. Archives of General Psychiatry, 61(3), 310-317.

Gulliver, A., Banfield, M., Reynolds, J., Miller, S., Galati, C., \& Morse, A. R. (2017). A Peer-Led Electronic Mental Health Recovery App in an Adult Mental Health Service: Study Protocol for a Pilot Trial. JMIR Research Protocols, 6(12), e248.

Gulliver, A., Griffiths, K. M., \& Christensen, H. (2010). Perceived barriers and facilitators to mental health help-seeking in young people: a systematic review. BMC Psychiatry, 10, 113.

Gun, S. Y., Titov, N., \& Andrews, G. (2011). Acceptability of Internet treatment of anxiety and depression. Australasian psychiatry: bulletin of Royal Australian and New Zealand College of Psychiatrists, 19(3), 259-264.

Guyatt, G. H., Mills, E. J., \& Elbourne, D. (2008). In the era of systematic reviews, does the size of an individual trial still matter. PloS Medicine, 5(1), e4.

Gyani, A., Shafran, R., Layard, R., \& Clark, D. M. (2013). Enhancing recovery rates: Lessons from year one of IAPT. Behavior Research Therapy, 51(9), 597-606.

Hallgren, M., Kraepelien, M., Ojehagen, A., Lindefors, N., Zeebari, Z., Kaldo, V., \& Forsell, Y. (2015). Physical exercise and internet-based cognitive behavioural therapy in the treatment of depression: randomised controlled trial. British Journal of Psychiatry, 207(3), 227-34.

Hamilton, K. E., \& Dobson, K. S. (2002). Cognitive therapy of depression: pretreatment patient predictors of outcome. Clinical Psychology Review, 22(6), 875-893.

Haner, D., \& Pepler, D. (2016). "Live chat" clients at kids help phone: individual characteristics and problem topics. Journal of the Canadian Academy of Child and Adolescent Psychiatry, 25(3), 138-144.

Hankin, B. L. (2006). Adolescent depression: description, causes, and interventions. Epilepsy and Behavior, 8(1), 102-114.

Hasler, G. (2010). Pathophysiology of depression: do we have any solid evidence. World Psychiatry, 9(3), 155-161.

Hatcher, R. L., \& Gillaspy, J. A. (2006). Development and validation of a revised short version of the working alliance inventory. Psychotherapy Research, 16(1), 12-25.

Hawton, K., \& van Heeringen, K. (2009). Suicide. Lancet, 373(9672), 1372-1381. 
Hedman, E., Ljotsson, B., \& Lindefors, N. (2012). Cognitive behavior therapy via the Internet: a systematic review of applications, clinical efficacy and cost-effectiveness. Expert Review of Neurotherapeutics, 12(6), 745-764.

Heim, C., \& Binder, E. B. (2012). Current research trends in early life stress and depression: review of human studies on sensitive periods, geneenvironment interactions, and epigenetics. Experimental Neurology, 233(1), 102-111.

Hetrick, S. E., McKenzie, J. E., Cox, G. R., Simmons, M. B., \& Merry, S. N. (2012). Newer generation antidepressants for depressive disorders in children and adolescents. The Cochrane Database of Systematic Reviews, 11, Cdoo4851.

Hill, C., Martin, J. L., Thomson, S., Scott-Ram, N., Penfold, H., \& Creswell, C. (2017). Navigating the challenges of digital health innovation: considerations and solutions in developing online and smartphoneapplication-based interventions for mental health disorders. British Journal of Psychiatry, 211(2), 65-69.

Hirschfeld, R. (2001). The comorbidity of major depression and anxiety disorders: recognition and management in primary care. Primary Care Companion to the Journal of Clinical Psychiatry, 3(6), 244-254.

Hoermann, S., McCabe, K. L., Milne, D. N., \& Calvo, R. A. (2017). application of synchronous text-based dialogue systems in mental health interventions: systematic review. Journal of Medical Internet Research, 19(8), e267.

Hofmann, S. G. (2011). An introduction to modern CBT: Psychological solutions to mental health problems. Oxford, UK: Wiley-Blackwell.

Hollis, C., Morriss, R., Martin, J., Amani, S., Cotton, R., Denis, M. \& Lewis, S. (2015). Technological innovations in mental healthcare: harnessing the digital revolution. British Journal of Psychiatry, 206(4), 263-265.

Holmes, E. A., Ghaderi, A., Harmer, C. J., Ramchandani, P. G., Cuijpers, P., Morrison, A. P., . . . Craske, M. G. (2018). The Lancet Psychiatry Commission on psychological treatments research in tomorrow's science. Lancet Psychiatry, 5(3), 237-286.

Holst, A., Nejati, S., Bjorkelund, C., Eriksson, M. C., Hange, D., Kivi, M., ... Petersson, E. L. (2017). Patients' experiences of a computerised self-help program for treating depression - a qualitative study of Internet mediated cognitive behavioural therapy in primary care. Scandinavian Journal of Primary Health Care, 35(1), 46-53.

Holländare, F., Johnsson, S., Randestad, M., Tillfors, M., Carlbring, P., Andersson, G., \& Engstrom, I. (2011). Randomized trial of Internetbased relapse prevention for partially remitted depression. Acta Psychiatrica Scandinavia, 124(4), 285-294. 
Horvath, A. O., \& Bedi, R. P. (2011). The alliance. In J. C. Norcross ( $2^{\text {nd }}$ Ed.). Psychotherapy relationships that work. New York: Oxford University Press.

Hovens, J. G., Giltay, E. J., Wiersma, J. E., Spinhoven, P., Penninx, B. W., \& Zitman, F. G. (2012). Impact of childhood life events and trauma on the course of depressive and anxiety disorders. Acta Psychiatrica Scandinavia, 126(3), 198-207.

Hu, T. W. (2006). Perspectives: an international review of the national cost estimates of mental illness, 1990-2003. The Journal of Mental Health Policy and Economics, 9(1), 3-13.

Hyde, J. S., Mezulis, A. H. \& Abramson, L. Y. (2008). The ABCs of depression: integrating affective, biological, and cognitive models to explain the emergence of the gender difference in depression. Psychological Review, 115(2), 291-313.

Ioannidis, J. P. (2008). Effectiveness of antidepressants: an evidence myth constructed from a thousand randomized trials? Philosophy, Ethics and Humanities in Medicine, 3, 14.

Jacmon, J., Malouff, J. M., \& Taylor, N. (2009). Treatment of major depression: effectiveness of cognitive-behavioural therapy with an internet course as a central component. Electronic Journal of Applied Psychology, 5(2), 1-8.

Jacobs, J., (2014). The do's and don'ts of web chat. Aspect: Chelmsford, MA. Accessed from www.aspect.com

Jacobson, N. S., Dobson, K. S., Truax, P. A., Addis, M. E., Koerner, K., Gollan, J. K., ... Prince, S. E. (1996). A component analysis of cognitive-behavioral treatment for depression. Journal of Consulting and Clinical Psychology, 64, 295-304.

Jacobson, N. S., \& Truax, P. (1991). Clinical significance: A statistical approach to defining meaningful change in psychotherapy research. Journal of Consulting and Clinical Psychology, 59, 12-19.

Johansson, R., \& Andersson, G. (2012). Internet-based psychological treatments for depression. Expert Review of Neurotherapeutics, 12(7), 861-869, 870.

Karlsson, L., Pelkonen, M., Ruuttu, T., Kiviruusu, O., Heila, H., Holi, M., . . . Marttunen, M. (2006). Current comorbidity among consecutive adolescent psychiatric outpatients with DSM-IV mood disorders. European Child \& Adolescent Psychiatry, 15(4), 220-231.

Karyotaki, E., Kemmeren, L., Riper, H., Twisk, J., Hoogendoorn, A., Kleiboer, A., ... Cuijpers, P. (2018). Is self-guided internet-based cognitive behavioural therapy (ICBT) harmful? An individual participant data meta-analysis. Psychological Medicine, 15, 1-11. 
Karyotaki, E., Riper, H., Twisk, J., Hoogendoorn, A., Kleiboer, A., Mira, A., . . . Cuijpers, P. (2017). Efficacy of self-guided internet-based cognitive behavioral therapy in the treatment of depressive symptoms: a metaanalysis of individual participant data. JAMA Psychiatry, 74(4), 351-359.

Karyotaki, E., Smit, Y., Holdt Henningsen, K., Huibers, M. J., Robays, J., de Beurs, D., \& Cuijpers, P. (2016). Combining pharmacotherapy and psychotherapy or monotherapy for major depression? A meta-analysis on the long-term effects. Journal of Affective Disorders, 194, 144-152.

Keeley, H., Williams, C., \& Shapiro, D. A. (2002). A United Kingdom survey of accredited cognitive behaviour therapists' attitudes towards and use of structured self-help materials. Behavioural and Cognitive Psychotherapy, 30, 193-203.

Keller, M. B., Lavori, P. W., Mueller, T. I., Endicott, J., Coryell, W., Hirschfeld, R. M., \& Shea, T. (1992). Time to recovery, chronicity, and levels of psychopathology in major depression. A 5-year prospective follow-up of 431 subjects. Archives of General Psychiatry, 49(10), 809-816.

Keller, M. B. (1994). Depression: a long-term illness. British Journal of Psychiatry, 165 (Suppl 26), 9-15.

Kemmeren, L. L., van Schaik, D. J., Riper, H., Kleiboer, A. M., Bosmans, J. E., \& Smit, J. H. (2016). Effectiveness of blended depression treatment for adults in specialised mental healthcare: study protocol for a randomised controlled trial. BMC Psychiatry, 16(1), 113.

Kendler, K. S., Gardner, C. O., Neale, M. C., \& Prescott, C. A. (2001). Genetic risk factors for major depression in men and women: similar or different heritabilities and same or partly distinct genes? Psychological Medicine, 31(4), 605-616.

Kendler, K. S., Gatz, M., Gardner, C. O., \& Pedersen, N. L. (2006). A Swedish national twin study of lifetime major depression. The American journal of Psychiatry, 163(1), 109-114.

Kennerley, H., Kirk, J., \& Westbrook, D. (2011). An Introduction to Cognitive Behaviour Therapy: Skills and Applications. London: SAGE Publications LTD.

Kessler, R. C. (1997). The effects of stressful life events on depression. Annual Review of Psychology, 48, 191-214.

Kessler, R. C. (2012). The costs of depression. Psychiatric Clinics of North America, 35(1), 1-14.

Kessler, R. C., Avenevoli, S., \& Ries Merikangas, K. (2001). Mood disorders in children and adolescents: an epidemiologic perspective. Biological Psychiatry, 49(12), 1002-14. 
Kessler, R. C., Berglund, P. A.., Bruce, M. L., Koch, J. R., Laska, E. M., Leaf, P. J., . . .Wang, P. S. (2001). The prevalence and correlates of untreated serious mental illness. Health Services Research Journal, 36(6 Pt 1), 987-1007.

Kessler, R. C., Berglund, P., Demler, O., Jin, R., Koretz, D., Merikangas, K. R., . . . Wang, P. S. (2003). The epidemiology of major depressive disorder: results from the National Comorbidity Survey Replication (NCS-R). JAMA, 289, 3095-3105.

Kessler, R. C., Berglund, P., Demler, O., Jin, R., Merikangas, K. R., \& Walters, E. E. (2005). Lifetime prevalence and age-of-onset distributions of DSM-IV disorders in the National Comorbidity Survey Replication. Archives of General Psychiatry, 62(6), 593-602.

Kessler, R. C., Chiu, W. T., Demler, O., Merikangas, K. R., \& Walters, E. E. (2005). Prevalence, severity, and comorbidity of 12-month DSM-IV disorders in the National Comorbidity Survey Replication. Archives of General Psychiatry, 62(6), 617-627.

Kessler, D., Lewis, G., Kaur, S., Wiles, N, King, M., Weich, S., . . Peters, T. J. (2009). Therapist-delivered internet psychotherapy for depression in primary care: a randomised controlled trial. Lancet, 374, 628-634.

Kessler, R. C., \& Walters, E. E. (1998). Epidemiology of DSM-III-R major depression and minor depression among adolescents and young adults in the National Comorbidity Survey. Depression and Anxiety, 7(1), 23-14.

Kessler, R. C., Zhao, S., Blazer, D. G., \& Swartz, M. (1997). Prevalence, correlates, and course of minor depression and major depression in the National Comorbidity Survey. Journal of Affective Disorders, 45(1-2), 19-30.

Kim-Cohen, J., Caspi, A., Moffitt, T. E., Harrington, H., Milne, B. J., \& Poulton, R. (2003). Prior juvenile diagnoses in adults with mental disorder: developmental follow-back of a prospective-longitudinal cohort. Archives of General Psychiatry, 60(7), 709-717.

Kivi, M., Eriksson, M. C. M., Hange, D., Petersson, E.-L., Björkelund, C., \& Johansson, B. (2015). Experiences and attitudes of primary care therapists in the implementation and use of internet-based treatment in Swedish primary care settings. Internet Interventions, 2(3), 248-256.

Kivi, M., Eriksson, M. C. M., Hange, D., Petersson, E. L., Vernmark, K., Johansson, B., \& Björkelund, C. (2014). Internet-based therapy for mild to moderate depression in swedish primary care: short term results from the prim-net randomized controlled trial. Cognitive Behaviour Therapy, 43(4), 289-298. 
Kleiboer, A., Smit, J., Bosmans, J., Ruwaard, J., Andersson, G., Topooco, N., .. . Riper, H. (2016). European COMPARative Effectiveness research on blended Depression treatment versus treatment-as-usual (ECOMPARED): study protocol for a randomized controlled, noninferiority trial in eight European countries. Trials, 17(1), 387.

Klein, J. B., Jacobs, R. H., \& Reinecke, M. A. (2007). Cognitive-behavioral therapy for adolescent depression: a meta-analytic investigation of changes in effect-size estimates. Journal of the American Academy of Child and Adolescent Psychiatry, 46(11), 1403-1413.

Klengel, T., \& Binder, B. (2015). Epigenetics of stress-related psychiatric disorders and gene $\times$ environment interactions. Neuron, 86(6), 1343-1357.

Kroenke, K., Spitzer, R. L., \& Williams, J. B. W. (2001). The PHQ-9: validity of a brief depression severity measure. Journal of General Internal Medicine, 16(9), 606-13.

Kuehner, C. (2017). Why is depression more common among women than among men? Lancet Psychiatry, 4(2), 146-158.

Kuester, A., Niemeyer, H., \& Knaevelsrud, C. (2016). Internet-based interventions for posttraumatic stress: A meta-analysis of randomized controlled trials. Clinical Psychology Review, 43, 1-16.

Kupfer, D. J., Frank, E., \& Phillips, M. L. (2012). Major depressive disorder: new clinical, neurobiological, and treatment perspectives. Lancet, 379(9820), 1045-1055.

Kupfer D. J, Frank, E., \& Wamhoff, J. (1996). Mood disorders: Update on prevention of recurrence. In: Mundt C, Goldstein M. J., editors. Interpersonal factors in the origin and course of affective disorders. London, England: Gaskell/Royal College of Psychiatrists; 1996. pp. 289-302.

Lecrubier, Y., Sheehan, D.V., Weiller, E., Amorim, P., Bonora, I., Harnett, Sheehan, K., \& Dunbar, G. C. (1997). The Mini International Neuropsychiatric Interview (MINI). A short diagnostic structured interview: reliability and validity according to the CIDI. European Psychiatry, 12(5), 224-31.

Lewinsohn, P. M. (1974). A behavioral approach to depression. In R. J. Friedman \& M. M. Katz (Eds.), The psychology of depression: Contemporary theory and research. Oxford, England: John Wiley \& Sons.

Lewinsohn, P. M., Rohde, P., Klein, D. N., \& Seeley, J. R. (1999). Natural course of adolescent major depressive disorder: I. Continuity into young adulthood. Journal of the American Academy of Child and Adolescent Psychiatry, 38(1), 56-63. 
Lewinsohn, P. M., Rohde, P., \& Seeley, J. R. (1995). Adolescent psychopathology: III. The clinical consequences of comorbidity. Journal of the American Academy of Child and Adolescent Psychiatry, 34(4), 510-519.

Li, M., D'Arcy, C., \& Meng, X. (2016). Maltreatment in childhood substantially increases the risk of adult depression and anxiety in prospective cohort studies: systematic review, meta-analysis, and proportional attributable fractions. Psychological Medicine, 46, 4, 717-730.

Lillevoll, K. R., Vangberg, H. C., Griffiths, K. M., Waterloo, K., \& Eisemann, M. R. (2014). Uptake and adherence of a self-directed internet-based mental health intervention with tailored e-mail reminders in senior high schools in Norway. BMC Psychiatry, 14, 14.

Little, R. J. A., Rubin, D. B. (2002). Statistical Analysis With Missing Data, 2nd ed. New York; John Wiley \& Sons.

Lorant, V., Deliege, D., Eaton, W., Robert, A., Philippot, P., \& Ansseau, M. (2003). Socioeconomic inequalities in depression: a meta-analysis. American Journal of Epidemiology, 157(2), 98-112.

Ly, K. H., Ly, A.-M., \& Andersson, G. (2017). A fully automated conversational agent for promoting mental well-being: A pilot RCT using mixed methods. Internet Interventions, 10, 39-46.

MacQueen, G. M., Frey, B. N., Ismail, Z., Jaworska, N., Steiner, M., Lieshout, R. J., ... Schulte-Korne, G. (2016). Canadian Network for Mood and Anxiety Treatments (CANMAT) 2016 Clinical Guidelines for the Management of Adults with Major Depressive Disorder: Section 6. Special Populations: Youth, Women, and the Elderly. Canadian Journal of Psychiatry, 61(9), 588-603.

Magnavita (2018). Using technology in mental health practice. Washington DC: American Psychological Association: APA Books.

March, J., Silva, S., Petrycki, S., Curry, J., Wells, K., Fairbank, J., . . S Severe, J. (2004). Fluoxetine, cognitive-behavioral therapy, and their combination for adolescents with depression: treatment for adolescents with Depression Study (TADS) randomized controlled trial. JAMA, 292, 807-820.

Martell, C. R., Dimidjian, S., \& Herman-Dunn, R. (2013) Behavioral activation for depression: A clinician's guide: Guilford Press.

Mathiasen, K., Andersen, T. E., Riper, H., Kleiboer, A. A., \& Roessler, K. K. (2016). Blended CBT versus face-to-face CBT: a randomised noninferiority trial. BMC Psychiatry, 16(1), 432.

Mazzucchelli, T., Kane, R., \& Rees, C. (2009). Behavioral Activation Treatments for Depression in Adults: A Meta-analysis and Review. Clinical Psychology: Science and Practice, 16(4), 383- 411. 
McDermott, B., Baigent, M., Chanen, A., Fraser, L., Graetz, B., Hayman, N., ... Spence, S. (2010). Clinical practice guidelines: Depression in adolescents and young adults. Melbourne, Australia: beyondblue the National Depression Initiative.

McHugh, R. K., Whitton, S. W., Peckham, A. D., Welge, J. A., \& Otto, M. W. (2013). Patient preference for psychological vs pharmacologic treatment of psychiatric disorders: a meta-analytic review. Journal of Clinical Psychiatry, 74(6), 595-602.

Melas, P. A., Tartani, E., Forsner, T., Edhborg, M., \& Forsell, Y. (2013). Mental health literacy about depression and schizophrenia among adolescents in Sweden. European Psychiatry, 28(7), 404-411.

Merry, S. N., Stasiak, K., Shepherd, M., Frampton, C., Fleming, T., \& Lucassen, M. F. (2012). The effectiveness of SPARX, a computerised self help intervention for adolescents seeking help for depression: randomised controlled non-inferiority trial. British Medical Journal, (Clinical research ed.), 344, e2598.

Mesko, B., Drobni, Z., Benyei, E., Gergely, B., \& Gyorffy, Z. (2017). Digital health is a cultural transformation of traditional healthcare. Mhealth, 3, 38 .

Moffitt, T. E., Harrington, H., Caspi, A., Kim-Cohen, J. Goldberg, D., Gregory, A. M., \& Pulton, R. (2007). Depression and generalized anxiety disorder: Cumulative and sequential comorbidity in a birth cohort followed prospectively to age 32 years. Archives of General Psychiatry, 64(6), 651-66o.

Mogoase, C., Cobeanu, O., David, O., Giosan, C., \& Szentagotai, A. (2017). Internet-based psychotherapy for adult depression: what about the mechanisms of change? Journal of Clinical Psychology, 73(1), 5-64.

Mohr, D. C., Hart, S. L., Julian, L., Catledge, C., Honos-Webb, L., Vella, L., \& Tasch, E. T. (2005). Telephone-administered psychotherapy for depression. Archives of General Psychiatry, 62, 1007-1014.

Mohr, D. C., Riper, H., \& Schueller, S. M. (2018). A solution-focused research approach to achieve an implementable revolution in digital mental health. JAMA Psychiatry, 75(2), 113-114.

Mohr, D. C., Vella, L., Hart, S., Heckman, T., \& Simon, G. (2008). The effect of telephone-administered psychotherapy on symptoms of depression and attrition: A meta-analysis. Journal of Clinical Psychology (New York), 15(3), 243-253.

Mohr, D. C., Weingardt, K. R., Reddy, M. \& Schueller, S. M. (2017). Three problems with current digital mental health research. and three things we can do about them. Psychiatric Services, 68(5), 427-429.

Montgomery, S. A. (1994). Clinically relevant effect sizes in depression. European Neuropsychopharmacology, 4(3), 283-284. 
Munder, T., Wilmers, F., Leonhart, R., Linster, H. W., \& Barth, J. (2010). Working alliance inventory-short Revised (WAI-SR): psychometric properties in outpatients and inpatients. Clinical Psychology $\&$ Psychotherapy, 17(3), 231-239.

Muñoz, R. F., Bunge, E. L., Chen, K., Schueller, S. M., Bravin, J. I., Shaughnessy, E. A., \& Pérez-Stable, E. J. (2016). Massive Open Online Interventions: A novel model for delivering behavioral-health services worldwide. Clinical Psychological Science, 4, 194-205.

Murdoch, J. W., \& Connor-Greene, P. A. (200o). Enhancing therapeutic impact and therapeutic alliance through electronic mail homework assignments. The Journal of Psychotherapy Practice and Research, 9(4), 232-237.

Möller, H. J., Muller, H., \& Volz, H. P. (1996). How to assess the onset of antidepressant effect: comparison of global ratings and findings based on depression scales. Pharmacopsychiatry, 29(2), 57-62.

Neil, A. L., Batterham, P., Christensen, H., Bennett, K., \& Griffiths, K. M. (2009). Predictors of adherence by adolescents to a cognitive behavior therapy website in school and community-based settings. Journal of Medical Internet Research, 11(1), $\mathrm{e} 6$.

Nobler, M. S., Sackeim, H. A., Moeller, J. R., Prudic, J., Petkova, E., \& Waternaux, C. (1997). Quantifying the speed of symptomatic improvement with electroconvulsive therapy: comparison of alternative statistical methods. Convulsive Therapy, 13(4), 208-221.

Nordstrom, A., \& Bodlund, O. (2008). Every third patient in primary care suffers from depression, anxiety or alcohol problems. Nordic Journal of Psychiatry, 62(3), 250-255.

O'Kearney, R., Kang, K., Christensen, H., \& Griffiths, K. (2009). A controlled trial of a school-based Internet program for reducing depressive symptoms in adolescent girls. Depression and Anxiety, 26(1), 65-72.

Olfson, M., Blanco, C., \& Marcus, S. C. (2016). treatment of adult depression in the united states. JAMA Internal Medicine, 176(10), 1482-1491.

O'Mahen, H. A., Richards, D. A., Woodford, J., Wilkinson, E., McGinley, J., Taylor, R. S., \& Warren, F. C. (2014). Netmums: a phase II randomized controlled trial of a guided Internet behavioural activation treatment for postpartum depression. Psychological Medicine, 44(8), 1675-1689.

Ormel, J., Petukhova, M., Chatterji, S., Aguilar-Gaxiola, S., Alonso, J., Angermeyer, M. C., ... Kessler, R. C. (2008). Disability and treatment of specific mental and physical disorders across the world. British Journal of Psychiatry, 192(5), 368-375. 
Osenbach, J. E., O'Brien, K. M., Mishkind, M., \& Smolenski, D. J. (2013). Synchronous telehealth technologies in psychotherapy for depression: a meta-analysis. Depression and Anxiety, 30(11), 1058-1067.

Otte, C., Gold, S. M., Penninx, B. W., Pariante, C. M., Etkin, A., Fava, M., ... Schatzberg, A. F. (2016). Major depressive disorder. Nature Review Disease Primers, 2, 16065.

Parikh, S. V., Quilty, L. C., Ravitz, P., Rosenbluth, M., Pavlova, B., Grigoriadis, S., ... Uher, R. (2016). Canadian network for mood and anxiety treatments (CANMAT) 2016 clinical guidelines for the management of adults with Major Depressive Disorder: Section 2. Psychological treatments. The Canadian Journal of Psychiatry, 61 (9), 524-39.

Patel, V., Flisher, A. J., Hetrick, S., \& McGorry, P. (2007). Mental health of young people: a global public-health challenge. Lancet, 369(9569), 1302-1313.

Patrick, K., Hekler, E. B., Estrin, D., Mohr, D. C., Riper, H., Crane, D., . . Riley, W. T. (2016). The pace of technologic change: implications for digital health behavior intervention research. American Journal of Preventive Medicine, 51(5), 816-824.

Payne, H. E., Lister, C., West, J. H., \& Bernhardt, J. M. (2015). Behavioral functionality of mobile apps in health interventions: a systematic review of the literature. JMIR mHealth and uHealth, 3(1), e2O.

Pennant, M. E., Loucas, C. E., Whittington, C., Creswell, C., Fonagy, P., Fuggle, P., ... Kendall, T. (2015). Computerised therapies for anxiety and depression in children and young people: A systematic review and meta-analysis. Behavior Research and Therapy, 67, 1-18.

Penninx, B. W. J. H. (2015). Depression and anxiety: their insidious dance. Lancet Psychiatry, 2(6), 479-480.

Penninx, B. W., Nolen, W. A., Lamers, F., Zitman, F. G., Smit, J. H., Spinhoven, P., ... Beekman, A. T. (2011). Two-year course of depressive and anxiety disorders: results from the Netherlands Study of Depression and Anxiety (NESDA). Journal of Affective Disorders, 133(1-2), 76-85.

Perle, J. G., Langsam, L. C., \& Nierenberg, B. (2011). Controversy clarified: An updated review of clinical psychology and tele-health. Clinical Psychology Review, 31, 1247-1258.

Piaggio, G., Elbourne D. R., Pocock, S. J., Evans, S. J., \& Altman, D. G. (2012). Reporting of noninferiority and equivalence randomized trials: extension of the CONSORT 2010 statement. JAMA, 308(24), 2594-604).

Post, R. M. (1992). Transduction of psychosocial stress into the neurobiology of recurrent affective disorder. American Journal of Psychiatry, 149(8), 999-1010. 
Powers, M. B., de Kleine, R. A., \& Smits, J. A. J. (2017). Core Mechanisms of Cognitive Behavioral Therapy for Anxiety and Depression: A Review. Psychiatric Clinics of North America, 40(4), 611-623.

Rao, U., Dahl, R. E., Ryan, N. D., Birmaher, B., Williamson, D. E., Giles, D. E., . . Nelson, B. (1996). The relationship between longitudinal clinical course and sleep and cortisol changes in adolescent depression. Biological Psychiatry, 40(6), 474-484.

Rhode, P., Lewinsohn, P. M., \& Seeley, J. R. (1997). Comparability of telephone and face-to- face interviews in assessing Axis I and II disorders. The American Journal of Psychiatry, 164, 1593-1598.

Richards, D. A., Ekers, D., McMillan, D., Taylor, R. S., Byford, S., Warren, F. C., . . Finning, K. (2016). Cost and Outcome of Behavioural Activation versus Cognitive Behavioural Therapy for Depression (COBRA): a randomised, controlled, non-inferiority trial. Lancet, 388(10047), 871-80.

Richardson, L. P., Ludman, E., McCauley, E., Lindenbaum, J., Larison, C., Zhou, C., ... Katon, W. (2014). Collaborative care for adolescents with depression in primary care: a randomized clinical trial. JAMA, 312(8), 809-816.

Richards, D., \& Richardson, T. (2012). Computer-based psychological treatments for depression: a systematic review and meta-analysis. Clinical Psychology Review, 32(4), 329-342.

Richardson, T., Stallard, P., \& Velleman, S. (2010). Computerised cognitive behavioural therapy for the prevention and treatment of depression and anxiety in children and adolescents: A systematic review. Clinical Child and Family Psychology Review, 13(3), 275-290.

Rickwood, D., Webb, M., Kennedy, V., \& Telford, N. (2016). Who are the young people choosing web-based mental health support? findings from the implementation of Australia's national web-based youth mental health service, eheadspace. Journal of Medical Internet Research, 3(3), e40.

Rosenberg, T. (2015, June 19). Depressed? Try therapy without the therapist. New York: The New York Times. Accessed from www.nytimes.com

Rozental, A. (2016). Negative effects of Internet-based cognitive behavior therapy: Monitoring and reporting deterioration and adverse and unwanted events. (Doctoral thesis), Department of Psychology, Stockholm University, Stockholm.

Rozental, A., Andersson, G., Boettcher, J., Ebert, D. D., Cuijpers, P., Knaevelsrud, C., ... Carlbring, P. (2014). Consensus statement on defining and measuring negative effects of Internet interventions. Internet Interventions, 1(1), 12-19. 
Rush A. J., Trivedi, M. H., Ibrahim, H. M., Carmody, T. J., Arnow, B., Klein, D. N., ... Keller, M. B. (2003). The 16-Item Quick Inventory of Depressive Symptomatology (QIDS), clinician rating (QIDS-C), and self-report (QIDS-SR): a psychometric evaluation in patients with chronic major depression. Biological Psychiatry, 54, 573-83.

Saito, M., Iwata, N., Kawakami, N., Matsuyama, Y., Ono, Y., Nakane, Y., . . Kikkawa, T. (2010). Evaluation of the DSM-IV and ICD-10 criteria for depressive disorders in a community population in Japan using item response theory. International Journal of Methods in Psychiatric Research, 19(4), 211-222.

Saxena, S., Thornicroft, G., Knapp, M., \& Whiteford, H. (2007). Resources for mental health: scarcity, inequity, and inefficiency. Lancet, 8, 370(9590), $878-89$.

Schmidt, F. M., Sander, C., Dietz, M.-E., Nowak, C., Schröder, T., Mergl, R., . . . Hegerl, U. (2017). Brain arousal regulation as response predictor for antidepressant therapy in major depression. Scientific Reports, 7, 45187.

Schröder, J., Berger, T., Meyer, B., Lutz, W., Hautzinger, M., Späth, C., . . . Moritz, S. (2017). Attitudes towards internet interventions among psychotherapists and individuals with mild to moderate depression symptoms. Cognitive Therapy and Research, 41(5), 745-756.

Schulz, K. F., \& Grimes, D. A. (2005). Sample size calculations in randomised trials: mandatory and mystical. Lancet, 365(9467), 1348-1353.

Seedat, S., Scott, K. M., Angermeyer, M. C., Berglund, P., Bromet, E. J., Brugha, T. S., ... Kessler, R. C. (2009). Cross-national associations between gender and mental disorders in the World Health Organization World Mental Health Surveys. Archives of General Psychiatry, 66(7), 785-795.

Sethi, S., Campbell, A. J., \& Ellis, L. A. (2010). The use of computerized self-help packages to treat adolescent depression and anxiety. Journal of Technology in Human Services, 28(3), 144-160.

Sheehan, D. V., Lecrubier, Y., Sheehan, K. H., Amorim, P., Janavs, J., Weiller, E., \& Dunbar, G. C. (1998) The Mini-International Neuropsychiatric Interview (M.I.N.I.): the development and validation of a structured diagnostic psychiatric interview for DSM-IV and ICD-10. Journal of Clinical Psychiatry, 59, Suppl 20, 22-33.

Shirk S. R., DePrince A. P., Crisostomo, P.S., \& Labus, J. (2014). Cognitive behavioral therapy for depressed adolescents exposed to interpersonal trauma: An initial effectiveness trial. Psychotherapy, 51, 167-179.

Simpson, S. G., \& Reid, C. L. (2014). Therapeutic alliance in videoconferencing psychotherapy: a review. Australian Journal of Rural Health, 22(6), 280-299. 
Sindahl, T. N. (2013). Chat Counselling for Children and Youth - a Handbook. Child Helpline International: Denmark.

Singal, A. G., Higgins, P. D. R., \& Waljee, A. K. (2014). A primer on effectiveness and efficacy trials. Clinical and Translational Gastroenterology, 5(1), e45.

Sleath, B. L., Rubin, R. H., \& Huston, S. A. (2001). Antidepressant prescribing to Hispanic and non-Hispanic white patients in primary care. Annals of Pharmacotherapy, 35(4), 419-423.

Sobocki, P., Ekman, M., Agren, H., Krakau, I., Runeson, B., Martensson, B., \& Jonsson, B. (2007). Resource use and costs associated with patients treated for depression in primary care. European Journal of Health Economics, 8(1), 67-76.

Stallard, P., Richardson, T., \& Velleman, S. (2010). Clinicians' attitudes towards the use of computerized cognitive behaviour therapy (cCBT) with children and adolescents. Behavioural and Cognitive Psychotherapy, 38(5), 545-560.

Stallard, P., Velleman, S., \& Richardson, T. (2010). Computer use and attitudes towards computerised therapy amongst young people and parents attending child and adolescent mental health services. Child and Adolescent Mental Health, 15(2), 80-84.

Stasiak, K., Hatcher, S., Frampton, C., \& Merry, S. N. (2014). A pilot double blind randomized placebo controlled trial of a prototype computer-based cognitive behavioural therapy program for adolescents with symptoms of depression. Behavioural and Cognitive Psychotherapy, 42(4), 385-401.

Statistics Sweden. (2016). 136,0oo children live with a step parent (136 ooo barn bor med en styvförälder). Accessed from www.scb.se

Statistics Sweden. (2018). Educational attainment of the population 2017. (Befolkningens utbildning 2017). Accessed from www.scb.se

Stiles-Shields, C., Corden, M. E., Kwasny, M. J., Schueller, S. M., \& Mohr, D. C. (2015). Predictors of outcome for telephone and face-to-face administered cognitive behavioral therapy for depression. Psychological Medicine, 45(15), 3205-3215.

Sundquist, J., Ohlsson, H., Sundquist, K., \& Kendler, K. S. (2017). Common adult psychiatric disorders in Swedish primary care where most mental health patients are treated. BMC Psychiatry, 17, 235.

Swedish Child and Adolescent Mental Health Services. (2016). Advice and facts. Do parents always know? (BUP: Råd och fakta. Får föräldrar alltid veta? Accessed from: www.bup.se/sv/Rad-och-fakta/Artiklar/Bra-att-vetaom-BUP/Far-foraldrar-alltid-veta 
Szegedi, A., Kohnen, R., Dienel, A., \& Kieser, M. (2005). Acute treatment of moderate to severe depression with hypericum extract WS 5570 (St John's wort): randomised controlled double blind non-inferiority trial versus paroxetine. British Medical Journal, (Clinical research ed.), $330(7490)$, 503.

Talkspace. (2018). Talkspace. Therapy for all. Talkspace: New York. Accessed from: www.talkspace.com

TELUS International. (2015). Comparing costs: Chat vs. voice customer service. Understanding the economics of chat. Best Practices Online Chat series. Accessed from www.telusinternational.com

Thapar, A., Collishaw, S., Pine, D.S., \& Thapar, A. K. (2012). Depression in adolescence. Lancet, 17, 379(9820), 1056-67.

Thase, M. E., Wright, J. H., Eells, T. D., Barrett, M. S., Wisniewski, S. R., Balasubramani, G. K., . . Brown, G. K. (2018). Improving the efficiency of psychotherapy for depression: computer-assisted versus standard CBT. The American Journal of Psychiatry, 175(3), 242-250.

The National Board of Health and Welfare. (2017a). National guidelines for depression and anxiety disorder care: support for management and management (Nationella riktlinjer för vård vid depression och ångestsyndrom: stöd för styrning och ledning). Socialstyrelsen: Stockholm.

The National Board of Health and Welfare. (2017b). Mental illness among children and young adults. Up to year 2016. (Utvecklingen av psykisk ohälsa bland barn och unga vuxna. Till och med 2016). Socialstyrelsen: Stockholm.

The National Institute for Health and Clinical Excellence. (2005). Depression in children and young people: identification and management. The British Psychological Society and The Royal College of Psychiatrists: London, England.

The National Institute for Health and Clinical Excellence. (2009). Depression in adults: recognition and management. The British Psychological Society and The Royal College of Psychiatrists: London, England.

Titov, N., Andrews, G., Choi, I., Schwencke, G., \& Mahoney, A. (2008). Shyness 3: randomized controlled trial of guided versus unguided Internet-based CBT for social phobia. Australian and New Zealand Journal of Psychiatry, 42, 1030-1040.

Titov, N., Andrews, G., Choi, I., Schwencke, G., \& Johnston, L. (2009). Randomized controlled trial of web-based treatment of social phobia without clinical guidance. Australian and New Zealand Journal of Psychiatry, 43, 913-919. 
Titov, N., Dear, B. F., McMillian, D., Andersson, T., Zou, J., \& Sunderland, M. (2011). Psychometric comparison of the PHQ-9 and BDI-II for measuring response during treatment of depression. Cognitive Behaviour Therapy, 40(2), p. 126-36.

Titov, N., Fogliati, V. J., Staples, L. G., Gandy, M., Johnston, L., Wootton, B., . . . Dear, B. F. (2016). Treating anxiety and depression in older adults: randomised controlled trial comparing guided v. self-guided internetdelivered cognitive-behavioural therapy. British Journal of Psychiatry Open, 2(1), 50-58.

Titzler, I., Saruhanjan, K., Berking, M., Riper, H., \& Ebert, D. D. (2018). Barriers and facilitators for the implementation of blended psychotherapy for depression: A qualitative pilot study of therapists' perspective. Internet Interventions, 12, 150-164.

Tracey, T. J., \& Kokotovic, A. M. (1989). Factor structure of the Working Alliance Inventory. Psychological Assessment: A Journal of Consulting and Clinical Psychology, 1(3), 207-210.

Trockel, M., Karlin, B. E., Taylor, C. B., \& Manber, R. (2014). Cognitive Behavioral Therapy for insomnia with Veterans: evaluation of effectiveness and correlates of treatment outcomes. Behaviour Research and Therapy, 53, 41-46.

Ustun, T. B., \& Kessler, R. C. (2002). Global burden of depressive disorders: the issue of duration. British Journal of Psychiatry, 181, 181-183.

van der Lem, R., van der Wee, N. J., van Veen, T., \& Zitman, F. G. (2012). Efficacy versus effectiveness: a direct comparison of the outcome of treatment for mild to moderate depression in randomized controlled trials and daily practice. Psychotherapy and Psychosomatics Journal, 81(4), 226-234.

van der Vaart, R., Witting, M., Riper, H., Kooistra, L., Bohlmeijer, E. T., \& van Gemert-Pijnen, L. J. (2014). Blending online therapy into regular faceto-face therapy for depression: content, ratio and preconditions according to patients and therapists using a Delphi study. $B M C$ Psychiatry, 14(1), 355.

van der Zanden, R., Kramer, J., Gerrits, R., \& Cuijpers, P. (2012). Effectiveness of an online group course for depression in adolescents and young adults: a randomized trial. Journal of Medical Internet Research, 14(3), e86.

Vanheusden, K., Mulder, C. L., van der Ende, J., van Lenthe, F. J., Mackenbach, J. P., \& Verhulst, F. C. (2008). Young adults face major barriers to seeking help from mental health services. Patient Education and Counseling, 73(1), 97-104. 
Verhaak, P. F. M., van Dijk, C. E., Nuijen, J., Verheij, R. A., \& Schellevis, F. G. (2012). Mental health care as delivered by Dutch general practitioners between 2004 and 2008. Scandinavian Journal of Primary Health Care, 30(3), 156-162.

Vessey, J. T., \& Howard, K. I. (1993). Who seeks psychotherapy? Psychotherapy: Theory, Research, Practice, Training, 30(4), 546- 553.

Vickers, A. J., \& Altman, D. G. (2001). Statistics notes: Analysing controlled trials with baseline and follow up measurements. British Medical Journal, (Clinical research ed.), 323(7321), 1123-1124.

Vigerland, S., Ljótsson, B., Gustafsson, F. B., Hagert, S., Thulin, U., Andersson, G., \& Serlachius, E. (2014). Attitudes towards the use of computerized cognitive behavior therapy (cCBT) with children and adolescents: A survey among Swedish mental health professionals. Internet Interventions, 1(3), 111-117.

Vis, C., Kleiboer, A., Prior, R., Bønes, E., Cavallo, M., Clark, S. A., . . Riper, H., (2015). Implementing and up-scaling evidence-based eMental health in Europe: The study protocol for the MasterMind project. Internet Interventions, 2(4), 399-409.

Vis, C., Mol, M., Kleiboer, A., Bührmann, L., Finch, T., Smit, J., \& Riper, H. (2018). Improving implementation of emental health for mood disorders in routine practice: systematic review of barriers and facilitating factors. Journal of Medical Internet Research, 5(1), e2o.

Vos, T., Haby, M. M., Barendregt, J. J., Kruijshaar, M., Corry, J., \& Andrews, G. (2004). The burden of major depression avoidable by longer-term treatment strategies. Archives of General Psychiatry, 61(11), 1097-1103.

Vostanis, P., Feehan, C., Grattan, E., \& Bickerton, W. (1996). Treatment for children and adolescents with depression: Lessons from a controlled trial. Journal of Affective Disorders, 40, 105-116.

Wang, P. S., Lane, M., Olfson, M., Pincus, H. A., Wells, K. B., \& Kessler, R. C. (2005). Twelve-month use of mental health services in the United States: results from the National Comorbidity Survey Replication. Archives of General Psychiatry, 62(6), 629-640.

Warren, J. S., Nelson, P. L., Mondragon, S. A., Baldwin, S. A., \& Burlingame, G. M. (2010). Youth psychotherapy change trajectories and outcomes in usual care: Community mental health versus managed care settings. Journal of Consulting and Clinical Psychology, 78(2), 144-155.

Webb, C. A., Auerbach, R. P., \& Derubeis, R. J. (2012). Processes of change in CBT of adolescent depression: review and recommendations. Journal of Clinical Child and Adolescent Psychology, 41(5), 654-665. 
Webb, C. A., DeRubeis, R. J., \& Barber, J. P. (2010). Therapist adherence/competence and treatment outcome: A meta-analytic review. Journal of Consulting and Clinical Psychology, 78, 200-211.

Weersing, V. R., Jeffreys, M., Do, M. T., Schwartz, K. T., \& Bolano, C. (2017). Evidence base update of psychosocial treatments for child and adolescent depression. Journal of Clinical Child and Adolescent Psychology, 46(1), 11-43.

Weissman, M. M., Bland R. C, Canino, G. J., Faravelli, C., Greenwald, S., Hwu, H. G., ... Yeh, E. K. (1996). Cross-national epidemiology of major depression and bipolar disorder. JAMA, 24-31, 276(4):293-9.

Weisz, J., Gordis, E., Chu, B., McLeod, B., Updegraff, A., Southam-Gerow, M.A., . .. Weiss B. (2009). Cognitive- behavioral therapy versus usual clinical care for youth depression: An initial test of transportability to community clinics and clinicians. Journal of Consulting and Clinical Psychology, 77, 383-396.

Weisz, J. R., McCarty, C. A., \& Valeri, S. M. (2006). Effects of psychotherapy for depression in children and adolescents: a meta-analysis. Psychological Bulletin, 132(1),132-149.

Weitz, E. S., Hollon, S. D., Twisk, J., van Straten, A., Huibers, M. J., David, D., . . . Cuijpers, P. (2015). Baseline depression severity as moderator of depression outcomes between cognitive behavioral therapy vs pharmacotherapy: an individual patient data meta-analysis. JAMA Psychiatry, 72(11), 1102-1109.

Wells, K. B., Burnam, M. A., Rogers, W., Hays, R., \& Camp, P. (1992). The course of depression in adult outpatients. Results from the Medical Outcomes Study. Archives of General Psychiatry, 49(10), 788-794.

Wentzel, J., van der Vaart, R., Bohlmeijer, E. T., \& van Gemert-Pijnen, J. E. (2016). Mixing online and face-to-face therapy: how to benefit from blended care in mental health care. Journal of Medical Internet Research, 3(1), eq.

Wenzel, A. (2017). Basic strategies of cognitive behavioral therapy. Psychiatric Clinics of North America, 40(4), 597-609.

Wittchen, H. U., Jacobi, F., Rehm, J., Gustavsson, A., Svensson, M., Jonsson, B., . . .Steinhausen, H. C. (2011). The size and burden of mental disorders and other disorders of the brain in Europe 2010. European Neuropsychopharmacology, 21(9), 655-679.

Wittkampf, K., Naeije, L., Schene, A. H., Huyser, J., \& van Weert, H. C. (2007). Diagnostic accuracy of the mood module of the Patient Health Questionnaire: a systematic review. General Hospital Psychiatry, 29, 38895, 48. 
World Childhood Foundation. (2012). Project report 2012. Supportive online relations via chat. (Tjejzonen: projektrapport 2012. Chattsyster - stödjande relationer online via chatt $i$ ideell verksamhet). World Childhood Foundation: Stockholm. Accessed from www.tjejzonen.se

World Health Organization. (1992). ICD-1o Classifications of Mental and Behavioural Disorder: Clinical Descriptions and Diagnostic Guidelines. World Health Organization: Geneva.

World Health Organization. (2011). Mental health atlas: 2011. WHO Document Production Services, World Health Organization: Geneva.

World Health Organization. (2016). Suicide. WHO Document Production Services, World Health Organization: Geneva.

World Health Organization. (2017). Depression and other common mental disorders. Global health estimates. WHO Document Production Services, World Health Organization: Geneva.

Wozney, L., Huguet, A., Bennett, K., Radomski, A. D., Hartling, L., Dyson, M., . . . Newton, A. S. (2017). How do ehealth programs for adolescents with depression work? a realist review of persuasive system design components in internet-based psychological therapies. Journal of Medical Internet Research, 19(8), e266.

Wray, N. R., Ripke, S., Mattheisen, M., Trzaskowski, M., Byrne, E. M., Abdellaoui, A., ... Sullivan, P. F. (2018). Genome-wide association analyses identify 44 risk variants and refine the genetic architecture of major depression. Nature Genetics, 50(5), 668-681.

Wright, J. H., Wright, A. S., Albano, A. M., Basco, M. R., Goldsmith, L. J., Raffield, T., \& Otto, M. W. (2005). Computer-assisted cognitive therapy for depression: Maintaining efficacy while reducing therapist time. American Journal of Psychiatry, 162, 1158-1164.

Zagorscak, P., Heinrich, M., Sommer, D., Wagner, B., \& Knaevelsrud, C. (2018). Benefits of individualized feedback in internet-based interventions for depression: a randomized controlled trial. Psychotherapy and Psychosomatics, 87(1), 32-45.

Zhou, X., Hetrick, S. E., Cuijpers, P., Qin, B., Barth, J., Whittington, C. J., . . X Xie, P. (2015). Comparative efficacy and acceptability of psychotherapies for depression in children and adolescents: A systematic review and network meta-analysis. World Psychiatry, 14(2), 207-222. 


\section{ACKNOWLEDGEMENTS IN SWEDISH}

Så många är ni som har bidragit till arbetet med den här avhandlingen, till alla berörda och er som jag glömt att nämna här - stort tack till er!

Tack till alla er som deltagit i studierna.

Gerhard Andersson, huvudhandledare. Tack för att du så generöst öppnat dörren till forskarvärlden och har tagit mig med på en vidunderlig resa genom internetbehandlingens land - det fält som du varit med och skapat från grunden. Jag har haft sån tur, och turen har fortsatt under fyra år. Genom din kunskap, klokhet, tilltro och erkända snabbhet så blev den här avhandlingen både möjlig, lärorik och rolig att genomföra. Enormt tack till dig för de här åren!

Lise Bergman Nordgren, bihandledare med svart akademiskt bälte. Du har tränat hästar så jag var svårt imponerad redan innan du plockade fram dina behavioristiska artikel-rariteter. Varmaste tack för alla handledningsstunder där du rett ut begrepp och gjort målbilden tydlig. Du har varit oersättlig som kliniskt ankare och stöd i forskningsstudierna, och med din input har skrivandet i forskningen - manualer, manus och behandlingsprogram varit roligt. Varmaste tack till dig Lise!

Den trevligaste och smartaste forskningsgruppen; Internet, hälsa och klinisk psykologi. Hoa Ly, avhandlingen hade inte påbörjats utan dig. Med det roligaste examensprojektet introducerade du mig till forskningsgruppen. Stort tack för all inspiration och din hjälp att senare förverkliga egna doktorandstudier! Tack Kristin Silfvernagel för all din fantastiska generositet och vänskap, från dag ett, i stort och litet. Det finns ingen som du! George Vlaescu, tack för att du varit en sån klippa in crime i studierna att för att du har gjort så många idéer till verklighet. Det har varit så roligt och jag är dig evigt tacksam! Tack Kristofer Vernmark för fint samarbete i E-COMPARED, inte minst din tunga insats med data - se fram emot fler frågor så länge du är affilierad. Robert Persson Asplund, Matilda Berg, Mats Dahlin, Jesper Dagöö, Elisabeth Ingo, Anton Käll, Peter Molander, Kristoffer N. T. Månsson, Tomas Nygren och Ali Sarkohi - tack för många trevliga pratstunder och luncher, kluriga forskningsfrågor, konferenser och Google hangout ihop!

Per Carlbring, professor och geni, däribland VR-geni, PR-geni, resegeni. Tack för att jag fått hänga med dig och Gerhard, på resor och konferenser nära och långt bort, och för din support. 
Kristoffer N. T. Månsson, Alexander Rozental, Hugo Hesser, stort tack för värdefull input på avhandlingen när bråda dagar närmade sig.

Jonna Torstensson, ekonomisk riddare. Tack för alla stunder bland miljoner av timesheets, man-months, RRs, kvittoberg; WP1 versus WP2 och WP vad, och för din hjälp att reda ut ekonomiska EU-deadlines. Ovärderligt och alltid mycket trevligt!

Britt-Marie Alfredsson-Svensson, stort tack för stöd i slutfasen med avhandlingen. Tack även Rowena Sarinas Bladh, och Roger Nilsson, Liu-Tryck. $\mathrm{Ni}$ tre fick det att fungera. Juni Crisp Topooco och Jonas Topooco, tack för det fina omslaget!

Tack Ellinor Sellgren och kursansvariga, och alla kollegor på avdelningen för psykologi, Linköpings Universitet för kollegial värme och trevliga luncher.

Professor Heleen Riper, genius and kindest; PI for the European E-COMPARED research project, along with co-managers Professor Jan Smit and Christiaan Vis. Thank you for the wonderful years that I got to spend with you in this project, together with so many great people. It has been a wonderful time and a truly invaluable research learning experience. My warmest thanks to you for believing in and supporting young researchers. Thank you all in the consortium, in particular for the surveyand trial collaboration, and for your help in co-authoring the paper (Study I).

Anna Wallin och Hanna Cederlund, tack för den fantastiska första resan med DELORES-studien, som blev Studie II i denna avhandling. Samarbetet med er fick mig att förstå hur kul forskning är!

Lisa Backlund, Linn Bengtsson och Liisa Luuk, en så enorm insats ni gjorde i DAY-studien (Studie III). Än en gång stort tack för er kämpaglöd och uthållighet! Stort tack till Ella Radvogin för ovärderlig hjälp med koordinering av studien i Västmanland, Erik Ödéhn, för klinisk handledning i Stockholms-filialen, Frida Kolasa och Lina Södergren, för ert bidrag med att följa upp deltagarna.

Tonårsgänget; Matilda Berg, nu doktorandkollega, Lina Liljethörn, Sofie Johansson, Ella Radvogin. Tack för det otroliga ni gjorde med den första tonårsstudien DEA (Studie IV). Sandra Byléhn, Ellen Dahlström, Jenny Holmlund, Johanna Lindegaard, Sanna Johansson och Linnea Åberg - tack för er lika fantastiska insats i den andra tonårsstudien, UNG (Studie V). Maria Zetterqvist, din medverkan som klinisk handledare i studierna gav ett ovärderligt perspektiv och kunskap till projektet. Stort tack även för din input på behandlingsprogrammet under tidspress. Elin Allard och Ida Ingves, tack för ert viktiga bidrag med att följa upp deltagarna. 
Urban Pettersson, Wemind, Ann-Charlotte Smedler och Aina Lindgren vid Psykoterapimottagningen vid Stockholms Universitet, Stockholm. Ansvariga för Studenthälsan och Psykologmottagningen vid Linköpings Universitet. Tack vare er kunde forskningskliniker uppstå. Utan er hade det inte varit möjligt att genomföra DELORES- och DAY-studien i Stockholm och Linköping. Tack för er gästfrihet och engagemang.

Tack till alla er som medverkande som behandlare i DELORES och DAY: Johanna Andersson, Daniel Björkander, Emma Birkehag, Marie Björnstjerna, Martina Brandel, Sonia Buck, Maria Cassel, Anneli von Cederwald, Michaela Dahlin, Jonna Engstrand, Katri Frankenstein, Smilla Färdig, Frida Gustafsson, Katja Hansson, Linda Hasbar, Jenni Häggkvist, Tor Ingvarsson, Nils Isacsson, Ulrika Jeppsson, Andreas Kristensson, Kamilla Larsson, Therese Lindström, Sofia Lu, Mikaela Nilsson, Åsa Persson, Sofie Tocklin Rohlén, Johanna Tunved, Olle Wiklund, Forough Zeraati, Alexander Örtenholm och Anton Käll - nu doktorandkollega!

Ida Flink och Sarah Vigerland, halvtidsgranskare och granskare på slutseminariet. Er noggranna läsning, feedback och frågor har hjälpt mig att lyfta blicken och se arbetet med nya ögon. Stort tack för värdefull feedback och viktiga synpunkter.

Dr. Heather O'Mahen, University of Exeter, thank you for being my opponent.

Nitya Jayaram-Lindström, Johan Reutfors, och alla kursare; tack för en fantastiskt lärorik och rolig tid i forskarskolan inom klinisk psykiatri.

Tobias Lundgren och kollegor, Kompetenscentrum för psykoterapi. Stort tack för att jag fick hänga mer er i er härliga miljö! Tack Andreas Larsson, Katarina Back, Daniel Bruchfeld och många fler för trevliga pratstunder.

John Airaksinen, avhandlingen hade inte påbörjats utan dig. Tack för att du tillsammans med Hoa Ly så generöst bjöd in mig till er värld och så många härliga människor, visioner och projekt. Psykologifabriken, Hoas Tool Shop - nu har världen Shim.

Tack till European Community's $\mathrm{FP}_{7}$ Programme, Riksbankens Jubileumsfond, Drottning Silvias Jubileumsfond, Svenska Läkaresällskapet, och Psykoterapistiftelsen för bidrag till forskningen.

Min familj och vänner. Jag är så tacksam för att ha er i mitt liv, ni vet hur mycket ni betyder. Tack för förståelse under slutspurten med avhandlingen.

Det finns en person som betyder mer än allt annat. Niels, tack för att jag får dela tillvaron med dig! 


\section{Papers}

The papers associated with this thesis have been removed for copyright reasons. For more details about these see:

http://urn.kb.se/resolve?urn=urn:nbn:se:liu:diva-148016 


\section{LINKÖPING STUDIES IN BEHAVIOURAL SCIENCE}

181. FREJD, PETER. Modes of Mathematical Modelling. An Analysis of how modelling is used and interpreted in and out of school settings. 2014. ISBN: 978-91-7519-414-1

182. AMAN, ROBERT. Impossible Interculturality? Education and the Colonial Difference in a Multicultural World. 2014. ISBN: 978-91-7519-348-9

183. NYLANDER, ERIK. Skolning i jazz. Värde, selektion och studiekarriär vid folkhögskolornas musiklinjer. 2014. ISBN: 97891-7519-347-2

184. GRADIN FRANZÈN, ANNA. Disciplining freedom: Treatment dilemmas and subjectivity at a detention home for young men. 2014. ISBN: 978-91-7519-344-1

185. ENGSTRÖM, ANNIKA. Lärande samspel för effektivitet. En studie av arbetsgrupper i ett mindre industriföretag. 2014. ISBN:978-91-7519-345-8

186. ELWÉR, ÅSA. Early Predictors of Reading Comprehension Difficulties. 2014. ISBN: 978-91-7519-281-9

187. LARSON, NICLAS. Matematikämnet och stadiebytet mellan grundskolan och gymnasieskolan. En enkät- och klassrumsstudie. 2014. ISBN: 978-91-7519-196-6

188. LY, HOA. Use of a Smartphone Application in the Treatment of Depression - The New Wave of Digital Tools for Psychological Treatment. 2015. ISBN: 978-91-7519-136-2

189. HANSSON, PER-OLOF. New ways of learning. Participatory action research and Kenyan runners' appropriation of smartphones to improve their daily lives and participation in m-learning. 2015. ISBN: 978-91-7519-124-9 
190. BOLLDÈN, KARIN. Online teaching practices. Sociomaterial matters in higher education settings. 2015. ISBN: 978-91-7519123-2

191. MALMQUIST, ANNA. Pride and Prejudice. Lesbian families in contemporary Sweden. 2015. ISBN: 978-91-7519-087-7

192. AVBY, GUNILLA. Evidence in Practice. On Knowledge Use and Learning in Social Work. 2015. ISBN: 978-91-74519-088-4

193. FORSBERG, CAMILLA. Students' Perspectives on Bullying. 2016. ISBN: 978-91-7685-874-5

194. MUHRMAN, KAROLINA. Inget klöver utan matematik. En studie av matematik i yrkesutbildning och yrkesliv. 2016. ISBN: 978-91-7685-851-6

195. SKAGERLUND, KENNY. Magnitude Processing in Developmental Dyscalculia. A Heterogeneous learning disability with different cognitive profiles. 2016. ISBN: 978-917685-831-8

196. EKEBLAD, ANNIKA. A Randomized Trial of Interpersonal Psychotherapy and Cognitive Behavioral Therapy for Major Depressive Disorder - Predictors of process and outcome. 2016. ISBN: 978-91-7685-803-5

197. MÅNSSON, KRISTOFFER N.T. Restructuring the Socially Anxious Brain. Using magnetic resonance imaging to advance our understanding of effective cognitive behaviour therapy for social anxiety disorder. 2016. ISBN: 978-91-7685-688-8

198. SILFVERNAGEL, KRISTIN. Individually tailored internet-based cognitive behavioural therapy for adolescents, young adults and older adults with anxiety. 2017. ISBN: 978-91-7685-566-9 
199. ELOFSSON, JESSICA. Children's early mathematics learning and development. Number game interventions and number line estimations. 2017. ISBN: 978-91-7685-517-1

200. ÅHLFELDT, EMANUEL. Hållbart utvecklingsarbete i vård och omsorg. Ett institutionellt perspektiv på projekt i en professionell och byråkratisk kontext. 2017. ISBN: 978-91-7685445-7

201. VERNMARK, KRISTOFER. Therapeutic alliance and different treatment formats when delivering internet-based CBT for depression. 2017. ISBN: 978-91-7685-436-5

202. FRANKL, MY. Psychotherapy for Substance Use Disorder - the importance of affects. 2017. ISBN: 978-91-7685-429-7

203. ABDULLA, AFRAH. Readiness or resistance? - Newly arrived adult migrants' experiences, meaning making, and learning in Sweden. 2017. ISBN: 978-91-7685-428-o

204. OLSSON, LINDA. “Count on me!”. Mathematical development, developmental dyscalculia and computer-based intervention. 2018. ISBN: 978-91-7685-409-9

205. COLLIANDER, HELENA, Being and becoming a teacher in initial literacy and second language education for adults. 2018. ISBN: 978-91-7685-304-7 